\title{
Dysregulated generation of follicular helper $T$ cells in the spleen triggers fatal autoimmune hepatitis in mice.
}

\section{$\operatorname{AUTHOR}(S)$ :}

Aoki, Nobuhiro; Kido, Masahiro; Iwamoto, Satoru; Nishiura, Hisayo; Maruoka, Ryutaro; Tanaka, Junya; Watanabe, Takeshi; ... Okazaki, Taku; Chiba, Tsutomu; Watanabe, Norihiko

\section{CITATION:}

Aoki, Nobuhiro ...[et al]. Dysregulated generation of follicular helper T cells in the spleen triggers fatal autoimmune hepatitis in mice.. Gastroenterology 2011, 140(4): 1322-1333.e5

\section{ISSUE DATE:}

2011-04

URL:

http://hdl.handle.net/2433/139747

\section{RIGHT:}

(C) 2011 AGA Institute Published by Elsevier Inc.; This is not the

published version. Please cite only the published version.; この論文は

出版社版でありません。引用の際には出版社版をご確認ご利用くださ い。 


\section{Dysregulated generation of follicular helper $T$ cells in the spleen triggers fatal autoimmune hepatitis in mice}

Nobuhiro Aoki ${ }^{1,2, \#}$, Masahiro Kido ${ }^{1,2, \#}$, Satoru Iwamoto ${ }^{1,2}$, Hisayo Nishiura ${ }^{1,2}$, Ryutaro Maruoka $^{1,2}$, Junya Tanaka ${ }^{1,2}$, Takeshi Watanabe ${ }^{1}$, Yoshimasa Tanaka ${ }^{1}$, Taku Okazaki ${ }^{3}$, Tsutomu Chiba ${ }^{2}$, and Norihiko Watanabe ${ }^{1,2, *}$

${ }^{1}$ Center for Innovation in Immunoregulative Technology and Therapeutics, and ${ }^{2}$ Department of Gastroenterology and Hepatology, Graduate School of Medicine, Kyoto University, Kyoto 606-8501, Japan ${ }^{3}$ Division of Immune Regulation, Institute for Genome Research, University of Tokushima, Tokushima 770-8503, Japan

\# These authors contributed equally to this work.

* Correspondence: Norihiko Watanabe, Tel:+81-75-751-4319, Fax:+81-75-751-4303, E-mail:norihiko@kuhp.kyoto-u.ac.jp

Running title: Induction mechanisms to autoimmune hepatitis

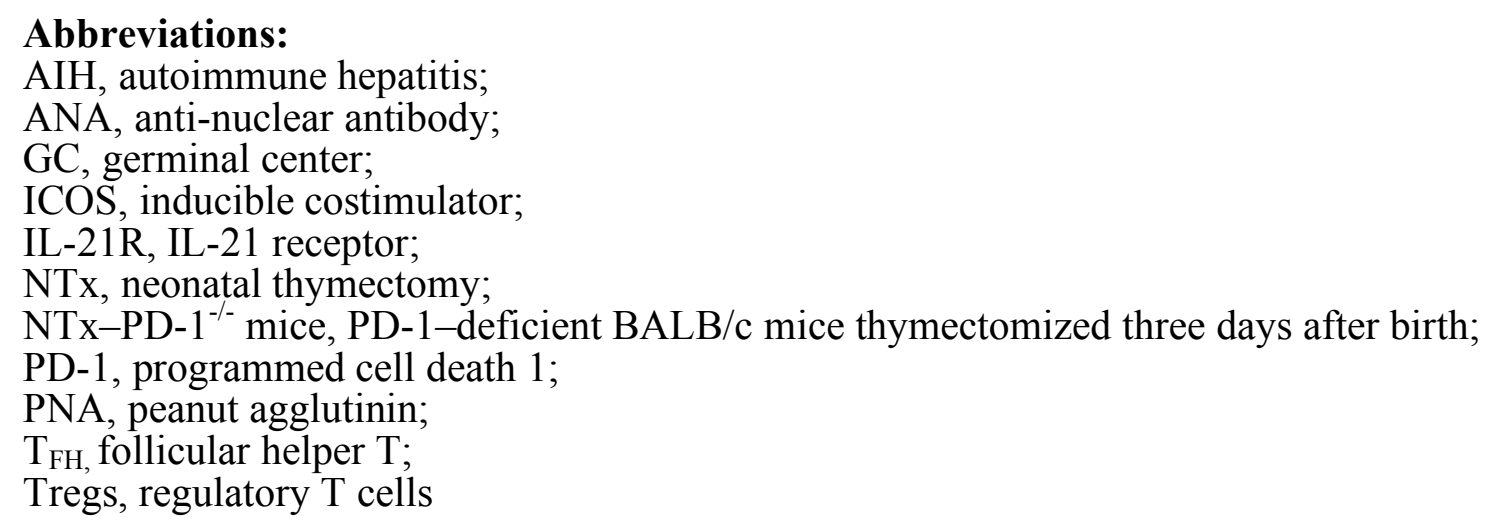




\section{Abstract}

BACKGROUD \& AIMS: To clarify mechanisms involved in the development of autoimmune hepatitis $(\mathrm{AIH})$, we recently developed a mouse model of spontaneous AIH by inducing a concurrent loss of Foxp $3^{+}$regulatory $\mathrm{T}$ cells and programmed cell death 1 (PD-1)-mediated signaling. Fatal AIH in these mice was characterized by severe T-cell infiltration and huge production of anti-nuclear antibodies (Abs). This study aims to identify induction sites, responsible T-cell subsets, and key molecules for induction of $\mathrm{AIH}$.

METHODS: To develop the mouse model of AIH, neonatal thymectomy (NTx) was performed on PD-1-deficient $\left(\mathrm{PD}-1^{-/}\right.$) mice. We then conducted neonatal splenectomy or in vivo administration of Abs to cytokines, chemokines, or cell-surface molecules.

RESULTS: In NTx-PD- $1^{-/-}$mice, either neonatal splenectomy or in vivo $\mathrm{CD}^{+} \mathrm{T}$-cell depletion suppressed $\mathrm{CD}^{+}$and $\mathrm{CD} 8^{+} \mathrm{T}$-cell infiltration in the liver. In the induction phase of $\mathrm{AIH}$, splenic $\mathrm{CD}^{+} \mathrm{T}$ cells were localized in B-cell follicles with huge germinal centers and showed the $\mathrm{Bcl}^{+} \mathrm{ICOS}^{+} \mathrm{IL}-21^{+} \mathrm{IL}-21 \mathrm{R}^{+}$follicular helper $\mathrm{T}\left(\mathrm{T}_{\mathrm{FH}}\right)$ cell phenotype. Blocking Abs to ICOS or IL-21 suppressed $\mathrm{T}_{\mathrm{FH}}$-cell generation and induction of AIH. In addition, IL-21 produced by $\mathrm{T}_{\mathrm{FH}}$ cells drove $\mathrm{CD} 8^{+} \mathrm{T}$-cell activation. Splenic $\mathrm{T}_{\mathrm{FH}}$ cells and $\mathrm{CD} 8^{+} \mathrm{T}$ cells expressed CCR6, and CCL20 expression was elevated in the liver. Administration of anti-CCL20 suppressed migration of these $\mathrm{T}$ cells to the liver and induction of AIH.

CONCLUSIONS: Dysregulated $\mathrm{T}_{\mathrm{FH}}$ cells in the spleen are responsible for the induction of fatal AIH, and CCR6-CCL20 axis-dependent migration of splenic T cells is crucial to induce AIH in NTx-PD-1 $1^{-/-}$mice.

Keywords: Autoimmune liver disease; pathogenesis; follicular helper T cells 


\section{Introduction}

Human autoimmune hepatitis $(\mathrm{AIH})$ shows varied clinical manifestations ranging from asymptomatic, mild chronic hepatitis to acute-onset fulminant hepatic failure. The histological findings of AIH are characterized by a mononuclear-cell infiltration invading the parenchyma, ranging from piecemeal necrosis to submassive lobular necrosis. ${ }^{1,2}$ The serologic hallmark of AIH is the production of a variety of characteristic circulating autoantibodies (autoAbs), including anti-nuclear Abs (ANAs). ${ }^{1,2}$ Although AIH appears to be a T-cell mediated autoimmune disease, it is unclear which type of effector $\mathrm{T}$ cells are involved and how the dysregulated $\mathrm{T}$ cells trigger the development of AIH.

Recently, we developed the first mouse model of spontaneous fatal AIH resembling acute-onset $\mathrm{AIH}$ presenting as fulminant hepatic failure in humans. ${ }^{3}$ Neither programmed cell death 1-deficient mice (PD-1 ${ }^{-/}$mice) nor BALB/c mice thymectomized three days after birth (NTx mice), which severely reduces the number of naturally arising Foxp $^{+}$regulatory $\mathrm{T}$ cells (Tregs) in periphery, developed inflammation of the liver. However, PD- $1^{-/-}$BALB/c mice with neonatal thymectomy (NTx-PD- $1^{-/-}$mice) developed fatal AIH, suggesting that immune dysregulation by a concurrent loss of naturally arising Tregs and PD-1-mediated signaling can induce fatal AIH. Because of the massive destruction of the parenchyma of the liver, these mice started to die as early as two weeks of age, with most dying by four weeks. In humans, liver tissue injury in $\mathrm{AIH}$ is mediated not only by $\mathrm{CD} 4^{+}$but also by $\mathrm{CD}^{+} \mathrm{T}$ cells. $^{4,5}$ Especially in acute-onset human $\mathrm{AIH}$, activated $\mathrm{CD}^{+} \mathrm{T}$ cells are thought to play a crucial role in the pathogenesis. ${ }^{6}$ Fatal AIH in NTx-PD- ${ }^{-/-}$mice was characterized by $\mathrm{CD}^{+}$and $\mathrm{CD}^{+}$T-cell infiltration with massive lobular necrosis and huge ANA production; activated $\mathrm{CD} 8^{+} \mathrm{T}$ cells were mainly involved in progression to fatal hepatic damage. ${ }^{3}$ We showed that the infiltrated $\mathrm{CD}^{+}$and $\mathrm{CD}^{+} \mathrm{T}$ cells in the severely damaged liver produced large amounts of inflammatory cytokines, such as IFN- $\gamma$ and TNF- $\alpha$. However, it is unclear whether these effector $\mathrm{T}$ cells are also crucial in the induction phase of the disease.

Follicular helper $\mathrm{T}\left(\mathrm{T}_{\mathrm{FH}}\right)$ cells are a newly defined effector $\mathrm{T}$ cell subset that provides powerful help to B cells in forming germinal centers (GCs). ${ }^{7-9} \mathrm{~T}_{\mathrm{FH}}$ cells arise from activated $\mathrm{T}$ cells that express Bcl6, a master transcription factor for $\mathrm{T}_{\mathrm{FH}}$-cell differentiation. ${ }^{8,9}$ Differentiated $\mathrm{T}_{\mathrm{FH}}$ cells express IL-21, IL-21 receptor (IL-21R), 
inducible costimulator (ICOS), CXCR5, and PD-1. IL-21 and ICOS are indispensable for $\mathrm{T}_{\mathrm{FH}}$-cell generation and helper function to $\mathrm{B}$ cells. ${ }^{7-9}$ CXCR5 promotes the colocalization of $\mathrm{T}_{\mathrm{FH}}$ cells and $\mathrm{B}$ cells in GCs. ${ }^{7-9}$ Although $\mathrm{CXCR} 5^{+} \mathrm{T}_{\mathrm{FH}}$ cells are localized mainly in the $\mathrm{GC}^{+} \mathrm{B}$-cell follicles, a recent study showed that circulating $\mathrm{T}$ cells resembling $\mathrm{T}_{\mathrm{FH}}$ cells existed in the peripheral blood of patients with B-cell mediated autoimmunity. ${ }^{10}$ In addition, IL-21 has the potential to modulate the activity of $\mathrm{CD}^{+} \mathrm{T}$ cells and other immune and non-immune cells in vivo. ${ }^{11}$ Although $\mathrm{AIH}$ appears to be a T-cell mediated autoimmune disease, it is characterized by hyper-gammaglobulinemia and the production of a variety of circulating autoAbs, suggesting that B-cell activation including B-cell mediated autoimmunity is associated with its development. Thus, it may be possible that dysregulated $\mathrm{T}_{\mathrm{FH}}$ cells are involved in both T-cell and B-cell mediated autoimmunity in AIH.

In this study, using our new mouse model of $\mathrm{AIH}$, we examined the $\mathrm{T}$ cell subsets responsible for induction of AIH and the mechanisms by which these $\mathrm{T}$ cells initiate fatal $\mathrm{AIH}$. We found that splenic $\mathrm{CD}^{+} \mathrm{T}$ cells are responsible for induction of fatal AIH. In these mice, splenic $\mathrm{CD}^{+} \mathrm{T}$ cells were autonomously differentiated into $\mathrm{T}_{\mathrm{FH}}$ cells. Moreover, dysregulated $\mathrm{T}_{\mathrm{FH}}$ cells not only promoted ANA production but also directly migrated into the liver, triggering the induction of fatal AIH. 


\section{Materials and Methods}

All protocols for mice, ELISA, administration of Abs in vivo, histological and immunohistological analysis, flow cytometry analysis and isolation of lymphocytes, adoptive transfer, real-time quantitative RT-PCR, and T-cell coculture are detailed in Supplementary Methods.

\section{Statistical analysis}

The data are presented as the mean values \pm SD. Statistical analysis was performed by the Student $t$ test for pairwise comparisons. Survival rates were estimated by the Kaplan-Meier method and compared with the Log-rank test. $P$-values below .05 were considered significant. 


\section{Results}

\section{Splenic $\mathrm{CD}^{+} \mathrm{T}$ cells are responsible for induction of fatal AIH}

Fatal AIH developed in three-week-old NTx-PD- $1^{-/-}$mice was characterized by severe $\mathrm{CD}^{+}$and $\mathrm{CD} 8^{+} \mathrm{T}$-cell infiltration. ${ }^{3}$ To examine whether $\mathrm{CD} 4^{+}$and/or $\mathrm{CD} 8^{+} \mathrm{T}$ cells are indispensable for the development of fatal AIH, NTx-PD-1 $1^{-/}$mice were injected intraperitoneally at one day after NTx and then once a week with either anti-CD4 or anti-CD8 mAbs. After four injections of anti-CD4 or anti-CD8, the number of $\mathrm{CD}^{+}$or $\mathrm{CD} 8^{+} \mathrm{T}$ cells in the periphery was greatly reduced, respectively, and fatal AIH was suppressed (Figure $1 A$ and data not shown). Importantly, depletion of $\mathrm{CD}^{+} \mathrm{T}$ cells inhibited the infiltration of $\mathrm{CD}^{+} \mathrm{T}$ cells in the liver, whereas depletion of $\mathrm{CD}^{+} \mathrm{T}$ cells allowed $\mathrm{CD} 4^{+} \mathrm{T}$ cells to infiltrate (Figure $1 B$ ). These data suggest that both $\mathrm{CD} 4^{+}$ and $\mathrm{CD}^{+} \mathrm{T}$ cells are indispensable for the development of fatal $\mathrm{AIH}$ and that the infiltration of $\mathrm{CD}^{+} \mathrm{T}$ cells in the liver is regulated by $\mathrm{CD} 4^{+} \mathrm{T}$ cells.

Three-week-old NTx-PD-1 ${ }^{-/}$mice with severe AIH showed splenomegaly, and the spleen in these mice became enlarged as early as two weeks of age (Figure $1 C$ ). To determine whether the spleen is an induction site for fatal AIH, we performed neonatal splenectomy in these mice. We found that neonatal splenectomy suppressed mononuclear infiltration as well as destruction of organ structure in the liver, leading to a significantly higher survival rate (Figure $1 D$ and $1 E$ ). We had previously demonstrated that transfer of total but not $\mathrm{CD}^{+}$T-cell depleted splenocytes from $\mathrm{NTx}-\mathrm{PD}-1^{-/-}$mice into RAG2 ${ }^{-/-}$mice induced the development of severe hepatitis. ${ }^{3}$ Taken together, these data suggest that the spleen is an induction site for AIH and that splenic $\mathrm{CD}^{+} \mathrm{T}$ cells are responsible for induction of fatal $\mathrm{AIH}$.

\section{Splenic $C D 4^{+}$T cells in NTx-PD-1 ${ }^{-/}$mice are preferentially localized within} GC-bearing B-cell follicles

After the spleen became enlarged at two weeks of age, hepatic damage from AIH was apparent at two to three weeks in NTx-PD- $1^{-/-}$mice. ${ }^{3}$ When we looked in situ at the spleen of two-week-old NTx-PD- $1^{-/-}$mice, most of the $\mathrm{CD} 4^{+} \mathrm{T}$ cells were preferentially localized within $\mathrm{B} 220^{+}$B-cell follicles, whereas $\mathrm{CD}^{+} \mathrm{T}$ cells were mainly localized outside the follicles. Interestingly, B-cell follicles with $\mathrm{CD}^{+}{ }^{+} \mathrm{T}$-cell accumulation autonomously developed $\mathrm{PNA}^{+}$GCs (Figure $1 F$ left lower panels and 
supplementary Figure 1). Seven days after thymectomy, 1.5-week-old NTx-PD-1 ${ }^{-/}$ mice showed scattered accumulation of $\mathrm{CD}^{+} \mathrm{T}$ cells with $\mathrm{B} 220^{+} \mathrm{B}$ cells in the spleen (Figure $2 A$ ). Diffuse accumulation of $\mathrm{CD}^{+} \mathrm{T}$ cells in the follicles with GC formation developed in the spleen of 2-week-old mice and progressed in 2.5-week-old mice. Although GC size was slightly increased in the spleen of three-week-old NTx-PD-1 ${ }^{-/}$ mice, localization of $\mathrm{CD}^{+} \mathrm{T}$ cells moved into the marginal region of follicles (Figure $2 A$, right panels).

The rapid accumulation of $\mathrm{CD}^{+} \mathrm{T}$ cells in the follicles with $\mathrm{GC}$ formation depended on concurrent loss of naturally arising Tregs and PD-1 mediated signaling, because neither PD-1/- mice nor NTx mice at two weeks of age showed any of these phenotypes (Figure $1 F$ ), nor did they develop fatal AIH. ${ }^{3}$ In addition, Foxp3 expression of splenic $\mathrm{CD}^{+} \mathrm{T}$ cells of NTx-PD- $1^{-/}$mice was severely reduced (Figure $2 B$ ), and transfer of Tregs from either normal $\mathrm{BALB} / \mathrm{c}$ or $\mathrm{PD}-1^{-/-}$mice into NTx-PD- $1^{-/-}$mice suppressed GC formations in the spleen (Figure $2 C$ and data not shown). On the other hand, concomitant administration of blocking mAbs to PD-L1 and PD-L2 induced an accumulation of $\mathrm{CD}^{+} \mathrm{T}$ cells in the follicles and development of GCs in the spleen of NTx mice at two weeks (Figure 2D). Interestingly, we found that in one of the PD-1 ligands, PD-L1 mRNA expression was upregulated in the liver of one- to three-week-old NTx-PD-1 ${ }^{-/}$mice (Figure $2 E$ ).

\section{Splenic $\mathrm{CD}^{+} \mathrm{T}$ cells in $\mathrm{NTX}-\mathrm{PD}-\mathrm{I}^{--}$mice display the molecular signature} of $T_{F H}$ cells and directly induce $A I H$

We next examined whether accumulated $\mathrm{CD}^{+} \mathrm{T}$ cells in the follicles of the spleen display the molecular signature of $\mathrm{T}_{\mathrm{FH}}$ cells. $\mathrm{CD} 4^{+} \mathrm{T}$ cells in the spleen of one-week-old NTx-PD-1 ${ }^{-/}$mice showed increased IL-21 mRNA expression (Figure $3 A$ ). In addition, $\mathrm{CD}^{+} \mathrm{T}$ cells isolated from the spleen of 2 - to 3 -week-old NTx-PD-1 ${ }^{-/-}$ mice also showed increased Bcl-6 and IL-21 mRNA expressions (Figure 3B). Protein expressions of Bcl-6, IL-21, ICOS, and CXCR5 were detectable in these cells (Figure $3 C$ and $D$ upper panels), indicating some key features of $\mathrm{T}_{\mathrm{FH}}$ cells. ${ }^{7-9}$ In addition, $\mathrm{B} 220^{+}$ B cells expressed FAS and GL7 (Figure $3 D$ lower panels), hallmarks of GC B cells. ${ }^{7-9}$ Moreover, GC size increased in the spleen of mice aged one to three weeks (supplementary Figure 2). Three-week-old NTx-PD-1 $1^{-/}$mice showed hyper-gammaglobulinemia and vast production of class-switched ANAs (supplementary 
Figure 3).

To investigate whether splenic $\mathrm{T}_{\mathrm{FH}}$ cells directly trigger the development of T-cell mediated AIH, we purified $\mathrm{ICOS}^{+} \mathrm{CD}^{+} \mathrm{T}_{\mathrm{FH}}$ cells or $\mathrm{ICOS}^{-} \mathrm{CD}^{+} \mathrm{T}$ cells from the spleen of 2.5-week-old NTx-PD-1 ${ }^{-/}$mice and transferred those $\mathrm{T}$ cells into $\mathrm{T}$ - and B-cell-deficient RAG2 ${ }^{-/-}$mice. In contrast to transfer of $\mathrm{ICOS}^{-} \mathrm{CD}^{+} \mathrm{T}$ cells, transfer of $\mathrm{ICOS}^{+} \mathrm{CD} 4^{+} \mathrm{T}_{\mathrm{FH}}$ cells induced mononuclear cell infiltrations in the portal area of the liver and significantly increased serum levels of AST and ALT in recipient mice at three weeks after transfer (Figure $3 E$ and $3 F$ ). These data suggest that splenic $\mathrm{T}_{\mathrm{FH}}$ cells in NTx-PD- ${ }^{-/}$mice can directly trigger T-cell-mediated AIH.

Key features of $T_{F H}$ cells, expressions of $I L-21$ and Bcl6 are sustained in splenic and hepatic $\mathrm{CD}^{+}{ }^{+}$cells in the development of $\mathrm{AIH}$

To further characterize $\mathrm{CD}^{+} \mathrm{T}$ cell subsets in the development of $\mathrm{AIH}$, we isolated splenic and hepatic $\mathrm{CD}^{+} \mathrm{T}$ cells from $\mathrm{NTx}-\mathrm{PD}-1^{-/-}$mice aged one to three weeks and measured expression levels of mRNA encoding master regulators and related cytokines for different $\mathrm{T}$-cell subsets. Although not only $\mathrm{T}_{\mathrm{FH}}$ cells but also Th17 cells are reported to express IL-21, ${ }^{12}$ isolated $\mathrm{CD}^{+} \mathrm{T}$ cells from the spleen and liver showed upregulated IL-21 but not IL-17A mRNA expression in NTx-PD-1 ${ }^{-/-}$mice (Figure $4 A$ ), suggesting these $\mathrm{CD}^{+} \mathrm{T}$ cells are not likely to be a Th17 subset. When we looked at master regulators for T-cell subsets, in $\mathrm{NTx}-\mathrm{PD}-1^{-/-}$mice at one week, splenic $\mathrm{CD} 4^{+} \mathrm{T}$ cells significantly upregulated mRNA expression of Bcl- 6 but not ROR $\gamma$ T, GATA-3 or T-bet (Figure $4 B$ ). In addition, in the induction phase of AIH in NTx-PD- ${ }^{-/}$mice at two weeks, not only splenic $\mathrm{CD}^{+}{ }^{\mathrm{T}}$ cells but also hepatic $\mathrm{CD}^{+} \mathrm{T}$ cells significantly upregulated mRNA expression of Bcl-6 but not others. Notably, although T-bet expression was also significantly upregulated in both splenic and hepatic CD4 ${ }^{+} \mathrm{T}$ cells in the progression phase of $\mathrm{AIH}$ in $\mathrm{NTx}-\mathrm{PD}-1^{-/}$mice at three weeks, upregulated expression of Bcl-6 was sustained in those $\mathrm{CD} 4^{+} \mathrm{T}$ cells.

Administration of either anti-ICOS or anti-IL-21 completely suppresses not only $T_{F H}$-cell generation but also induction of fatal AIH

IL-12 is decisive in the development of Th1 subsets whereas ICOS and IL-21 are indispensable for $\mathrm{T}_{\mathrm{FH}^{-}}$-ell differentiation and maturation. ${ }^{7-9}$ To further examine whether differentiation of $\mathrm{Th} 1 \mathrm{and} /$ or $\mathrm{T}_{\mathrm{FH}}$ subsets is critical in the induction of $\mathrm{AIH}$, we 
administered blocking mAbs to IL-12p40, ICOS or IL-21. Although production of ANA in both IgG1 and IgG2a subclass increased in NTx-PD-1 ${ }^{-/-}$mice (supplementary Figure 3), injections of anti-IL-12p40 induced reciprocal alteration of ANA in Th1-dependent IgG2a and Th2-dependent IgG1 subclasses (supplementary Figure 4). However, the neutralization of IL-12 did not significantly reduce the size of GCs in the spleen at four weeks (Figure $4 C$ ). In contrast, after four injections of either anti-ICOS or anti-IL-21, $\mathrm{NTx}-\mathrm{PD}-1^{-/-}$mice at four weeks showed markedly suppressed GC formation in the spleen and accumulation of $\mathrm{CD}^{+} \mathrm{T}$ cells in the follicles (Figures $4 C, 4 D$ and supplementary Figures $5 A$ and $6 A$ ). In addition, hyper-gammaglobulinemia and ANA production, including class-switched Abs, were greatly reduced in those mice (supplementary Figure $5 C$ and data not shown). Importantly, although neutralizing IL-12 did not suppress AIH development, either anti-ICOS or anti-IL-21 injections completely suppressed infiltration of not only $\mathrm{CD}^{+} \mathrm{T}$ cells but also $\mathrm{CD} 8^{+} \mathrm{T}$ cells in the liver as well as liver destruction, resulting in a significantly higher survival rate (Figure $4 D-F$ and supplementary Figures $5 B$ and $6 B$ ). These data suggest a link between generation of $\mathrm{T}_{\mathrm{FH}}$ cells and induction of AIH.

\section{IL-21 is a key cytokine for not only $T_{F H}$ generation but also activation of} $\mathrm{CDS}^{+} \mathrm{T}$ cells

Next, we examined how $\mathrm{CD}^{+} \mathrm{T}$ cells help $\mathrm{CD}^{+} \mathrm{T}$ cells in developing AIH. In the induction phase in two-week-old mice, $\mathrm{CD}^{+} \mathrm{T}$ cells not only in the liver but also in the spleen showed $\mathrm{Ki}-67^{\text {high }}$ activated T-cell phenotype with highly proliferating potential (Figure $5 A$ ). IL-21 potentially modulates activity of $\mathrm{CD}^{+} \mathrm{T}$ cells, ${ }^{11}$ and $\mathrm{T}_{\mathrm{FH}}$ cells in the spleen produced IL-21 (Figure $3 A-C$ and $4 A$ ). Moreover, IL-21R mRNA expression in splenic $\mathrm{CD}^{+} \mathrm{T}$ cells was elevated in $\mathrm{NTx}-\mathrm{PD}-1^{-/-}$mice (Figure $5 B$ ). Therefore, to examine whether $\mathrm{CD} 4^{+} \mathrm{T}$-cell help for $\mathrm{CD} 8^{+} \mathrm{T}$-cell activation in the spleen depends on IL-21 in the induction phase of $\mathrm{AIH}, \mathrm{CD}^{+} \mathrm{T}$ cells were purified from the spleen of $\mathrm{PD}-1^{-/-}$mice. These $\mathrm{CD} 8^{+} \mathrm{T}$ cells were cultured with $\mathrm{CD} 4^{+} \mathrm{T}$ cells from the spleen of two-week-old PD- $1^{-/-}$mice with or without NTx. After one day of culture, $\mathrm{CD}^{+} \mathrm{T}$ cells cultured with $\mathrm{CD} 4^{+} \mathrm{T}$ cells from NTx-PD- $1^{-/-}$mice showed a significant increase of $\mathrm{Ki}^{+} 7^{+}$cells in the $\mathrm{CD} 8^{+} \mathrm{T}$-cell population, indicating that activated $\mathrm{CD} 4^{+} \mathrm{T}$ cells in the spleen of $\mathrm{NTX}-\mathrm{PD}-1^{-/-}$mice have the potential to induce $\mathrm{CD} 8^{+} \mathrm{T}$-cell activation (Figure 5C). In addition, neutralizing antibodies to IL-21 suppressed increase 
of $\mathrm{Ki}^{+} 7^{+}$cells in $\mathrm{CD} 8^{+} \mathrm{T}$-cell population cultured with those $\mathrm{CD} 4^{+} \mathrm{T}$ cells, suggesting that IL-21 produced by $\mathrm{T}_{\mathrm{FH}}$ cells drives activation of $\mathrm{CD}^{+} \mathrm{T}$ cells (Figure 5D). Moreover, recombinant IL-21 further increased $\mathrm{Ki}_{6} 7^{+} \mathrm{CD} 8^{+} \mathrm{T}$ cells cultured with those $\mathrm{CD}^{+} \mathrm{T}$ cells dose-dependently (Figure $5 E$ ). These data suggest that IL-21 is a key cytokine for not only $\mathrm{T}_{\mathrm{FH}}$ generation but also activation of $\mathrm{CD}^{+} \mathrm{T}$ cells in $\mathrm{AIH}$ development.

The CCR6-CCL20 axis is crucial for splenic T-cell migration into the liver,

\section{inducing fatal $\mathrm{AIH}$}

Finally, to examine how dysregulated $\mathrm{T}_{\mathrm{FH}}$ cells and activated $\mathrm{CD}^{+} \mathrm{T}$ cells migrate from the spleen into the liver in the induction phase of $\mathrm{AIH}$, we analyzed chemokine receptor expression of $\mathrm{T}$ cells in the spleen and liver by flow cytometry. Previously we showed that $\mathrm{CD}^{+}{ }^{+}$cells in the spleen and liver expressed chemokine receptor CCR6 in NTx-PD- $1^{-/}$mice. ${ }^{3}$ In $\mathrm{CD}^{+} \mathrm{T}$ cells of two-week-old NTx-PD-1 ${ }^{-/-}$ mice, $\mathrm{CCR}^{+}$and, to a lesser extent, $\mathrm{CCR}^{+}$cells increased (Figure 6A). The predominant increase of $\mathrm{CCR} 6^{+}$cells was observed only at two weeks in the spleen and liver but not in mesenteric lymph nodes. In contrast, in three-week-old mice, CXCR3 ${ }^{+}$ cells were predominant in splenic and hepatic $\mathrm{CD}^{+} \mathrm{T}$ cells compared with $\mathrm{CCR} 6^{+}$or $\mathrm{CCR}^{+}$cells (Figure $6 B$ ). Splenic $\mathrm{CCR}^{+} \mathrm{CD}^{+} \mathrm{T}$ cells in $\mathrm{NTx}-\mathrm{PD}-1^{-/-}$mice contained $\mathrm{CXCR}^{+} \mathrm{CCR}^{+}$population (Figure $6 \mathrm{C}$ left panels), suggesting that these $\mathrm{T}$ cells retained the molecular signature of $\mathrm{T}_{\mathrm{FH}}$ cells. In three-week-old mice, $\mathrm{CXCR} 5^{+} \mathrm{CCR} 6^{-}$ population was further increased whereas the $\mathrm{CXCR} 5^{+ \text {or- }} \mathrm{CCR}^{+}$population was decreased (Figure 6 C right panels), suggesting preferential loss of CCR6 ${ }^{+}$cells from the spleen after induction of $\mathrm{AIH}$. In addition to $\mathrm{CD}^{+} \mathrm{T}$ cells, in $\mathrm{CD}^{+} \mathrm{T}$ cells, predominant increases of $\mathrm{CCR}^{+}$cells in the spleen and liver were also found in the induction phase of $\mathrm{AIH}$ (Figure $6 D$ and $6 E$ ). Moreover, gene expression of CCR6 ligand CCL20, but not CCR9 ligand CCL25, was elevated in the liver of 1.5- and 2-week-old NTx-PD-1 ${ }^{-/-}$mice (Figure $6 F$ ). These data suggest that CCR6 expressing T cells in the spleen may migrate into CCL20-expressing liver and trigger the development of fatal AIH.

To determine whether the CCR6-CCL20 axis is critical for migration of splenic $\mathrm{T}$ cells into the liver and triggering fatal $\mathrm{AIH}$, we administered mAbs blocking to CCL20. After three injections of anti-CCL20 Abs, the spleen of three-week-old 
$\mathrm{NTx}-\mathrm{PD}-1^{-/-}$mice showed further accumulation of $\mathrm{T}_{\mathrm{FH}}$ cells in the $\mathrm{GC}^{+}$follicles diffusely (Figure $7 A$ and Figure $7 B$ left panel). These findings contrasted with the spleens of non-injected three-week-old NTx-PD-1 ${ }^{-/-}$mice, in which splenic $\mathrm{T}_{\mathrm{FH}}$ cells were mainly localized in the marginal region of follicles (Figure 7A), and with the spleens from anti-ICOS or anti-IL-21 injected mice, in which splenic CD4 ${ }^{+} \mathrm{T}$ cells were greatly reduced (Figure 4D). Importantly, administering anti-CCL20 suppressed infiltration of $\mathrm{CD}^{+}$and $\mathrm{CD}^{+} \mathrm{T}$ cells into the liver and liver destruction, with a significantly increased survival rate at four weeks (Figure $7 B$ right panel, $7 C$ and $7 D$ ). These data suggest that in the induction phase of AIH, the CCR6-CCL20 axis is crucial for migration of dysregulated $\mathrm{T}_{\mathrm{FH}}$ cells and activated $\mathrm{CD} 8^{+} \mathrm{T}$ cells from the spleen into the liver. 


\section{Discussion}

We demonstrated herein that in our mouse model of spontaneous AIH induced by a concurrent loss of Tregs and PD-1-mediated signaling, splenic $\mathrm{CD}^{+} \mathrm{T}$ cells are crucial in the development of fatal AIH. In the induction phase, splenic $\mathrm{CD}^{+} \mathrm{T}$ cells in these mice showed the $\mathrm{T}_{\mathrm{FH}}$-cell phenotype, and CCR6-expressing $\mathrm{T}_{\mathrm{FH}}$ cells and activated $\mathrm{CD}^{+} \mathrm{T}$ cells in the spleen preferentially recruited to the liver via CCL20, triggering the induction of fatal AIH.

We found that $\mathrm{CD}^{+} \mathrm{T}$ cells in the induction site of $\mathrm{AIH}$, the spleen, were exclusively localized in GC-bearing B-cell follicles. In the induction phase of AIH, these $\mathrm{CD}^{+} \mathrm{T}$ cells upregulated expression of Bcl6, the master transcription factor for $\mathrm{T}_{\mathrm{FH}}$-cell differentiation, and showed the IL-21 ${ }^{+} \mathrm{IL}-21 \mathrm{R}^{+} \mathrm{ICOS}^{+} \mathrm{CXCR} 5^{+} \mathrm{T}_{\mathrm{FH}}$-cell phenotype. ${ }^{7-9}$ In addition, B cells in the spleen contained $\mathrm{FAS}^{+} \mathrm{GL}^{+} \mathrm{GC} \mathrm{B}$ cells, and hyper-gammaglobulinemia, and huge production of class-switched ANAs were observed in the serum from NTx-PD- $1^{-/}$mice. Moreover, in vivo administration of blocking Abs to ICOS or IL-21, indispensable for $\mathrm{T}_{\mathrm{FH}}$-cell generation and maturation ${ }^{7-9}$, inhibited accumulation of $\mathrm{CD}^{+}{ }^{+} \mathrm{T}$ cells in B-cell follicles and $\mathrm{GC}$ formation in the spleen, and suppressed hyper-gammaglobulinemia, class-switched ANA production as well as induction of AIH. Importantly, adaptive transfer of the splenic $\mathrm{T}_{\mathrm{FH}}$ cells from NTx-PD-1 ${ }^{-/}$mice directly triggered T-cell-mediated AIH. From these data, we concluded that in our mouse model, the responsible $\mathrm{CD}^{+} \mathrm{T}$-cell subset in the induction site of $\mathrm{AIH}$ is $\mathrm{T}_{\mathrm{FH}}$ cells.

Previously, we reported that severely inflamed livers in three-week-old $\mathrm{NTx}-\mathrm{PD}-1^{-/-}$mice contained a massive infiltration of activated $\mathrm{CD} 4^{+}$and $\mathrm{CD} 8^{+} \mathrm{T}$ cells producing inflammatory cytokines, such as IFN- $\gamma$ and TNF- $\alpha .^{3}$ In contrast, we found in this study that in the induction phase of AIH, IL-21-producing splenic $\mathrm{T}_{\mathrm{FH}}$ cells were responsible for the initiation of liver inflammation. Thus, dysregulated $\mathrm{T}_{\mathrm{FH}}$ cells and Th1-like cells appear to operate at different time points in the development of fatal AIH. Recent studies show that although in experimental autoimmune encephalomyelitis (EAE), a $\mathrm{CD}^{+} \mathrm{T}$ cell-mediated disease of the central nervous system, Th1 cells are present in EAE lesions during its active phase, in its induction phase, Th17 cells directly initiate inflammation and trigger the entry of a second wave of Th1 cells that migrate into the lesions. ${ }^{13}$ Because we found upregulation of bcl-6 and t-bet in both splenic and hepatic $\mathrm{CD}^{+} \mathrm{T}$ cells of three-week-old NTx-PD-1 ${ }^{-/-}$mice, it might be that in the 
progression phase of $\mathrm{AIH}$, dysregulated $\mathrm{T}_{\mathrm{FH}}$ cells directly differentiate into Th1-like cells in the spleen and give rise to the migration of a second wave of Th1-like cells into the liver.

In this mouse model, infiltration of both $\mathrm{CD}^{+}$and $\mathrm{CD}^{+} \mathrm{T}$ cells in the liver are required for progression to fatal $\mathrm{AIH}$, and the infiltration of $\mathrm{CD} 8^{+} \mathrm{T}$ cells in the liver depends on $\mathrm{CD}^{+} \mathrm{T}$ cells. In the induction phase of $\mathrm{AIH}$, splenic $\mathrm{CD} 8^{+} \mathrm{T}$ cells showed $\mathrm{Ki}-67^{\text {high }}$ activated $\mathrm{T}$ cell phenotype. $\mathrm{CD} 4^{+} \mathrm{T}$ cells from the spleen of two-week-old $\mathrm{NTx}-\mathrm{PD}-1^{-/-}$mice induced IL-21-driven $\mathrm{CD} 8^{+} \mathrm{T}$-cell activation. In addition, activated $\mathrm{CD}^{+} \mathrm{T}$ cells in the spleen expressed CCR6 and were preferentially recruited to the liver via CCL20. However, the precise roles of $\mathrm{CD}^{+} \mathrm{T}$ cells in the induction phase of AIH are still unclear. Because a large number of $\mathrm{CD}^{+} \mathrm{T}$ cells infiltrated into the liver during $\mathrm{AIH}$ progression, $\mathrm{CD}^{+} \mathrm{T}$ cells infiltrated in the induction phase might be involved in triggering the subsequent expansion and/or infiltration of inflammatory $\mathrm{T}$ cells in the progression phase.

We showed here that the CCR6-CCL20 axis is essential for splenic $\mathrm{T}_{\mathrm{FH}}$ cells to migrate into the liver, triggering inflammation. CCR6 is also expressed on Th17 cells and is vital to the initiation of Th17-cell migration to target tissues. ${ }^{13-15}$ CCR6 is expressed on not only Th17 cells but also Tregs in mice, ${ }^{14,15}$ and human T cells that produce both IL-17 and IFN- $\gamma$ as well as Th1 cells. ${ }^{16}$ Taken together, these data suggest that the CCR6-CCL20 axis plays an important role in the migration of instructed CD4 ${ }^{+}$ $\mathrm{T}$ cells into target tissues.

We also showed that NTx-PD-1 ${ }^{-/-}$mice but not NTx mice at two weeks generated $\mathrm{T}_{\mathrm{FH}}$ cells in the spleen. In addition, concomitant administration of blocking mAbs to PD-L1 and PD-L2 generated $\mathrm{T}_{\mathrm{FH}}$ cells in the spleen of NTx mice at two weeks. Moreover, purified CD4 $4^{+} \mathrm{T}$ cells in the spleen of one-week-old NTx-PD- $1^{-/-}$mice had greater IL-21 mRNA expression than those in NTx mice. In this regard, recent studies suggested that $\mathrm{PD}-1$ deficiency increased $\mathrm{T}_{\mathrm{FH}^{-}}$-cell numbers but reduced IL-21 production by $\mathrm{T}_{\mathrm{FH}}$ cells in long-term humoral immunity, ${ }^{17}$ and that $\mathrm{T}_{\mathrm{FH}}$-cell differentiation requires strong signals through the $\mathrm{T}$ cell receptor. ${ }^{18}$ Thus, in our model, PD-1-deficiency may induce enhanced production of IL-21 by activated autoreactive $\mathrm{CD}^{+} \mathrm{T}$ cells to differentiate into $\mathrm{T}_{\mathrm{FH}}$ cells in the induction phase. On the other hand, we found that PD-L1 but not PD-L2 mRNA expression was upregulated in the liver of NTx-PD- $1^{-/}$mice. Because PD-1 and PD-Ls expressions are increased in the livers of 
most AIH patients, ${ }^{19,20}$ it is possible that PD-1/PD-L1 interaction is insufficient to completely suppress liver inflammation but may halt progression to fatal AIH.

In humans, it is unknown at present whether the spleen is the induction site of $\mathrm{AIH}$ or $\mathrm{T}_{\mathrm{FH}}$ cells are the $\mathrm{T}$ cell subset responsible for induction of $\mathrm{AIH}$. In patients with active AIH, splenomegaly is a common clinical finding. However, splenectomy for these patients has not been reported to be therapeutic. Therefore, splenectomy may help patients at the early phase of AIH, but not those with more advanced cases. Notably, because patients with severe AIH have a high potential for recurrence after liver transplantation and the recurrence of AIH leads to a greater probability of graft loss, ${ }^{21,22}$ splenectomy might be a therapeutic option to prevent recurrence after liver transplantation. On the other hand, it may be that dysregulated $\mathrm{T}_{\mathrm{FH}}$ cells are involved in both B-cell and T-cell mediated autoimmunity in human AIH. Indeed, $\mathrm{T}_{\mathrm{FH}}$ cells not only offer powerful help to B cells in forming germinal centers in humoral immunity but also induce B-cell mediated systemic autoimmunity in humans and mice. ${ }^{7-9,23}$ In addition, although $\mathrm{T}_{\mathrm{FH}}$ cells are mainly localized in B-cell follicles in lymphoid organs, circulating $\mathrm{T}$ cells resembling $\mathrm{T}_{\mathrm{FH}}$ cells exist in the peripheral blood of patients with systemic lupus erythematosus. ${ }^{10}$ Furthermore, IL-21 secreted by effector $\mathrm{T}$ cells including $\mathrm{T}_{\mathrm{FH}}$ cells can modulate the activity of $\mathrm{CD}^{+} \mathrm{T}$ cells and other immune and non-immune cells in humans and mice. ${ }^{11}$

In conclusion, we demonstrated in the present study that Tregs and PD-1-mediated signaling are important in regulating $\mathrm{T}_{\mathrm{FH}}$ cells and that dysregulated $\mathrm{T}_{\mathrm{FH}}$ cells in the spleen are responsible for induction of fatal AIH in NTx-PD- ${ }^{-/}$mice. In addition, CCR6-CCL20 axis-dependent migration of $\mathrm{T}_{\mathrm{FH}}$ cells is crucial for initiation of AIH. These data may lead to novel therapeutic approaches to human AIH, especially acute-onset fulminant $\mathrm{AIH}$. 


\section{Acknowledgments}

We thank Dr. Dovie Wylie for assistance in preparation of the manuscript; Ms. Chigusa Tanaka for excellent technical assistance; Drs. Tasuku Honjo, Shuh Narumiya, Nagahiro Minato, Shimon Sakaguchi, and Ichiro Aramori for critical discussion and suggestions.

\section{Grant Support}

Center for Innovation in Immunoregulative Technology and Therapeutics is supported in part by the Special Coordination Funds for Promoting Science and Technology of the Japanese Government and in part by Astellas Pharma Inc. in the Formation of Innovation Center for Fusion of Advanced Technologies Program. 


\section{References}

1. Krawitt EL. Autoimmune hepatitis. N Engl J Med 2006;354:54-66.

1. Manns MP, Vogel A. Autoimmune hepatitis, from mechanisms to therapy. Hepatology 2006;43:S132-144.

2. Kido M, Watanabe N, Okazaki T, et al. Fatal autoimmune hepatitis induced by concurrent loss of naturally arising regulatory $\mathrm{T}$ cells and PD-1-mediated signaling. Gastroenterology 2008;135:1333-1343.

3. Diamantis I, Boumpas DT. Autoimmune hepatitis: evolving concepts. Autoimmun Rev 2004;3:207-214.

4. Ichiki Y, Aoki CA, Bowlus CL, et al. T cell immunity in autoimmune hepatitis. Autoimmun Rev 2005;4:315-321.

5. Suzuki Y, Kobayashi M, Hosaka T, et al. Peripheral CD8+/CD25+ lymphocytes may be implicated in hepatocellular injuries in patients with acute-onset autoimmune hepatitis. J Gastroenterol 2004;39:649-653.

6. McHeyzer-Williams LJ, Pelletier N, Mark L, et al. Follicular helper T cells as cognate regulators of B cell immunity. Curr Opin Immunol 2009;21:266-273.

7. King C. New insights into the differentiation and function of $\mathrm{T}$ follicular helper cells. Nat Rev Immunol 2009;9:757-766.

8. Yu D, Batten M, Mackay CR, et al. Lineage specification and heterogeneity of T follicular helper cells. Curr Opin Immunol 2009;21:619-625.

9. Simpson N, Gatenby PA, Wilson A, et al. Expansion of circulating $\mathrm{T}$ cells resembling follicular helper $\mathrm{T}$ cells is a fixed phenotype that identifies a subset of severe systematic lupus erythematosus. Arthritis Rheum 2010;62:234-244.

10. Monteleone G, Pallone F, Macdonald TT. Interleukin-21 (IL-21)-mediated pathways in $\mathrm{T}$ cell-mediated disease. Cytokine Growth Factor Rev 2009;20:185-191.

11. Korn T, Bettelli E, Oukka M, et al. IL-17 and Th17 Cells. Annu Rev Immunol 2009;27:485-517.

12. Reboldi A, Coisne C, Baumjohann D, et al. C-C chemokine receptor 6-regulated entry of TH-17 cells into the CNS through the choroid plexus is required for the initiation of EAE. Nat Immunol 2009;10:514-523.

13. Hirota K, Yoshitomi $\mathrm{H}$, Hashimoto $\mathrm{M}$, et al. Preferential recruitment of 
CCR6-expressing Th17 cells to inflamed joints via CCL20 in rheumatoid arthritis and its animal model. J Exp Med 2007;204:2803-2812.

14. Yamazaki T, Yang XO, Chung $\mathrm{Y}$, et al. CCR6 regulates the migration of inflammatory and regulatory T cells. J Immunol 2008;181:8391-8401.

15. Acosta-Rodriguez EV, Rivino L, Geginat J, et al. Surface phenotype and antigenic specificity of human interleukin 17-producing $\mathrm{T}$ helper memory cells. Nat Immunol 2007;8:639-646.

16. Good-Jacobson KL, Szumilas CG, Chen L, et al. PD-1 regulates germinal center $\mathrm{B}$ cell survival and the formation and affinity of long-lived plasma cells. Nat Immunol 2010;11:535-542.

17. Fazilleau N, McHeyzer-Williams LJ, Rosen H, et al. The function of follicular helper $\mathrm{T}$ cells is regulated by the strength of $\mathrm{T}$ cell antigen receptor binding. Nat Immunol 2009;10:375-384.

18. Oikawa $\mathrm{T}$, Takahashi $\mathrm{H}$, Ishikawa $\mathrm{T}$, et al. Intrahepatic expression of the co-stimulatory molecules programmed death-1, and its ligands in autoimmune liver disease. Pathol Int 2007;57:485-492.

19. Kassel R, Cruise MW, Iezzoni JC, et al. Chronically inflamed livers up-regulate expression of inhibitory B7 family members. Hepatology 2009;50:1625-1637.

20. Vogel A, Heinrich E, Bahr MJ, et al. Long-term outcome of liver transplantation for autoimmune hepatitis. Clin Transplant 2004;18:62-69.

21. Rowe IA, Webb K, Gunson BK, et al. The impact of disease recurrence on graft survival following liver transplantation: a single centre experience. Transpl Int 2008;21:459-465.

22. Linterman MA, Rigby RJ, Wong RK, et al. Follicular helper T cells are required for systemic autoimmunity. J Exp Med 2009;206:561-576. 


\section{Figure legends}

\section{Figure 1}

Splenic $\mathrm{CD}^{+} \mathrm{T}$ cells are responsible for induction of fatal $\mathrm{AlH}$. ( $A$ and $\left.B\right)$ NTx-PD- ${ }^{-/-}$mice were injected intraperitoneally at one day after NTx and then once a week with anti-CD4 $(n=5)$, anti-CD8 $(n=5)$, or isotype $(n=5)$ Abs. After four injections, mice at four weeks of age were sacrificed and the livers were harvested. Survival rate of the mice $(A)$ and stainings of the liver for hematoxylin and eosin (HE), CD4 and CD8 at four weeks $(B) .(C)$ Macroscopic view of the liver and spleen from indicated mice. ( $D$ and $E$ ) Survival rate $(D)$ and histology of the liver $(E)$ from 4-week-old NTx-PD-1 ${ }^{-/-}$mice with $(n=7)$ or without $(n=9)$ neonatal splenectomy (NSplx). ( $F$ ) The spleens from indicated mice at two weeks of age were stained with FITC-conjugated anti-CD4, anti-CD8 or PNA (green) and biotin-labeled anti-B220 followed by Texas red-conjugated avidin (red). Scale bars, $1 \mathrm{~cm}$ in $(C)$ and others, $100 \mu \mathrm{m} .{ }^{*}$; $\mathrm{P}<0.05$.

\section{Figure 2}

Autonomous localization of splenic $\mathrm{CD}^{+} \mathrm{T}$ cells within $\mathrm{GC}^{+}$follicles depends on concurrent loss of naturally arising Tregs and PD-1 mediated signaling. $(A)$ The spleens from indicated mice at one to three weeks of age were stained as described in Figure 1F. $(B)$ Foxp3 mRNA expression by $\mathrm{CD}^{+} \mathrm{T}$ cells from the spleen of indicated mice $(C)$ Double immunostainings of the spleen from 2-week-old NTx-PD-1 ${ }^{-/-}$mice transferred with splenic Tregs from normal BALB/c mice. The spleens were stained as Figure 1F. $(D)$ Double immunostainings of the spleen in 2-week-old NTx mice injected at days 3 and 10 with anti-PD-L1 and anti-PD-L2. The spleens were stained as described in Figure 1F. $(E)$ PD-L1 and PD-L2 mRNA expressions of liver and spleen of PD- $1^{-/-}$mice at indicated age in weeks with (closed bars) or without (open bars) NTx. Bars indicate the mean of each group, and short bars indicate the SD. *; $\mathrm{P}<0.05$. N.D.; not detected. All scale bars, $100 \mu \mathrm{m}$.

\section{Figure 3}


Splenic CD4 ${ }^{+}$T cells in NTX-PD- $1^{-/-}$mice display the molecular signature of $\mathrm{T}_{\mathrm{FH}}$ cells and directly trigger $\mathrm{AlH}$. (A) IL-21 mRNA expressions by isolated splenic $\mathrm{CD}^{+} \mathrm{T}$ cells in indicated mice at one week of age. $(B) \mathrm{Bcl} 6$ and IL-21 mRNA expressions by isolated splenic $\mathrm{CD}^{+} \mathrm{T}$ cells and $\mathrm{B} 220^{+} \mathrm{B}$ cells in 2.5 -week-old PD- $1^{-/-}$mice with (closed bars) or without (open bars) NTx. (C) Double immunostainings of isolated splenic $\mathrm{CD}^{+} \mathrm{ICOS}^{+} \mathrm{T}$ cells from 2.5 -week-old NTx-PD-1 ${ }^{-/-}$mice with DAPI and anti-Bcl6, anti-IL-21, or the isotype controls. (D) Flow cytometric analysis of $\mathrm{CD}^{+}{ }^{+} \mathrm{T}$ cells (upper panels) and $\mathrm{B}^{2} 20^{+}$cells (lower panels) in indicated mice at two or three weeks of age. The cells were stained with indicated Abs as described in Methods. Numbers in plots indicate percent cells in each gate. ( $E$ and $F$ ) $\mathrm{CD}^{+}{ }^{+} \mathrm{COS}^{+} \mathrm{T}$ cells or $\mathrm{CD}^{+}{ }^{+} \mathrm{ICOS}^{-} \mathrm{T}$ cells from the spleen of 2.5-week-old NTx-PD-1 ${ }^{-/-}$mice were transferred into RAG2 ${ }^{-/-}$ mice intravenously. Staining of the liver for HE three weeks after transfer $(E)$. Serum levels of the liver transaminase, aspartate aminotransferase (AST), and alanine aminotransferase (ALT) $(F)$. Bars indicate the mean of each group, and horizontal short bars indicate the SD. *; P < 0.05. N.D.; not detected. Scale bars, $10 \mu \mathrm{m}$ in $(C)$ and others, $100 \mu \mathrm{m}$.

\section{Figure 4}

$\mathrm{T}_{\mathrm{FH}}$-cell generation rather than Th1 differentiation is primarily involved in the induction of fatal AlH. ( $A$ and $B$ ) Splenic and hepatic $\mathrm{CD}^{+}{ }^{+} \mathrm{T}$ cells were isolated from indicated aged PD-1/- mice with (closed bars) or without (open bars) NTx. Real-time quantitative RT-PCR analysis was performed to measure the expression levels of mRNA encoding indicated master regulators for $\mathrm{T}$ cell subsets and related cytokines. (C-F) NTx-PD-1/- mice were intraperitoneally injected as described in Figure $1 B$ with anti-IL-12p40, anti-ICOS, or anti-IL-21 Abs. After four injections, mice at four weeks of age were sacrificed and the spleens and livers harvested. In Figure 4C, the size of GCs in the spleen of indicated mice. Spleens were stained as Figure $1 F$. Each open circle represents a size of GC measured in high-power fields $(C) . \mathrm{CD}^{+} \mathrm{T}$ cell numbers in the follicles of the spleen (left) or the liver (right) of indicated mice $(D)$. HE staining of 
the liver and survival rate in NTx-PD-1 ${ }^{-/-}$mice injected with anti-IL-12p40 (n=5) or isotype $(n=5)$ Abs $(E)$. Survival rate in NTx-PD-1 $1^{-/-}$mice with anti-ICOS $(n=5)$ or isotype $(n=7)$ Abs and those with anti-IL-21 $(n=5)$ or isotype $(n=5)$ Abs $(F)$. Bars indicate the mean of each group, and short bars indicate the SD. *; P < 0.05. N.D.; not detected. All scale bars, $100 \mu \mathrm{m}$.

\section{Figure 5}

IL-21 is a key cytokine for $\mathrm{CD}^{+} \mathrm{T}$-cell activation induced by $\mathrm{CD} 4^{+} \mathrm{T}$ cells. $(A)$ Flow cytometric analysis of cells in the spleen and liver of 2-week-old NTx-PD- $1^{-/-}$mice. Phenotypes of $\mathrm{CD} 3^{+} \mathrm{CD} 4^{+}$and $\mathrm{CD} 3^{+} \mathrm{CD} 8^{+} \mathrm{T}$ cells were shown. Filled histograms represent anti-Ki-67 staining; open histograms represent the isotype controls. Numbers indicate percent of $\mathrm{Ki} 67^{+}$cells. Data represent one of three separate experiments. (B) IL-21R mRNA expressions by isolated CD4 ${ }^{+}$, $\mathrm{CD}^{+} \mathrm{T}$ cells, and $\mathrm{B} 22 \mathrm{O}^{+} \mathrm{B}$ cells of the spleen and liver in 2.5-week-old PD- $1^{-/-}$ mice with (closed bars) or without (open bars) NTx. Bars indicate the mean of each group, and horizontal short bars indicate the SD. (C-E) Flow cytometric analysis of $C D 8^{+} \mathrm{T}$ cells. CD8 ${ }^{+} \mathrm{T}$ cells were purified from the spleen of $\mathrm{PD}-1^{-/-}$ mice and then cultured with $C D 4^{+} \mathrm{T}$ cells from the spleen of two-week-old PD- $1^{-/-}$ mice with or without NTx. After one day of culture with indicated conditions, percent of $\mathrm{Ki}^{+} 7^{+}$cells in $\mathrm{CD}^{+} \mathrm{T}$-cell population was determined by flow cytometry. Bars indicate the mean of triplicated wells of each group, and horizontal short bars indicate the SD. *; $\mathrm{P}<0.05$.

\section{Figure 6}

$\mathrm{CCR}^{+}$cells are predominantly increased in $\mathrm{CD}^{+}$and $\mathrm{CD}^{+}{ }^{\mathrm{T}}$ cells in the spleen and liver only in the induction phase of $\mathrm{AlH}$. $(A-E)$ Cells in the spleen, liver and mesenteric lymph nodes (MLN) of NTx-PD-1 $1^{-/-}$mice at the indicated age were stained with FITC-anti-CD3e, APC-Cy7-anti-CD4 and PE-anti-CCR6, -anti-CCR9, or -anti-CXCR3 ( $A, B$ and $D$ upper panles), with FITC-anti-CXCR5, PE-anti-CCR6, and APC-Cy7-anti-CD4 (C), or with FITC-anti-CD3e, PE-anti-CCR6 APC-anti-CD8 (D lower panels and E). Flow cytometric analyses 
were assessed as in Figure 3D. Numbers of indicated T cell populations were calculated by (percentage of the cells in viable cells) $x$ (no. of viable cells) $(A, B$, $C$ right panels, and $E$ ). Numbers indicate percent of indicated gates ( $C$ left panels, $D) .(F)$ CCL20 or CCL25 mRNA expressions in the spleen and liver of $\mathrm{PD}-1^{-/-}$mice at indicated age with (closed bars) or without (open bars) NTx. Bars indicate the mean of each group, and horizontal short bars indicate the SD. *; $P$ $<0.05$.

\section{Figure 7}

The CCR6-CCL20 axis plays a crucial role for both migration of splenic $\mathrm{T}_{\mathrm{FH}}$ cells into the liver and induction of fatal AIH. $(A-D)$ NTX-PD-1 ${ }^{-/-}$mice were injected intraperitoneally as described in Figure 1 with anti-CCL20 $(n=10)$ or isotype $(n=10)$ Abs. The spleen and liver were stained as in Figure $1 B$ and $1 F$. Double immunostainings of the spleen of 3 -week-old mice $(A)$. CD4 ${ }^{+} \mathrm{T}$ cell numbers in the follicles of the spleen of 3-week-old (left) and in the liver of 4-week-old (right) of indicated mice $(B)$. Immunostainings for CD4, and CD8, and HE staining of the liver of 4-week-old mice $(C)$. Survival rate of each group of 4-week-old mice $(D)$. Bars indicate the mean of each group and horizontal short bars indicate the SD. *; $\mathrm{P}<0.05$. All scale bars, $100 \mu \mathrm{m}$. 

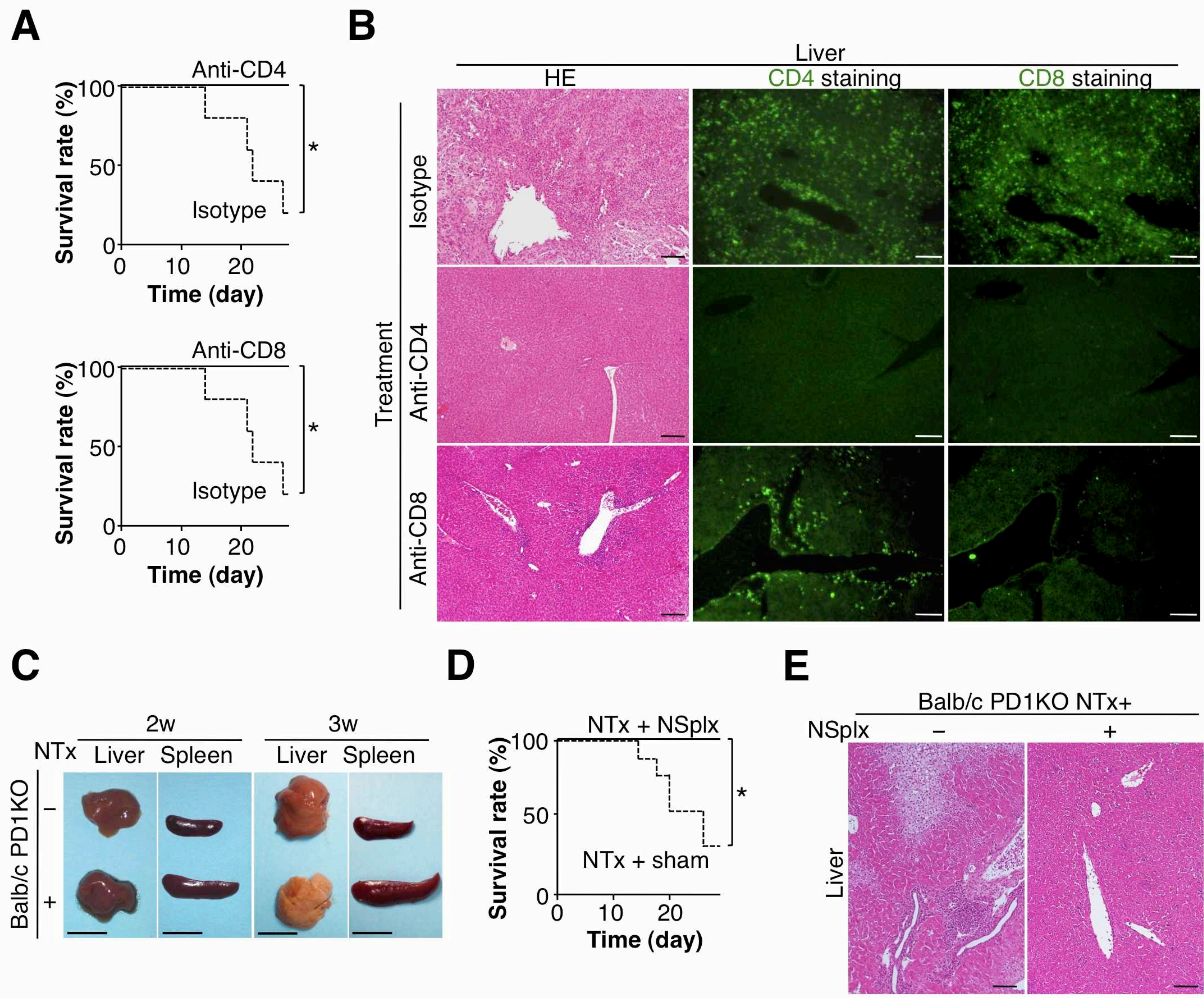

$\mathbf{F}$

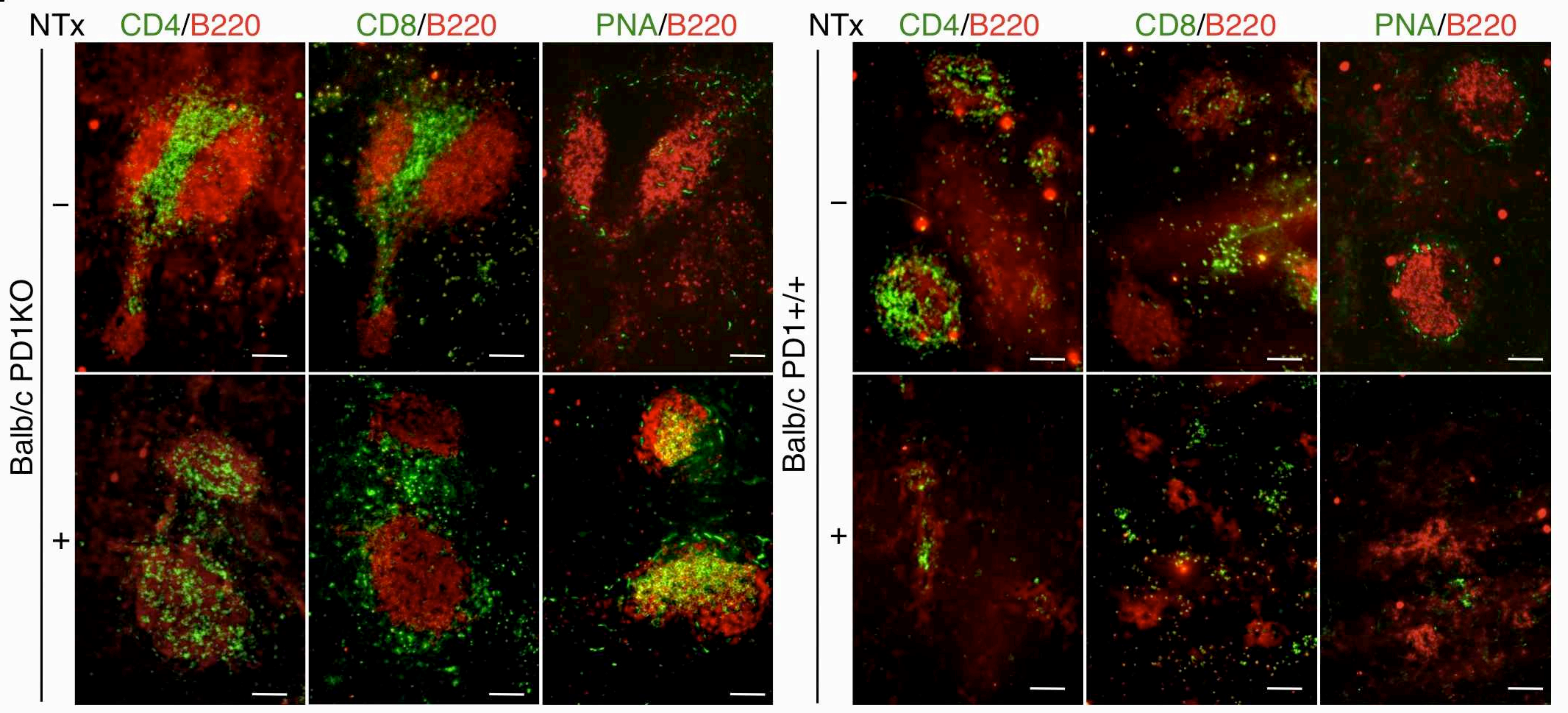


A

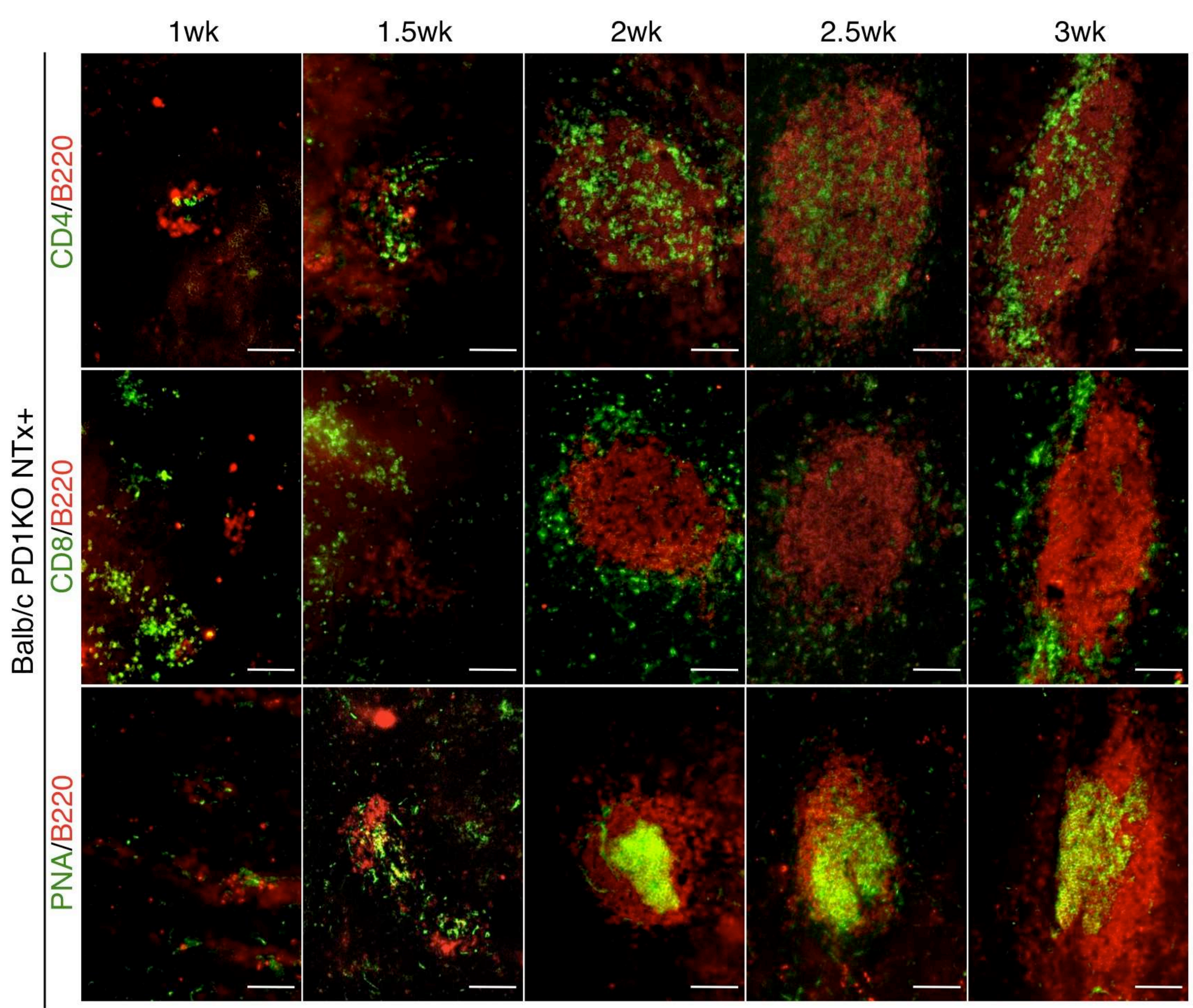

B

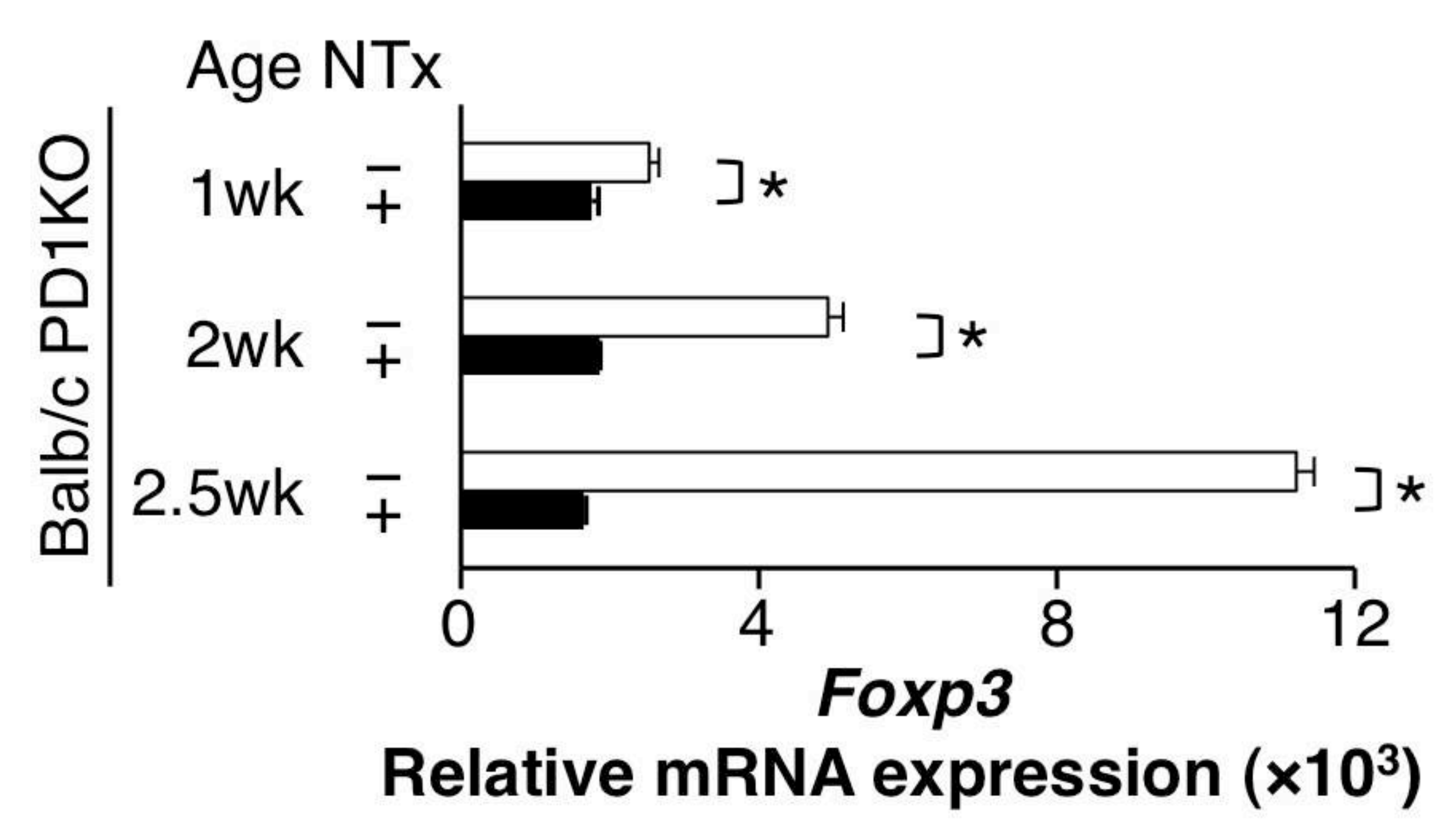

D

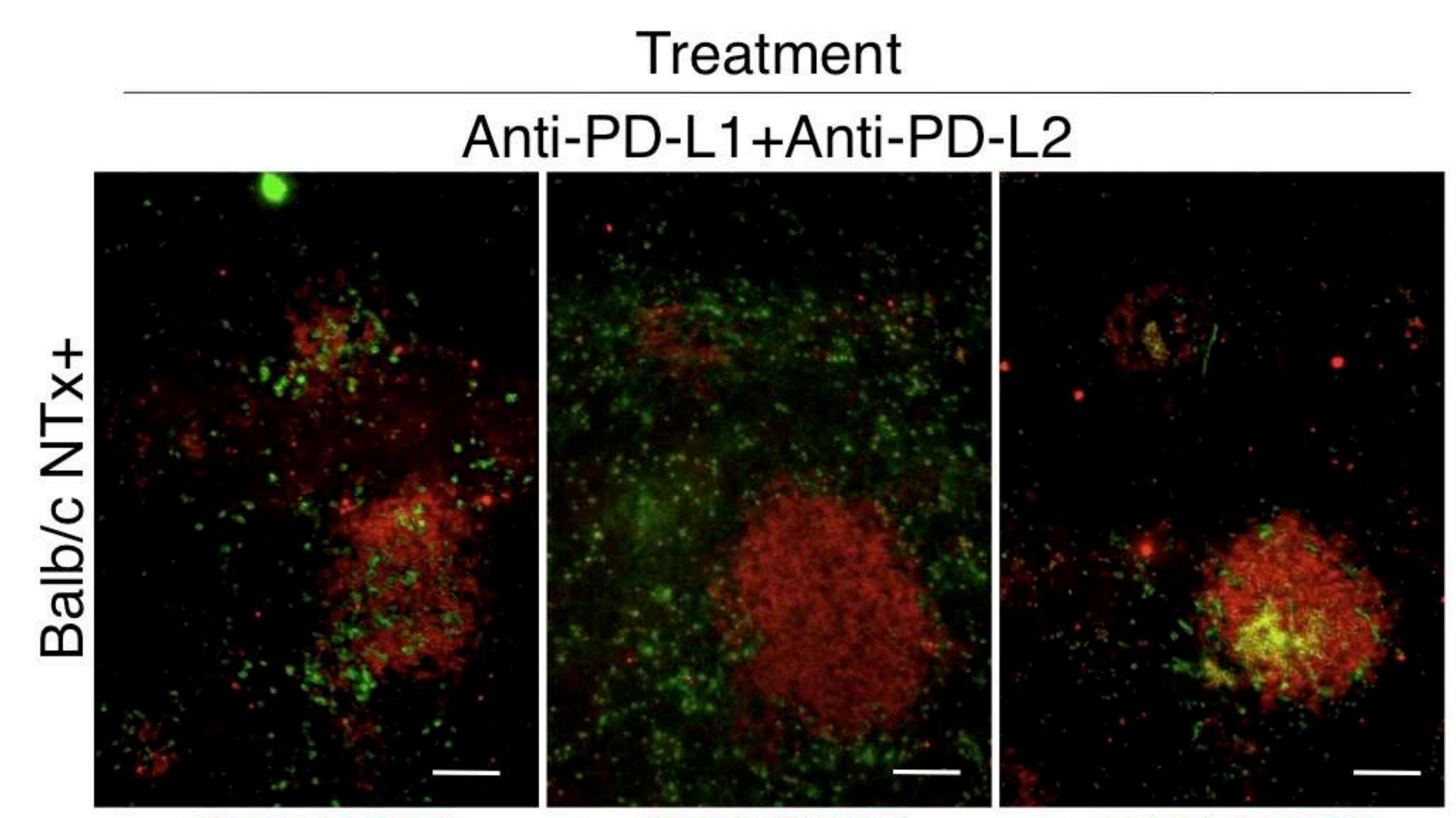

C

Treatment

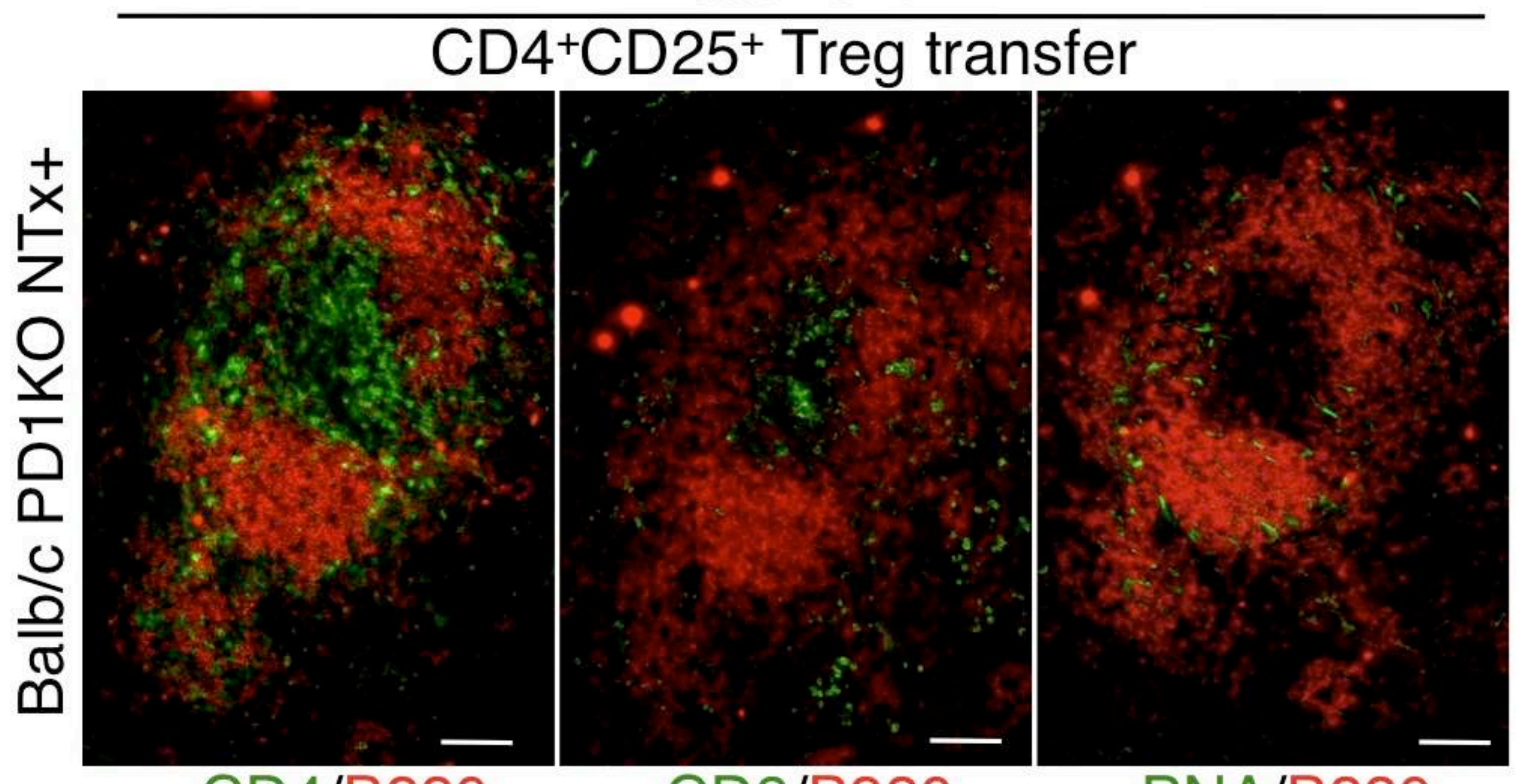

E

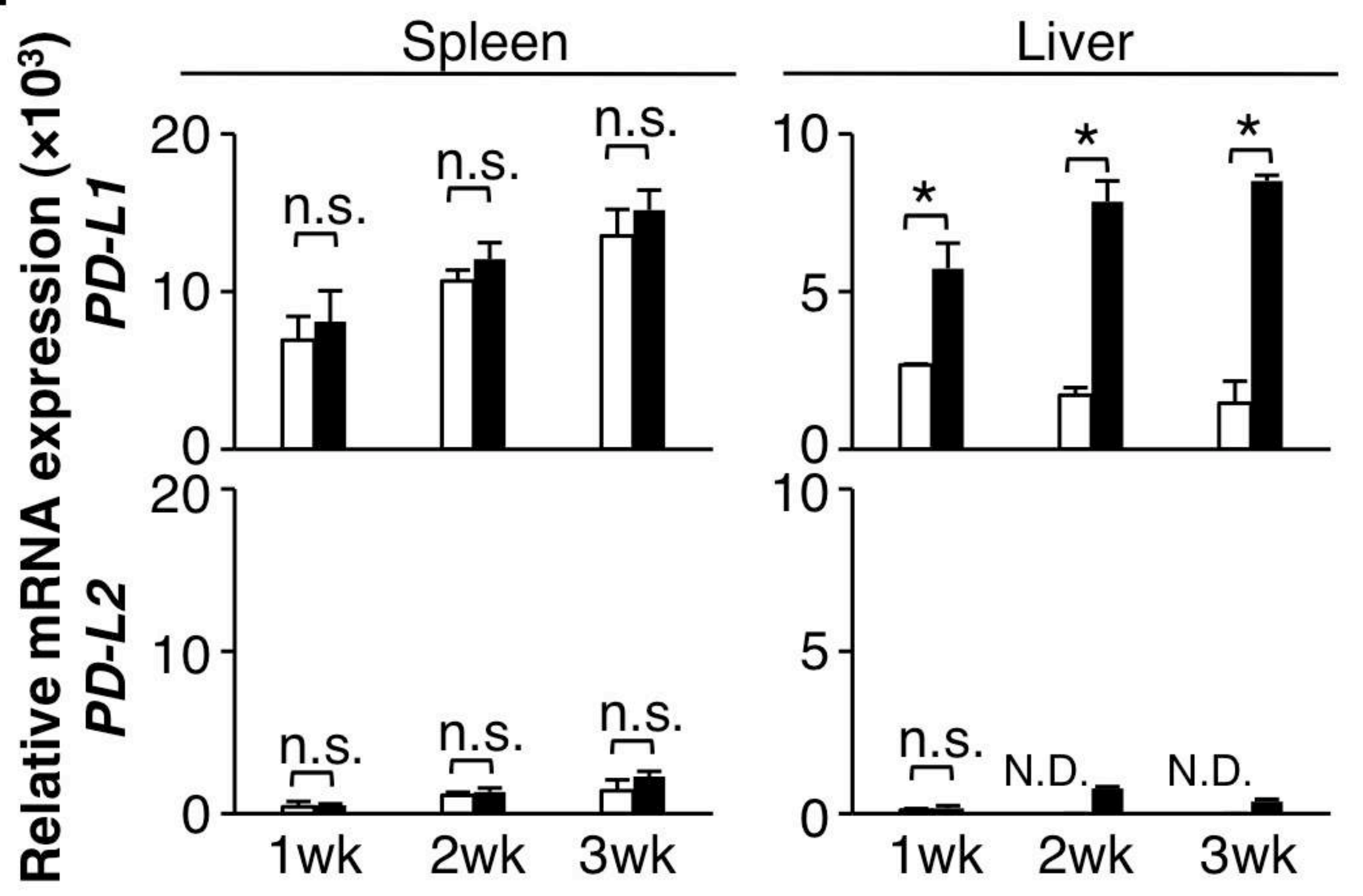


A

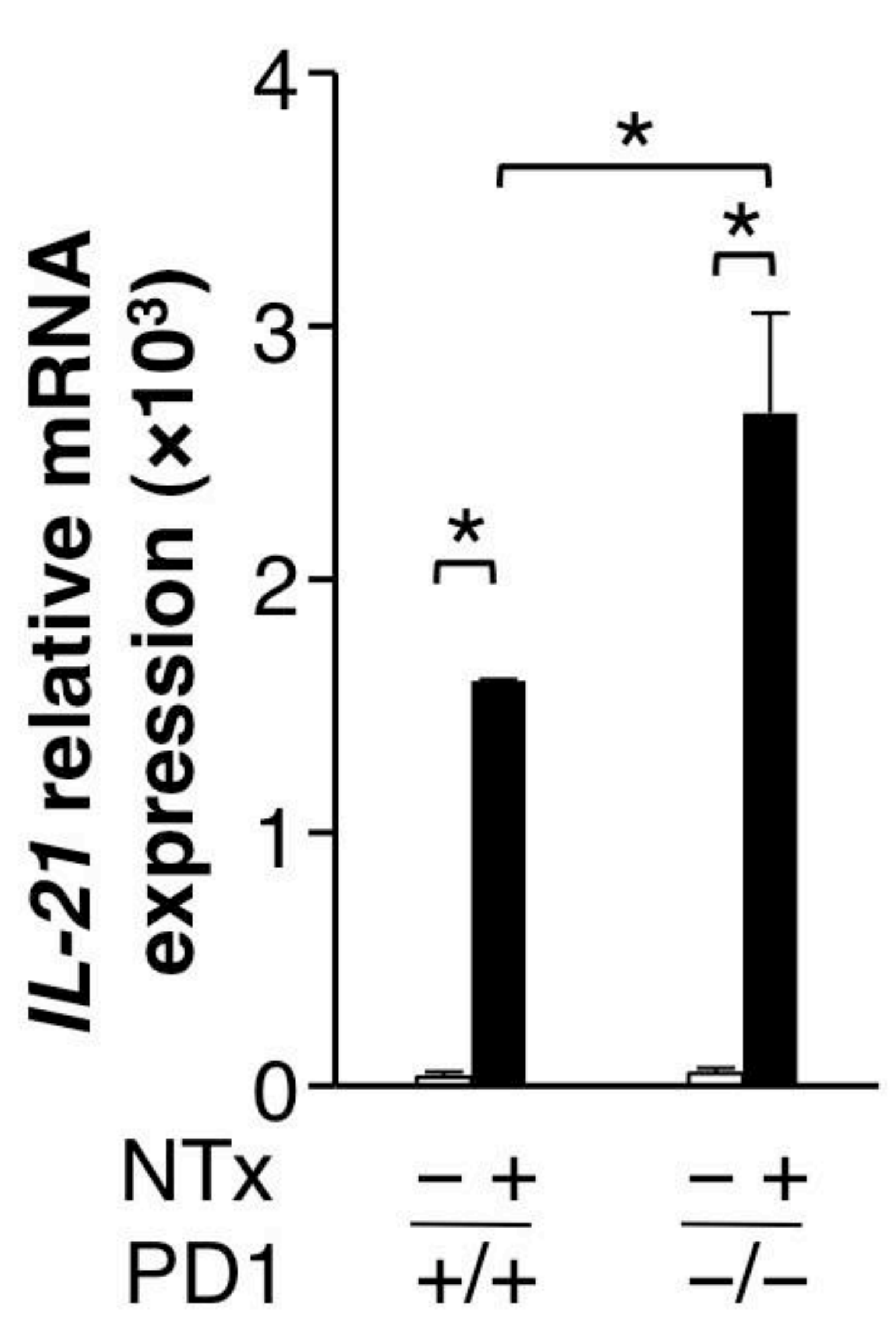

C
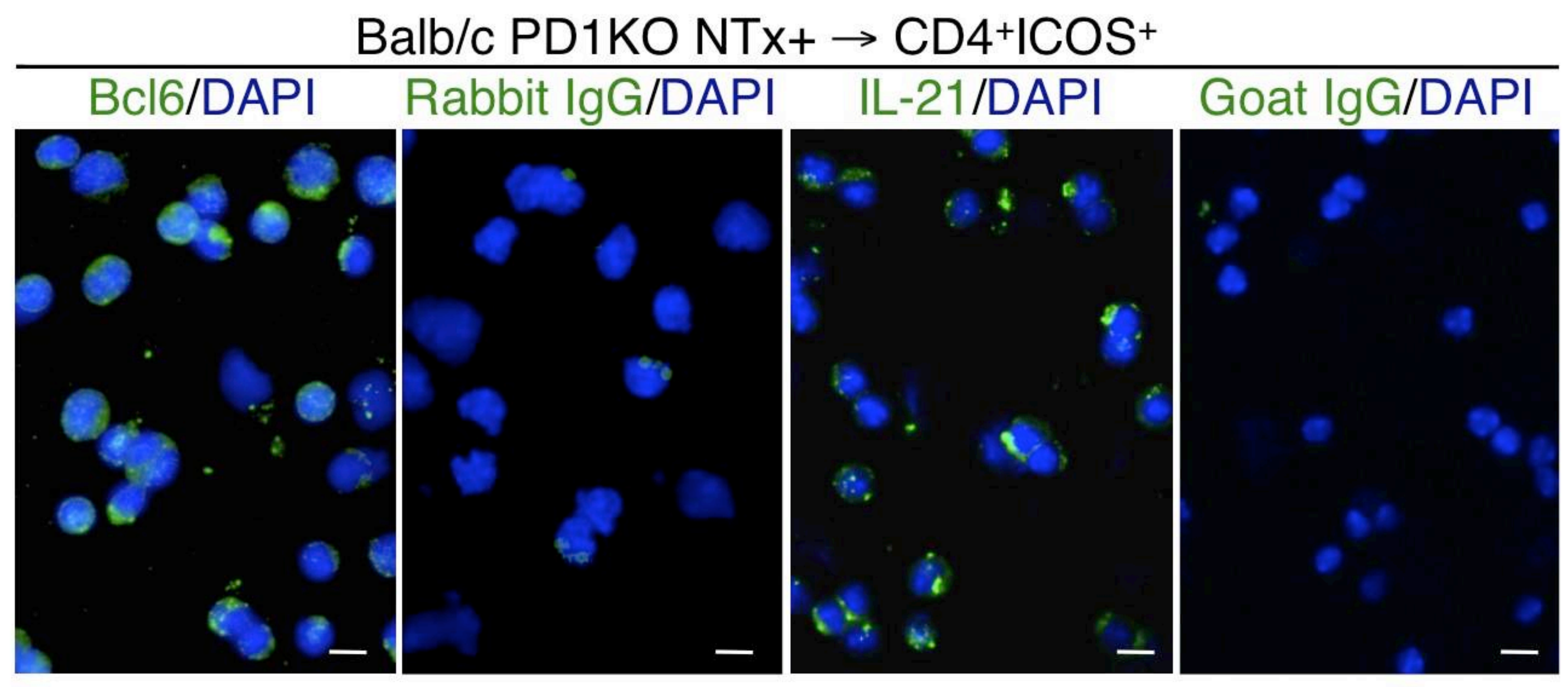

E

Balb/c PD1KO NTx+ Spleen

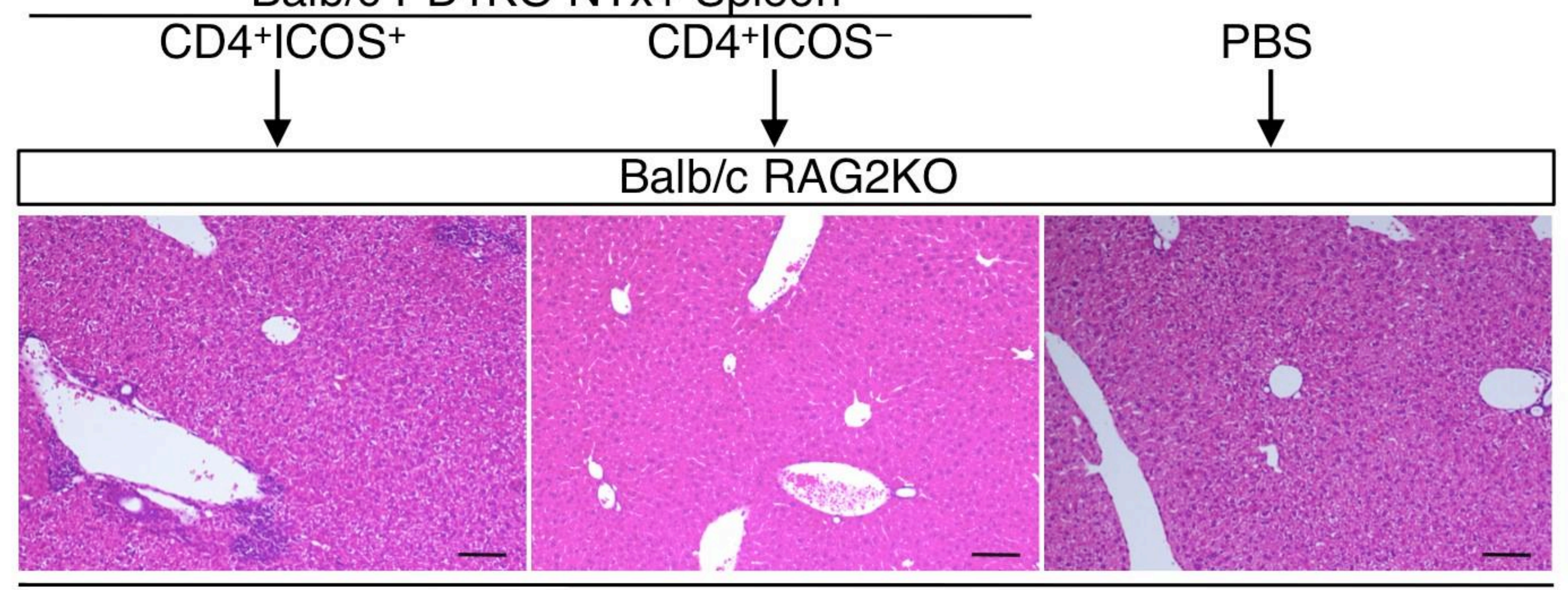

Liver
D
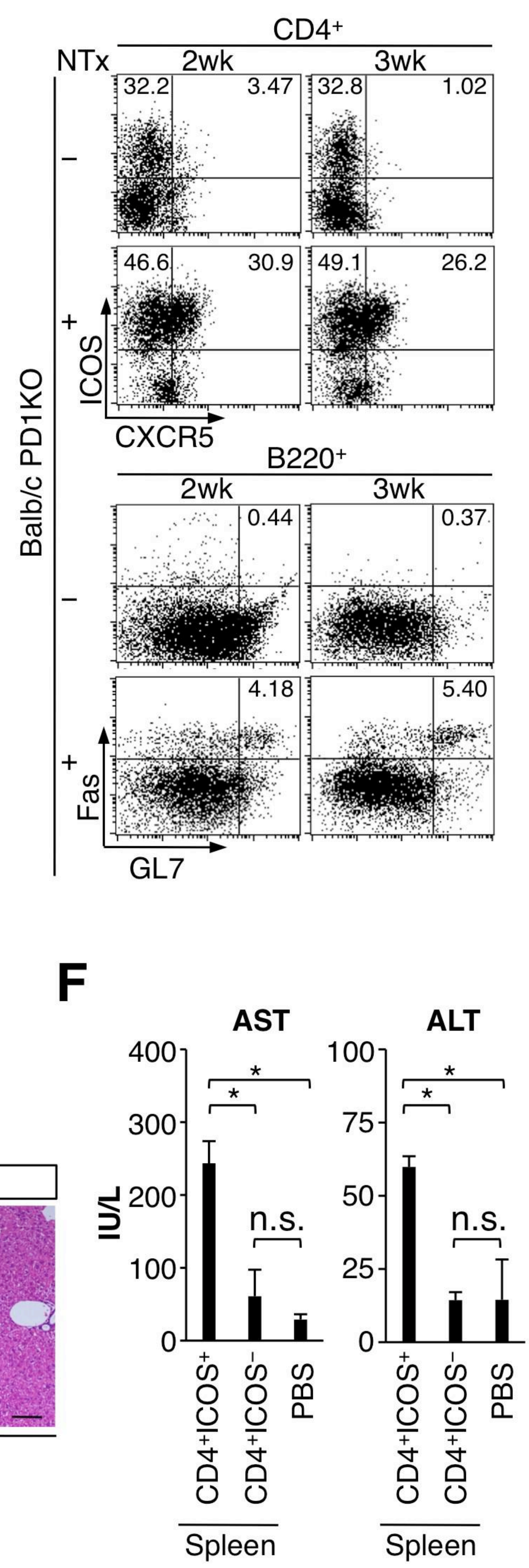


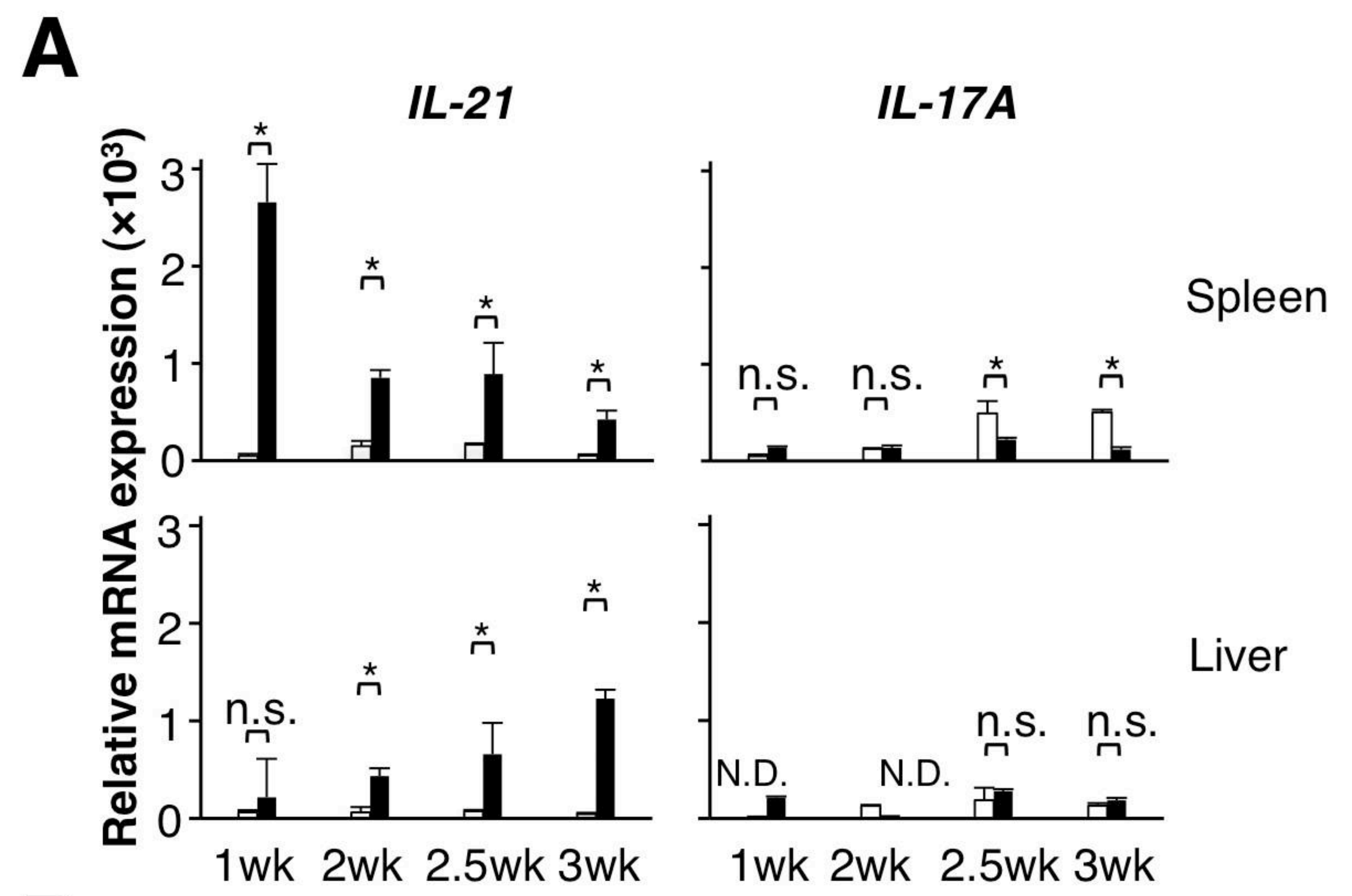

B

Bcl-6
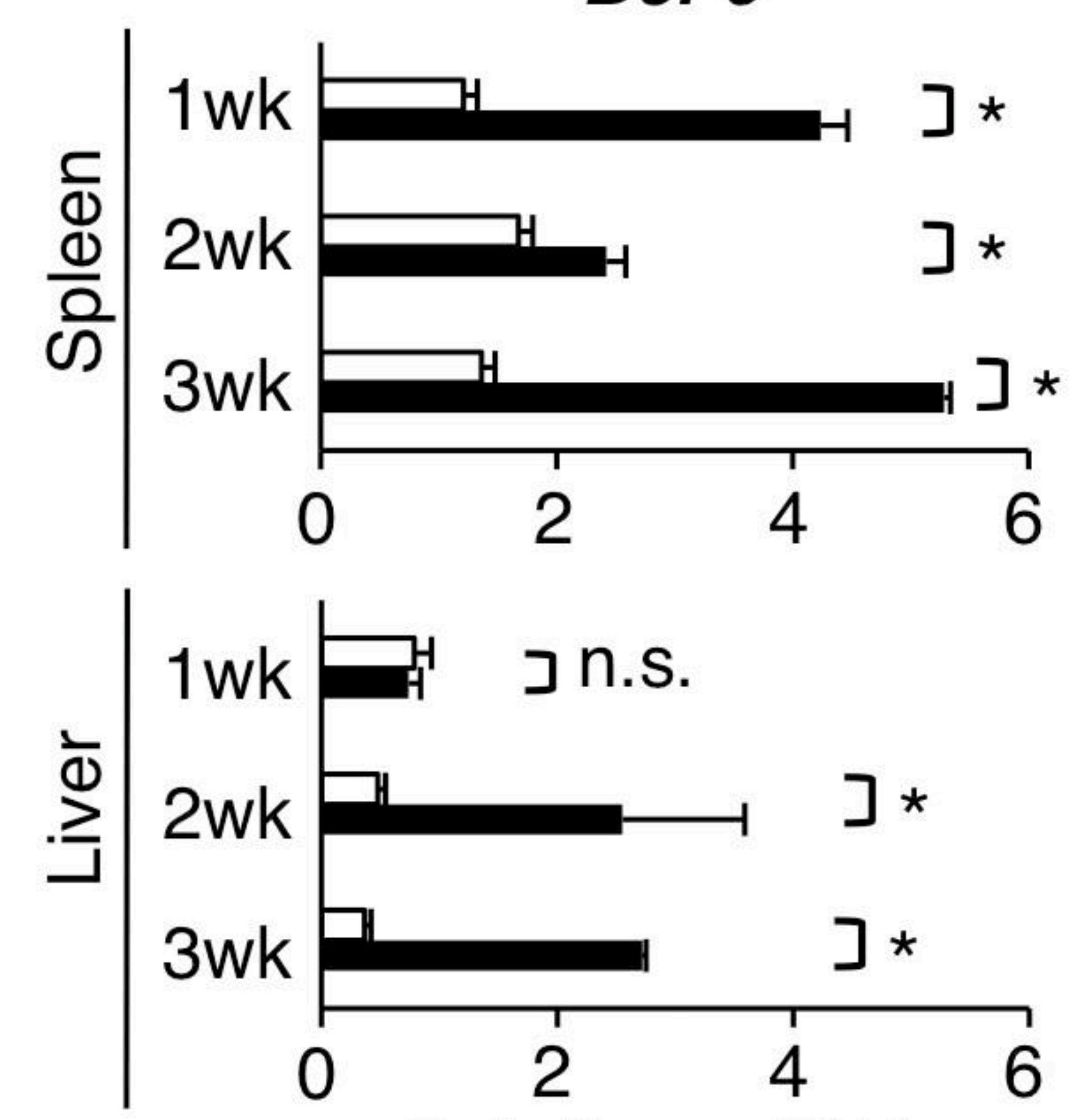

Relative mRNA expression $\left(\times 10^{3}\right)$

C

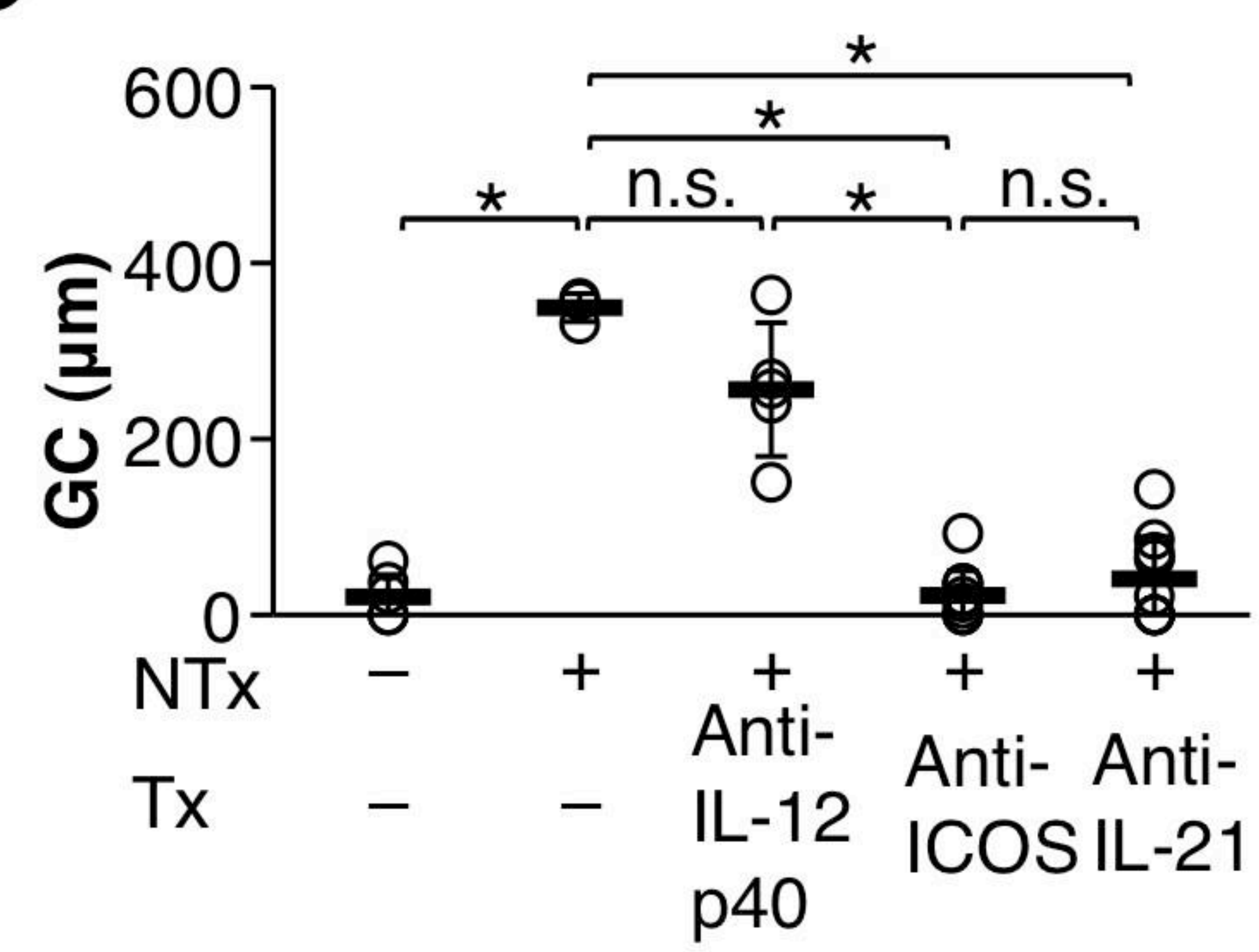

E

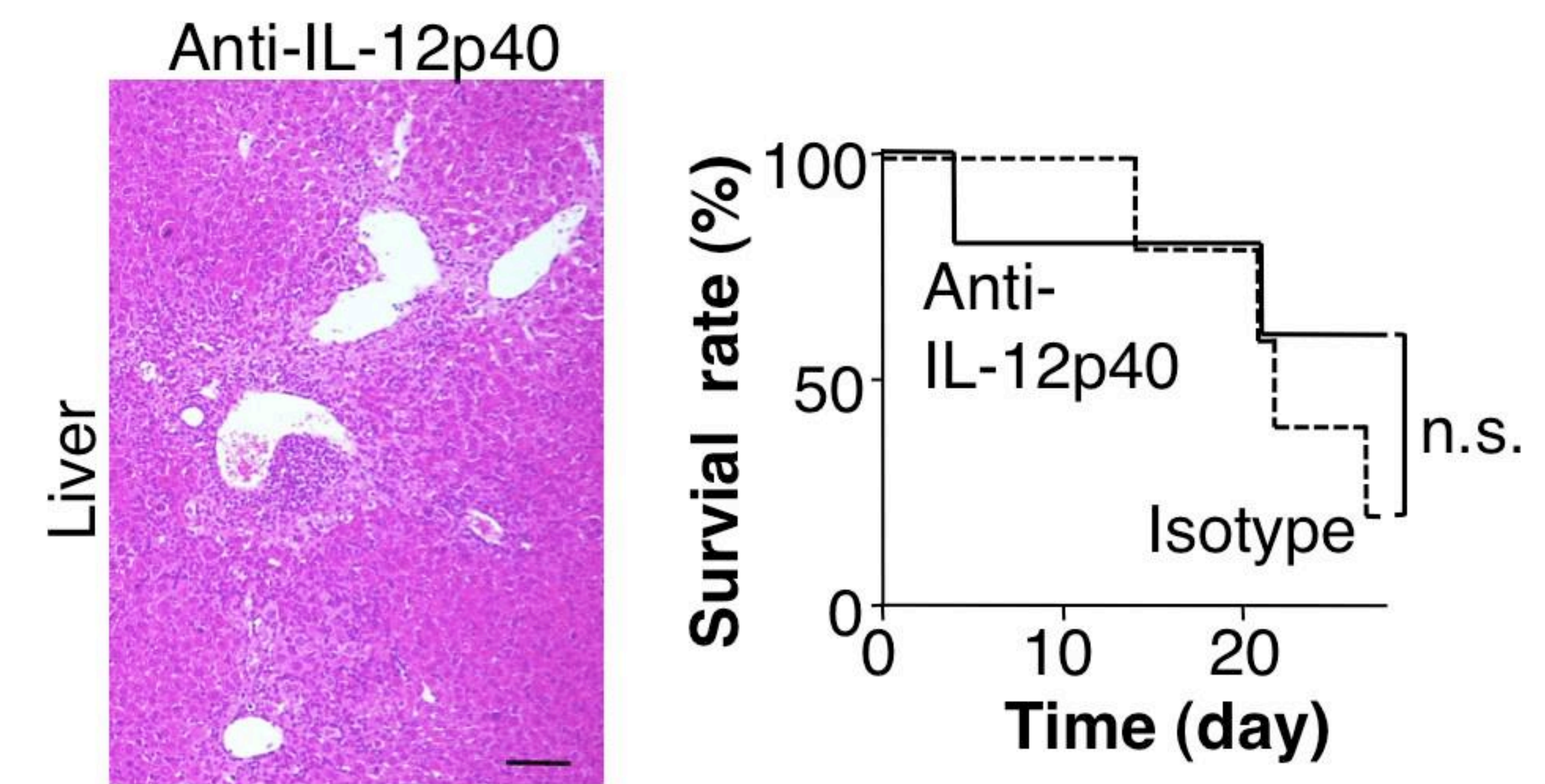

GATA-3
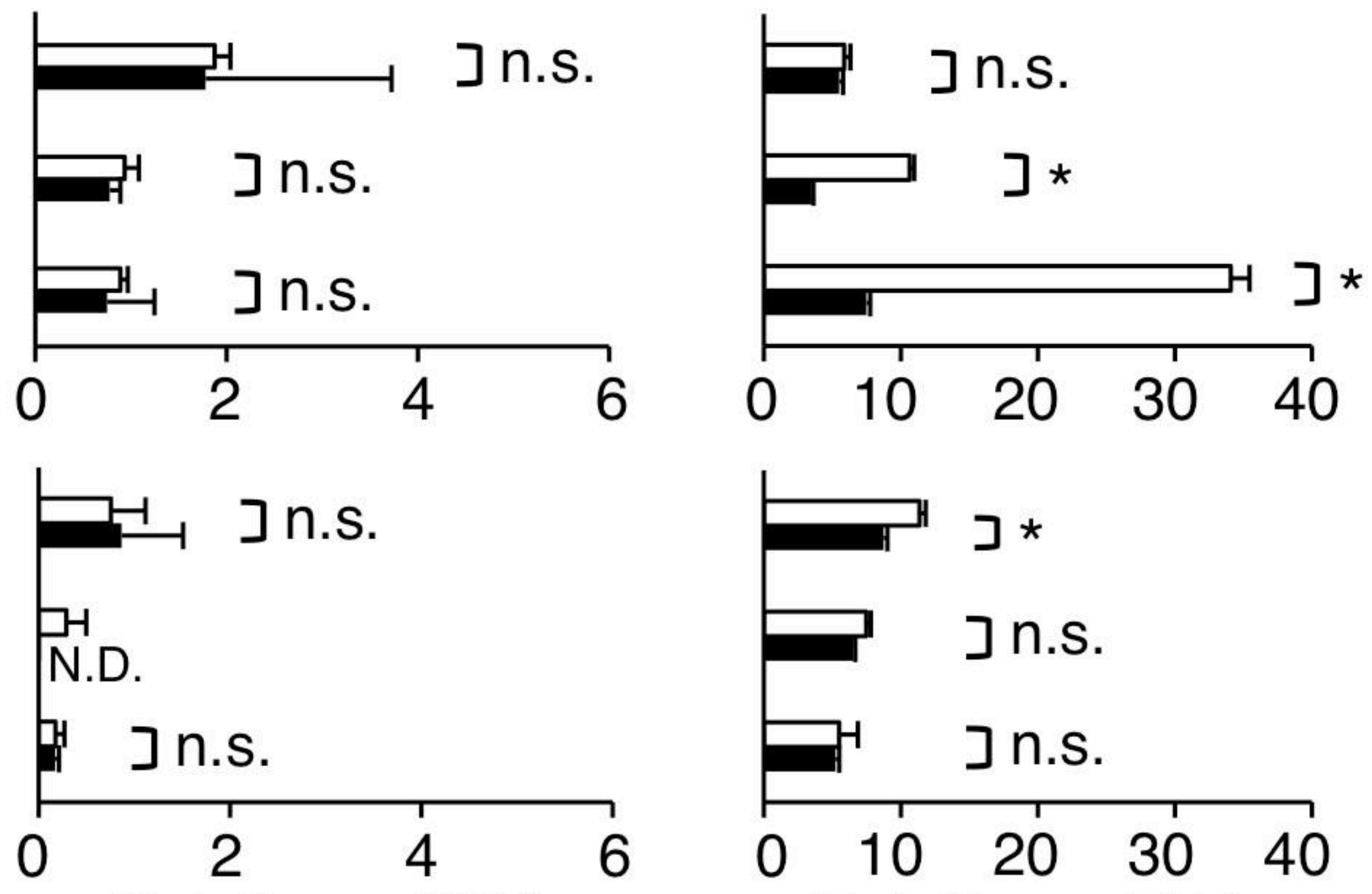

Relative mRNA expression $\left(\times 10^{3}\right)$

RORYT
D
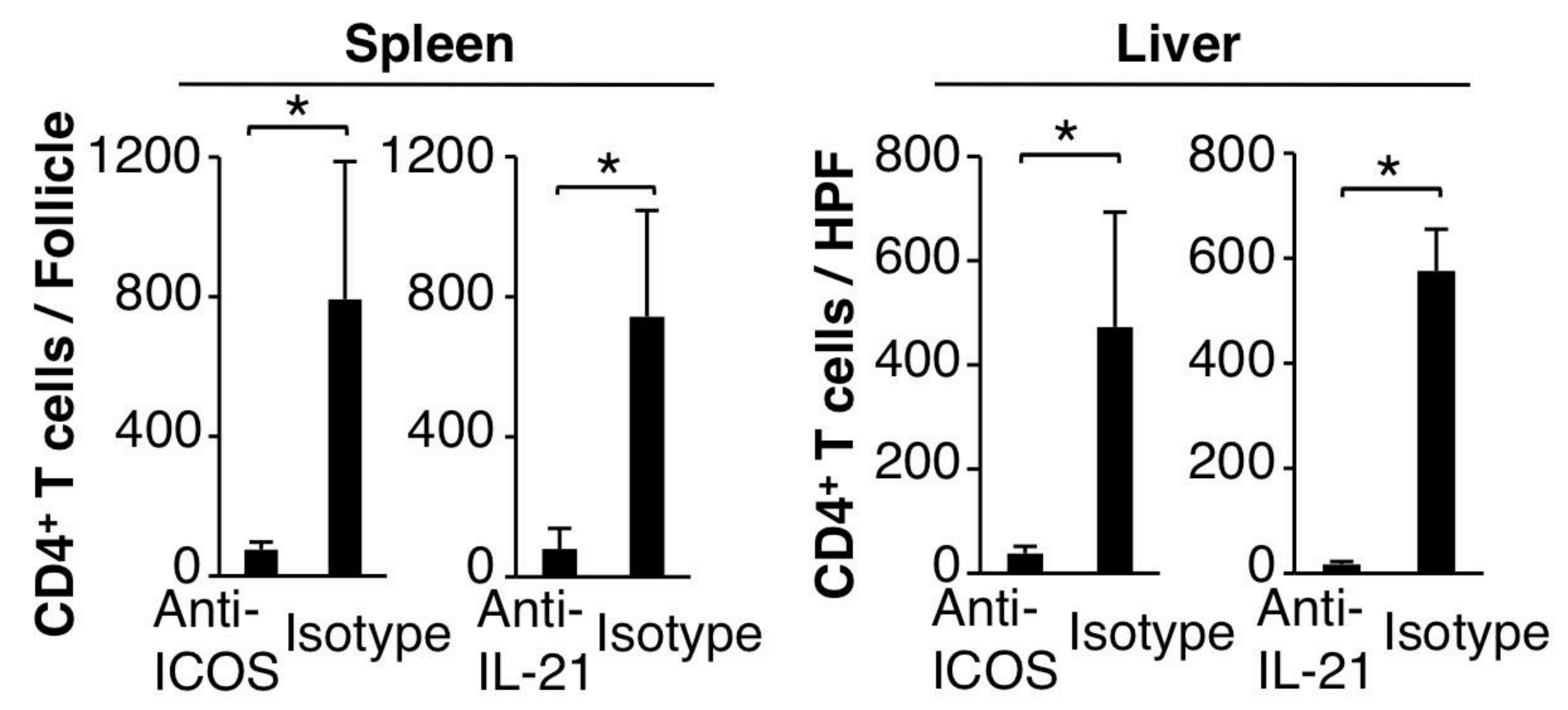

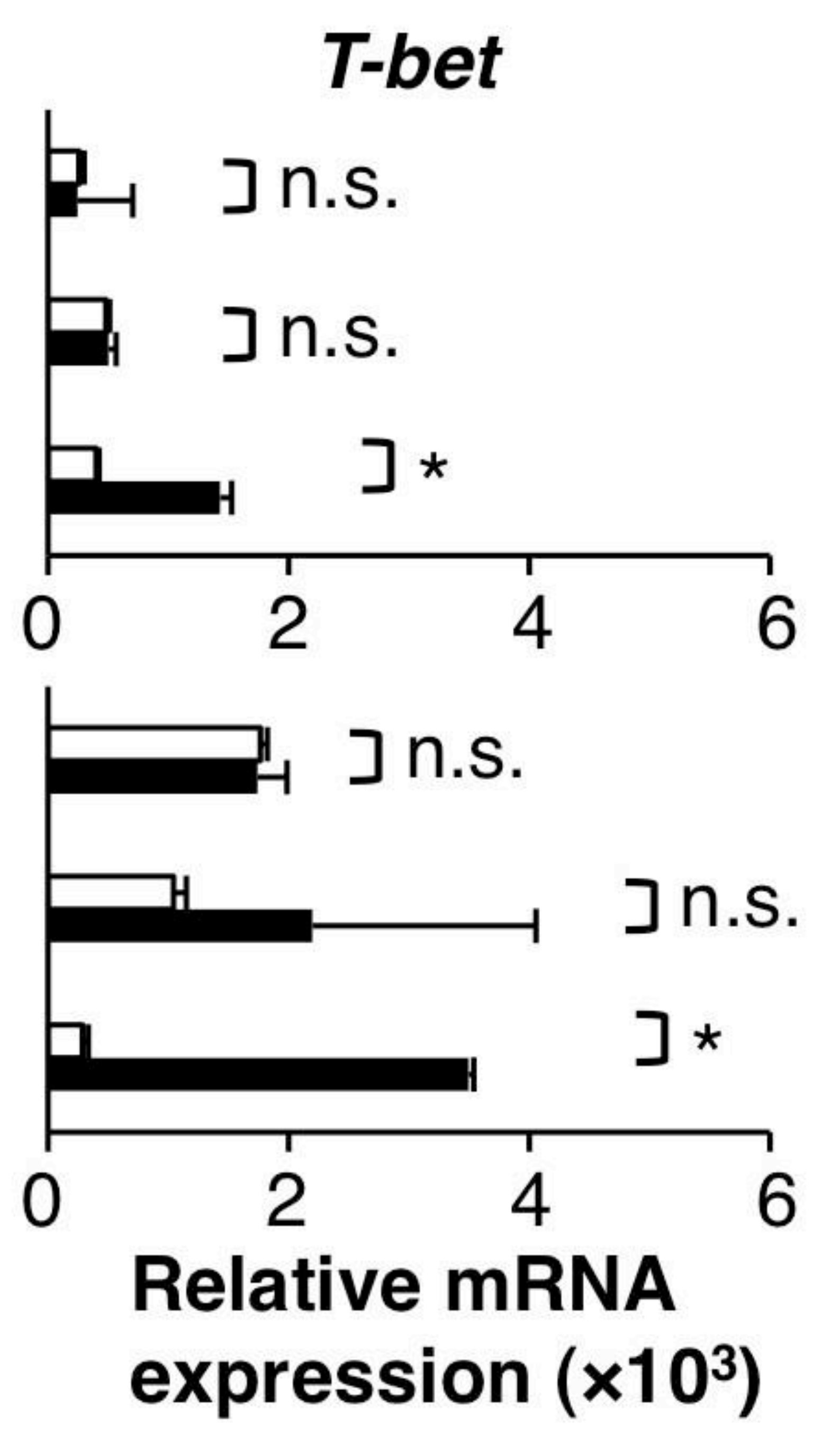


A

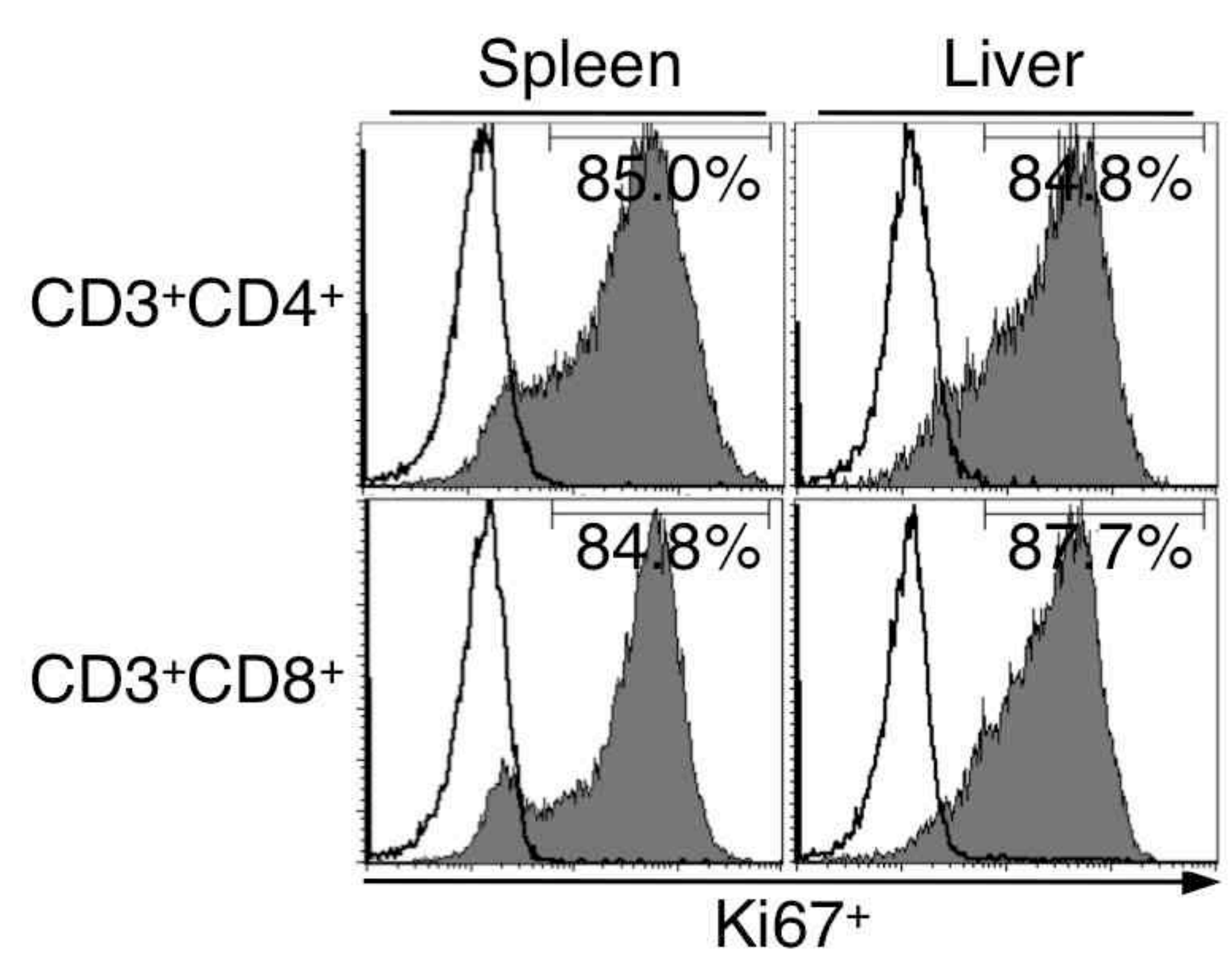

B

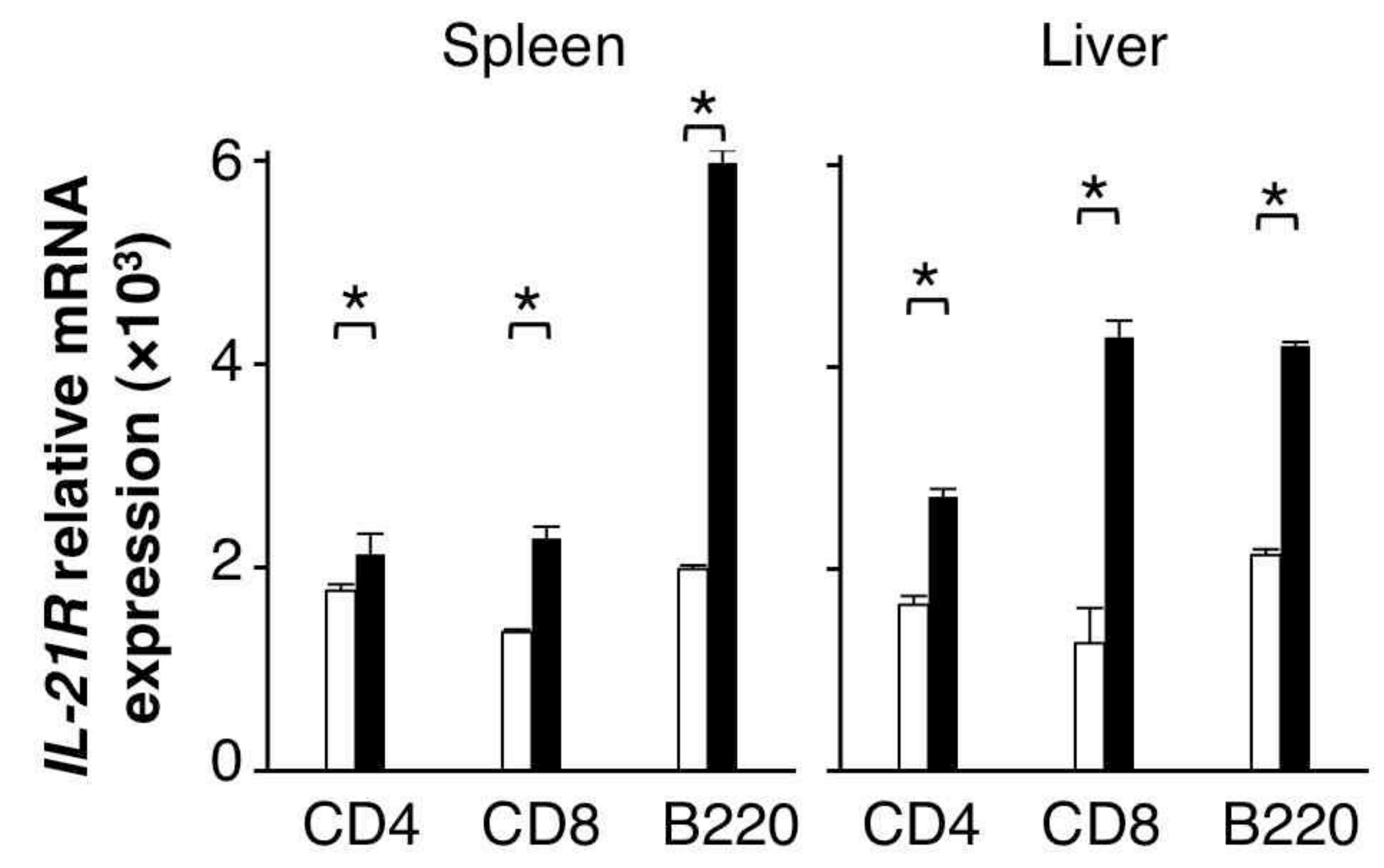

E

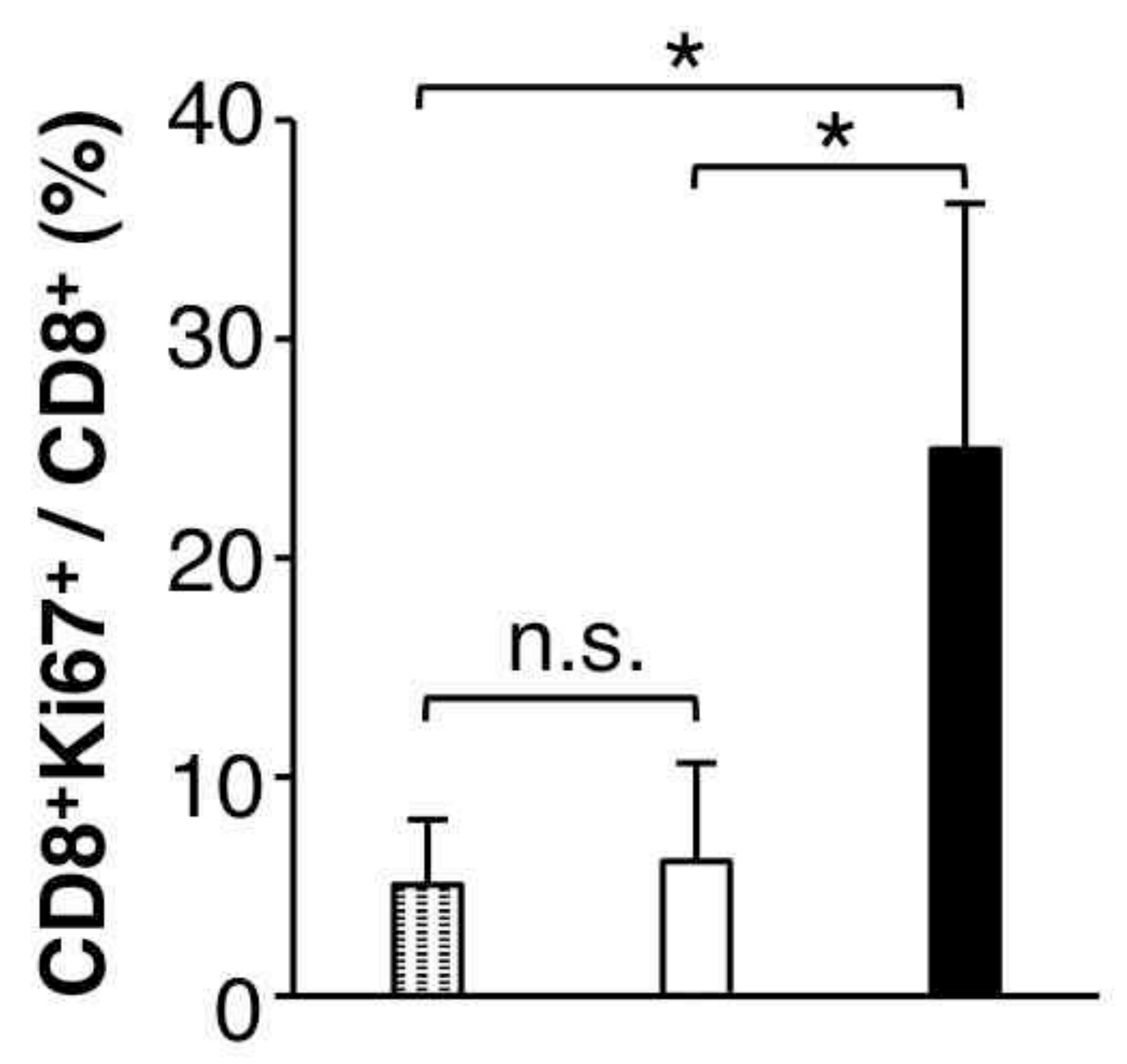

PD1KO NTx- $\rightarrow \mathrm{CD}^{+}+\boldsymbol{+}+\boldsymbol{+}$ $\mathrm{PD} 1 \mathrm{KO} N \mathrm{NX}_{-} \rightarrow \mathrm{CD}^{+}-\mathbf{+}-$ $\mathrm{PD} 1 \mathrm{KO} N \mathrm{NT}+\rightarrow \mathrm{CD}^{+}+\mathbf{C}^{+}+$

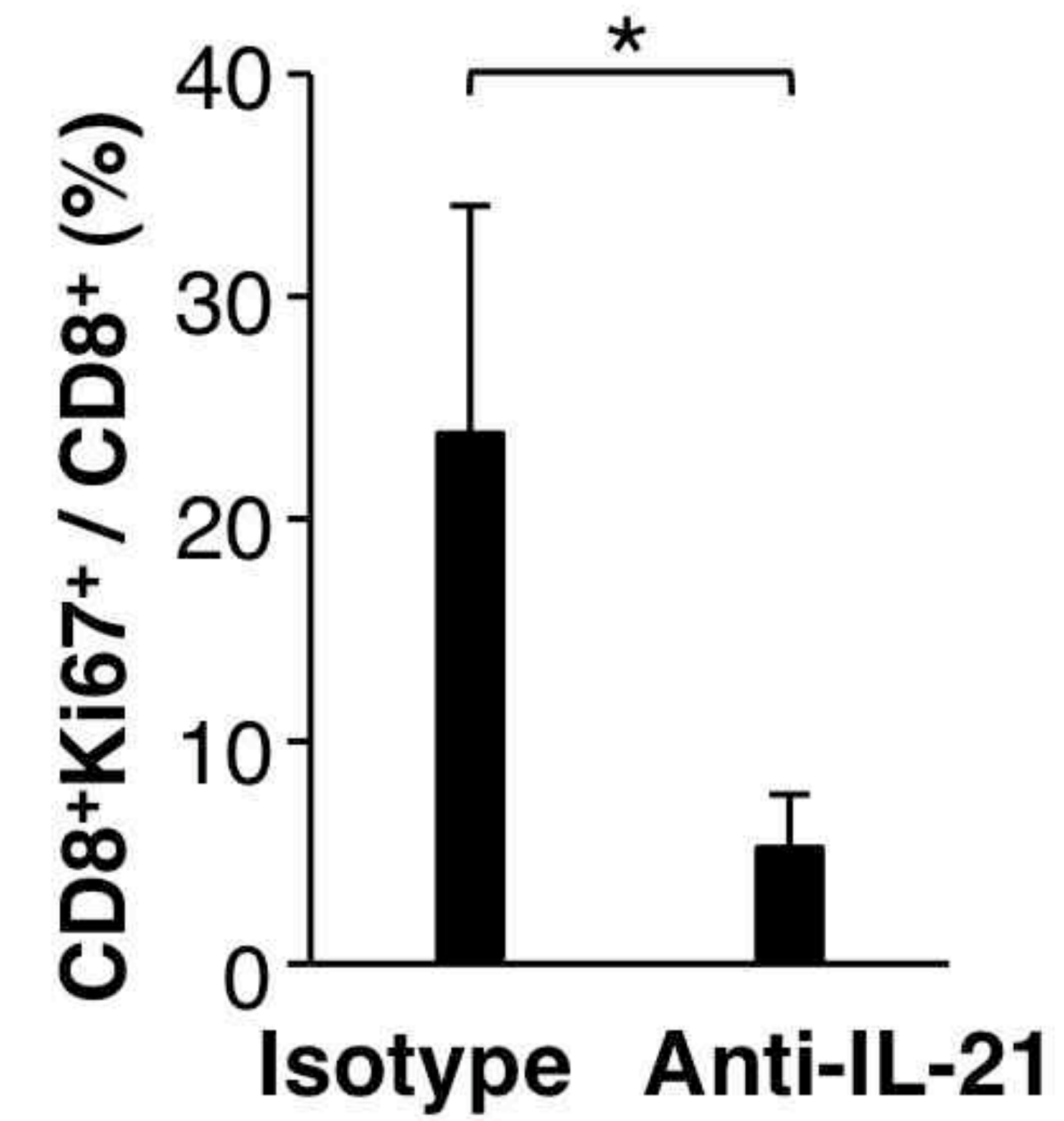

$\mathrm{PD} 1 \mathrm{KO} \mathrm{NTx}-\rightarrow \mathrm{CD}^{+}$

$\mathrm{PD} 1 \mathrm{KO} N T \mathrm{x}+\rightarrow \mathrm{CD}^{+}$

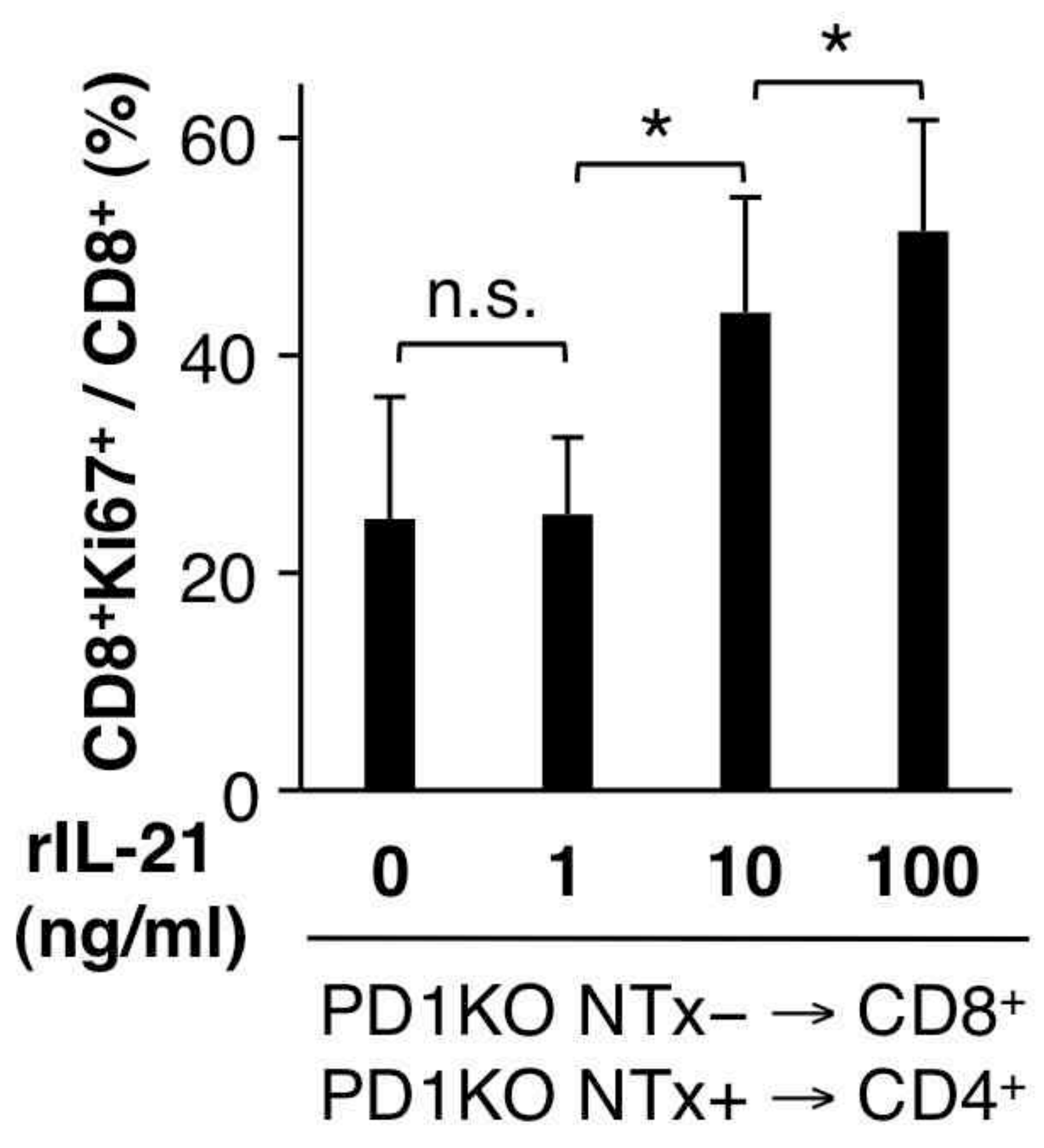


A

CCR6+

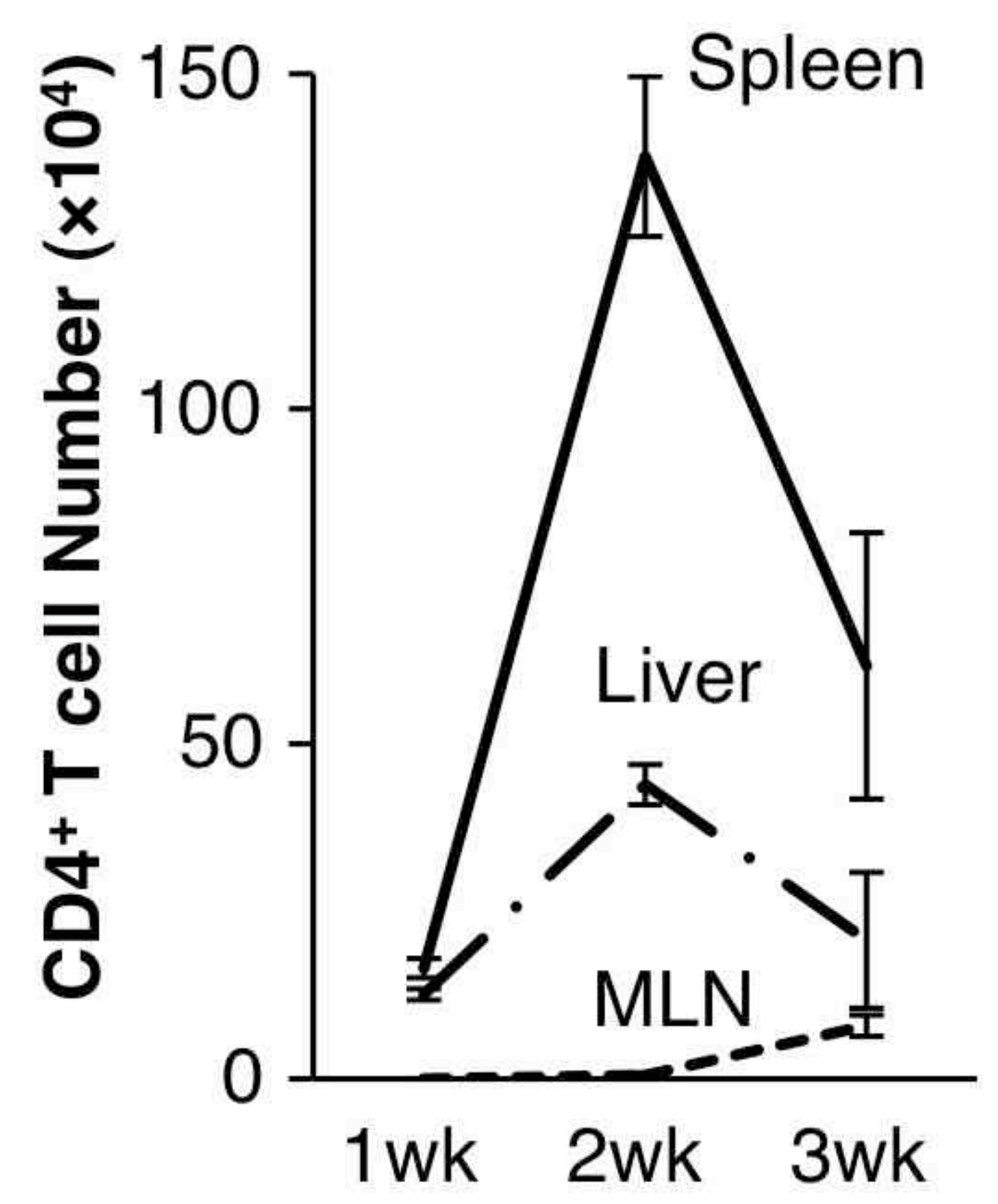

CCR9+

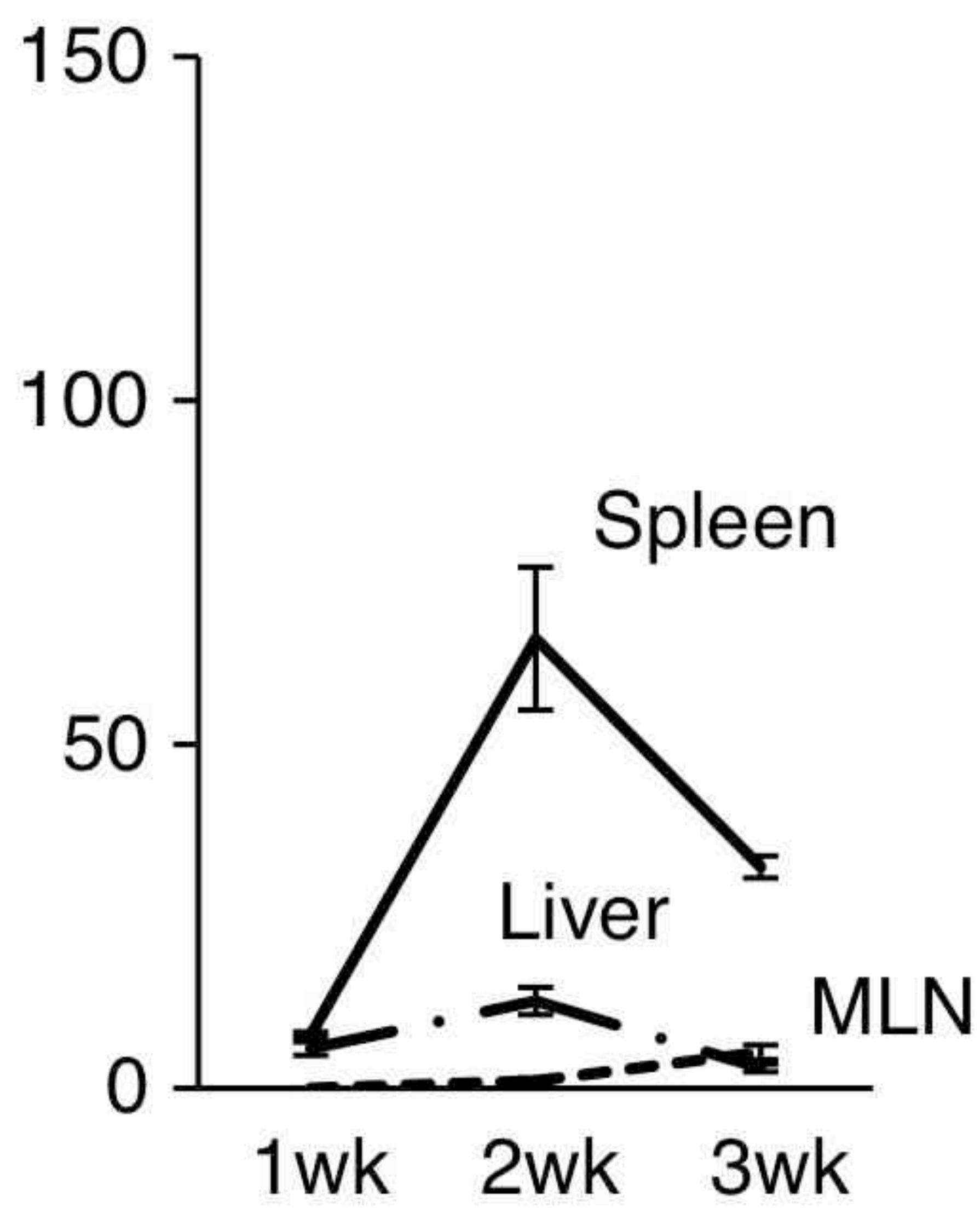

B

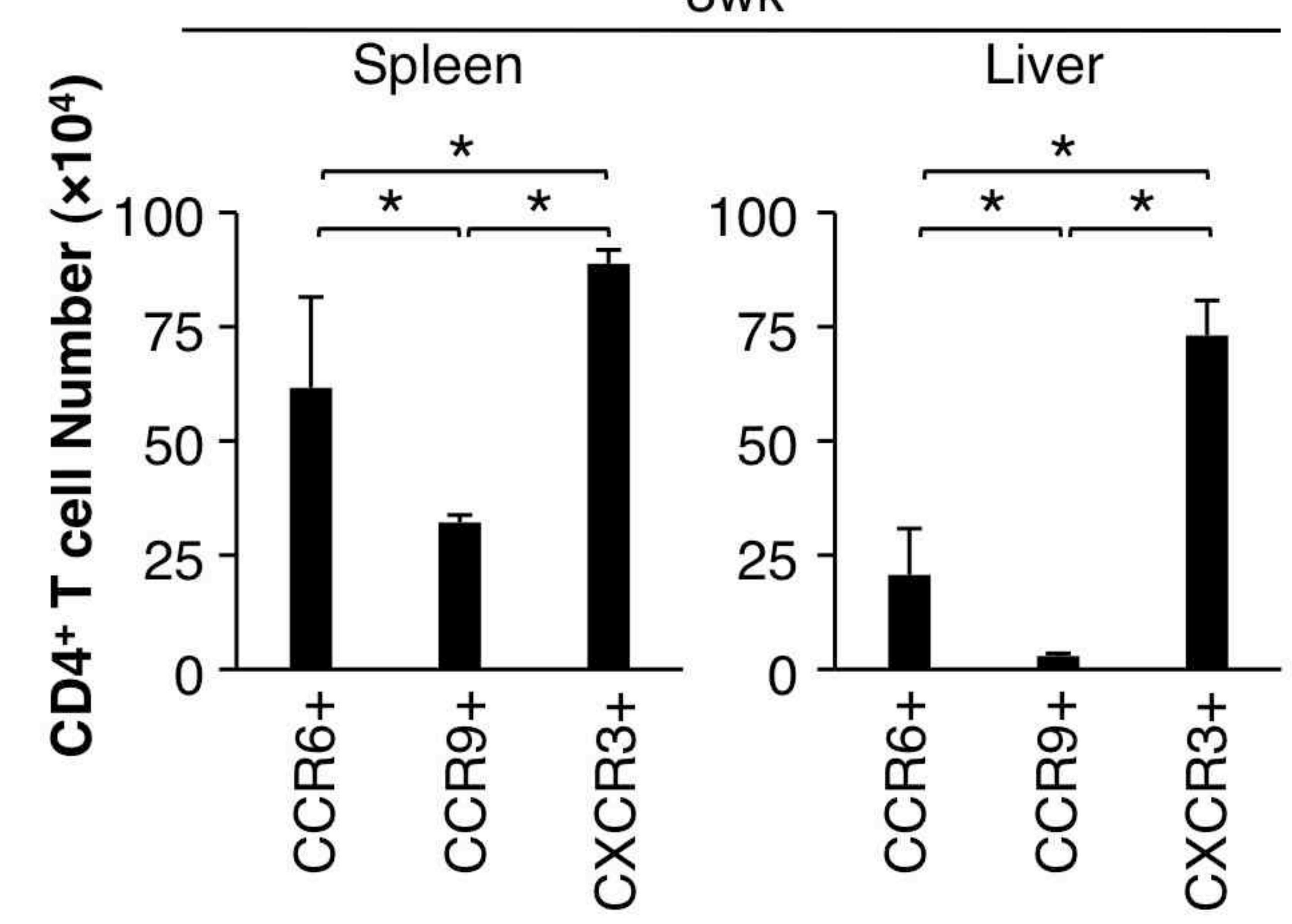

C
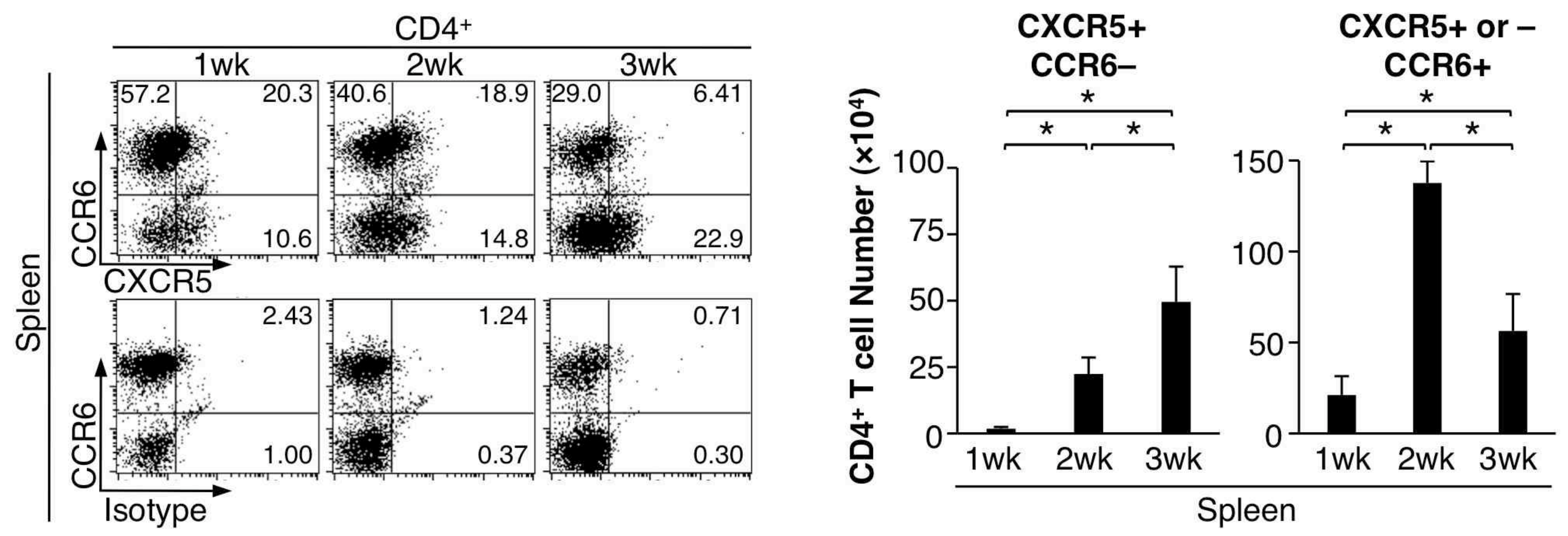

D

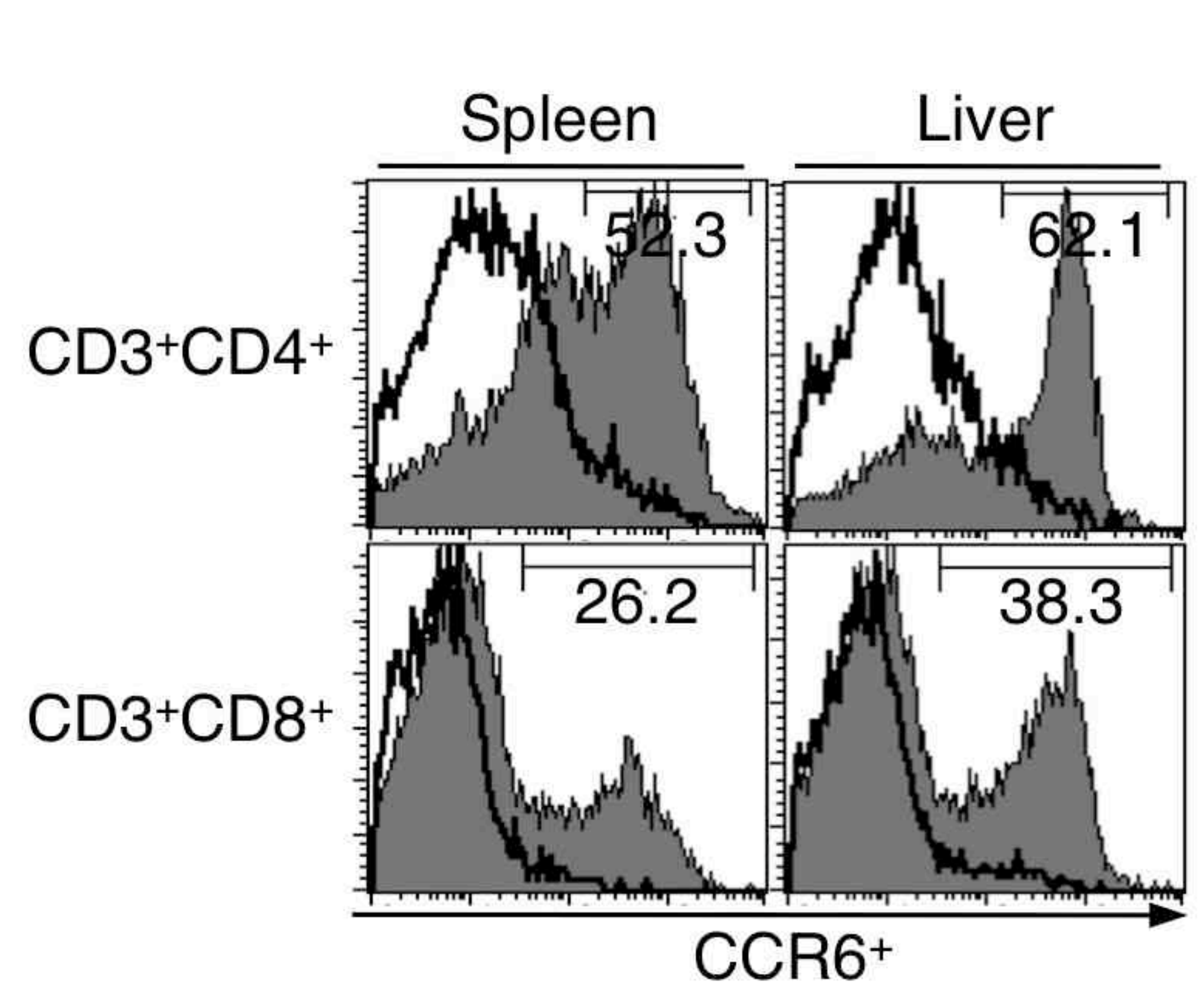

E

E
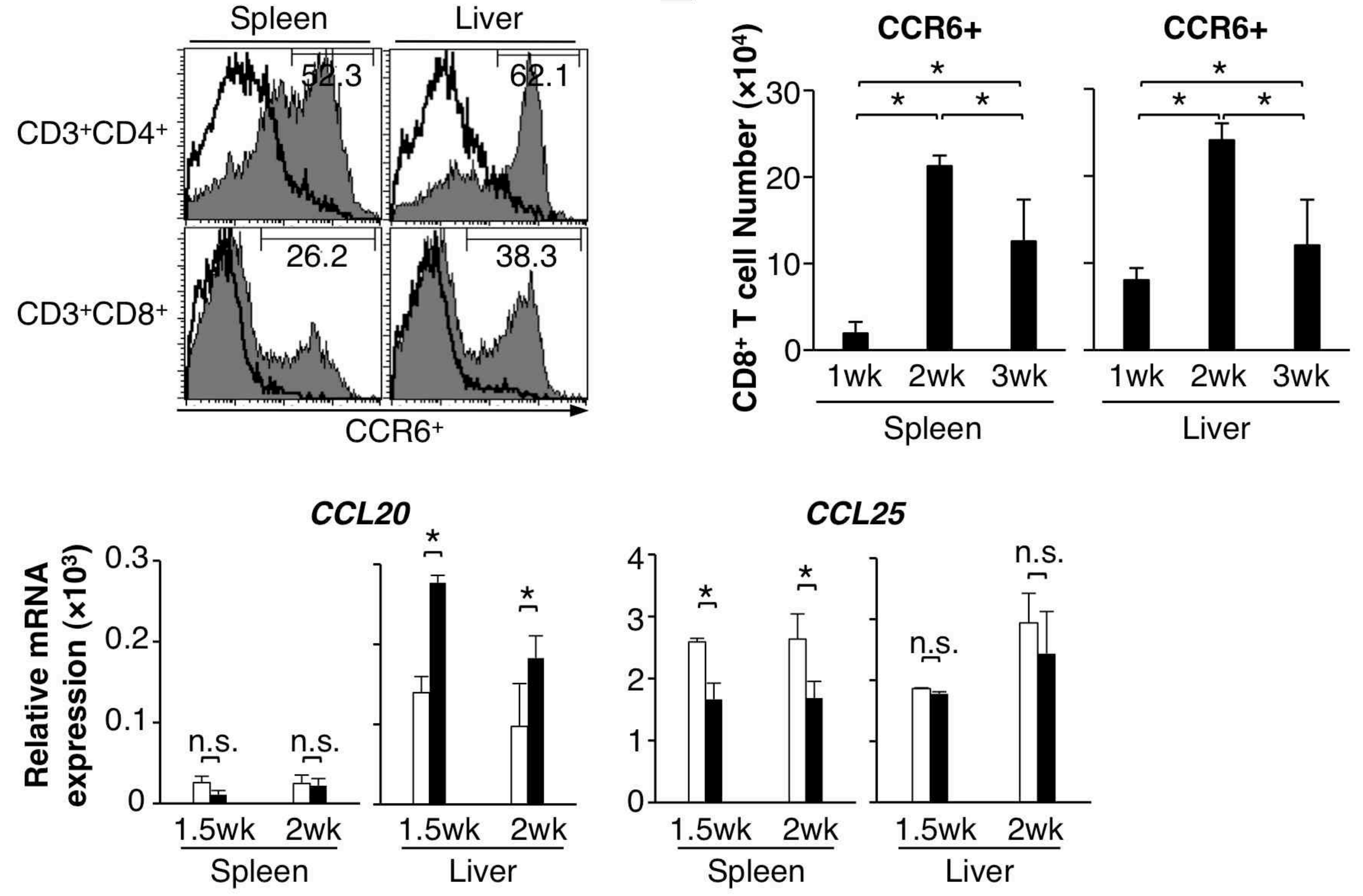
A

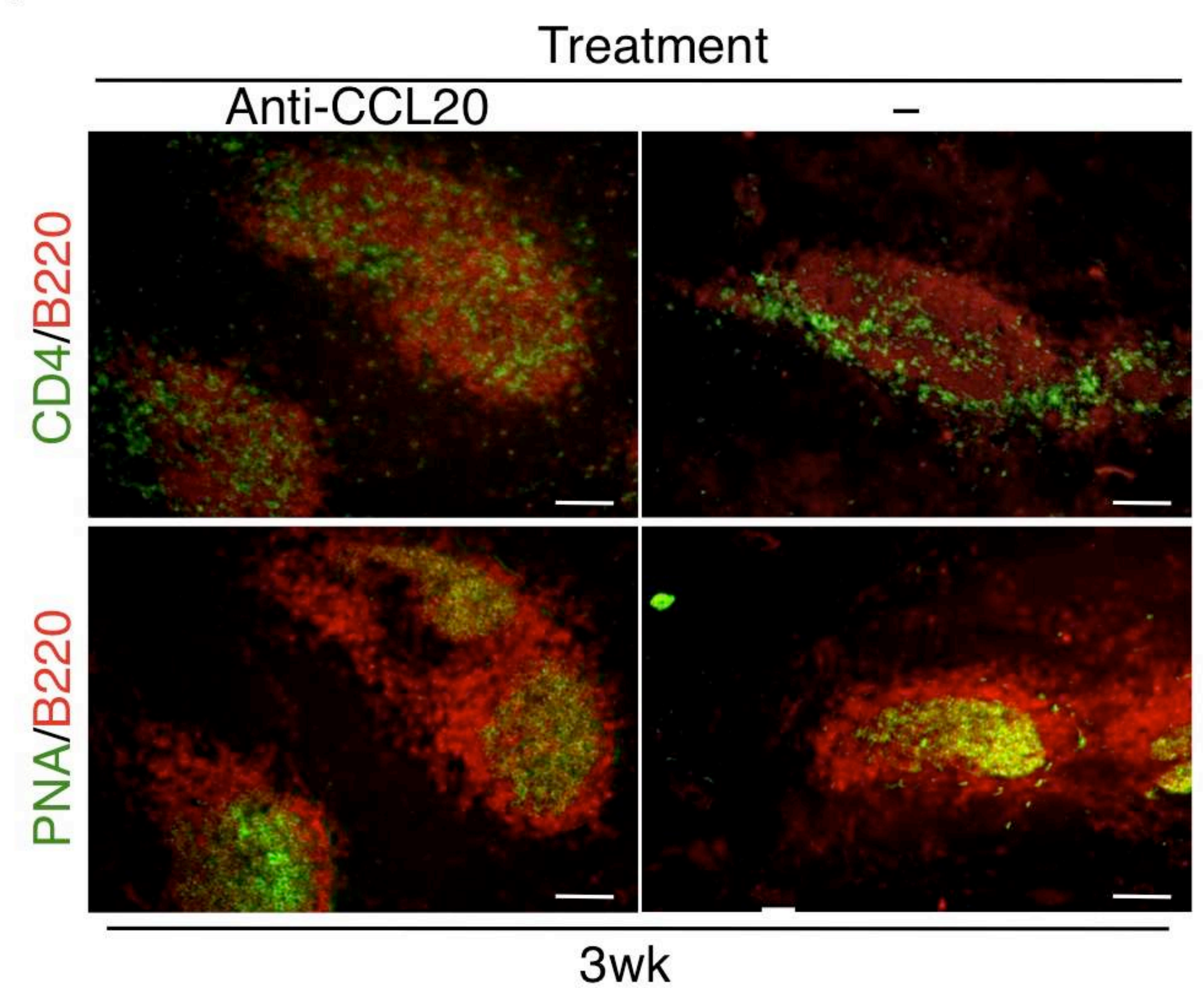

C

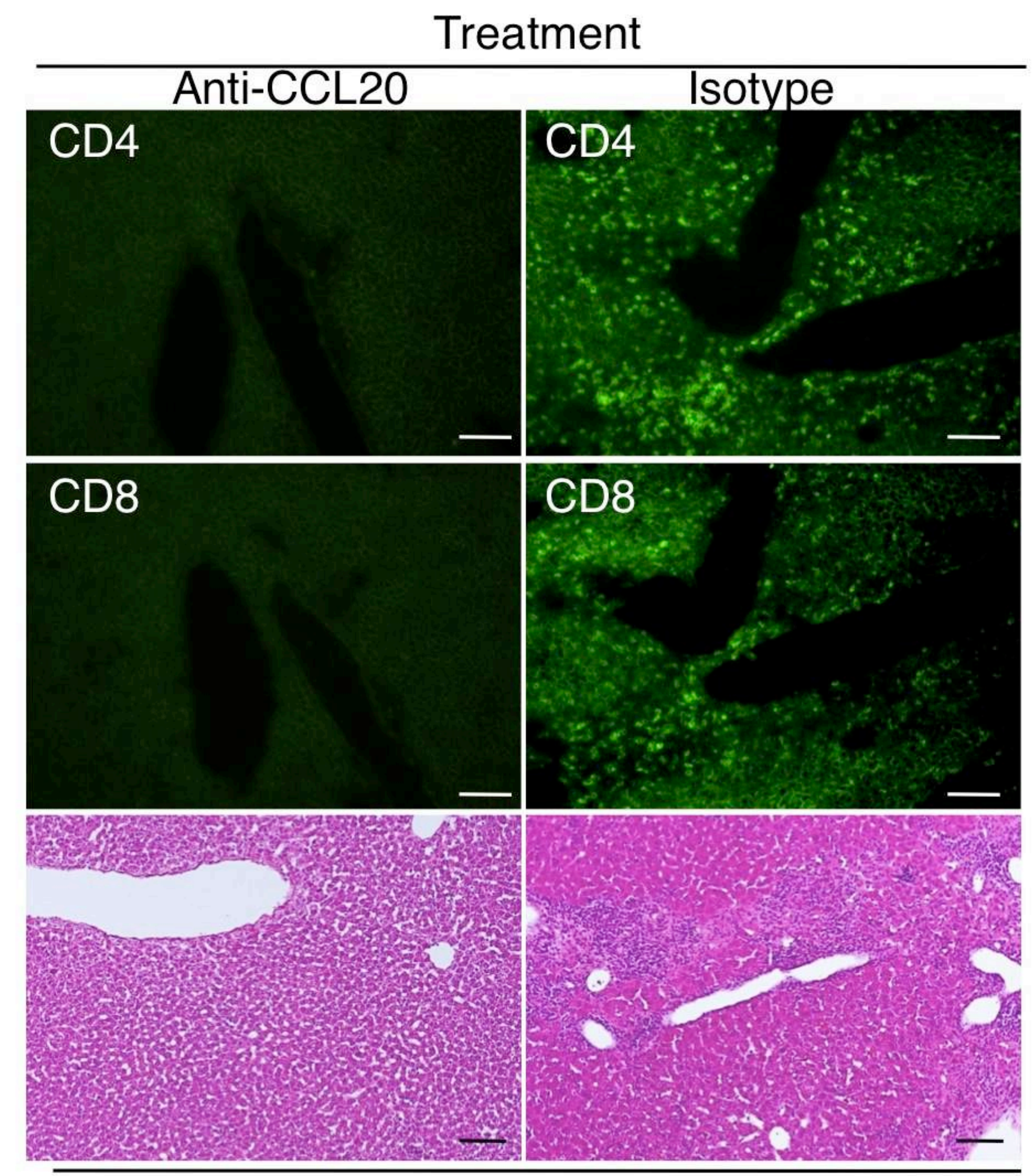

Liver
B

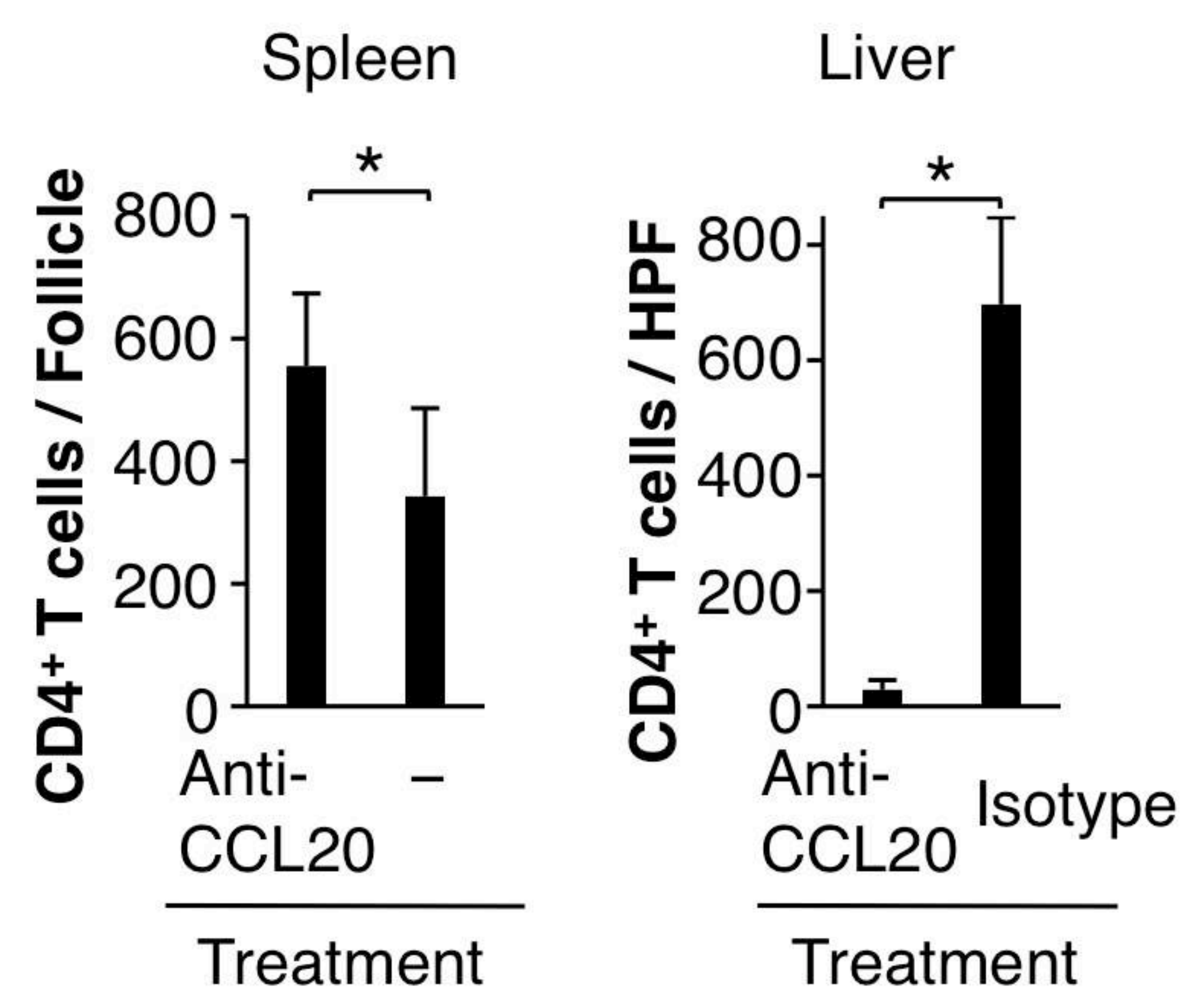

D

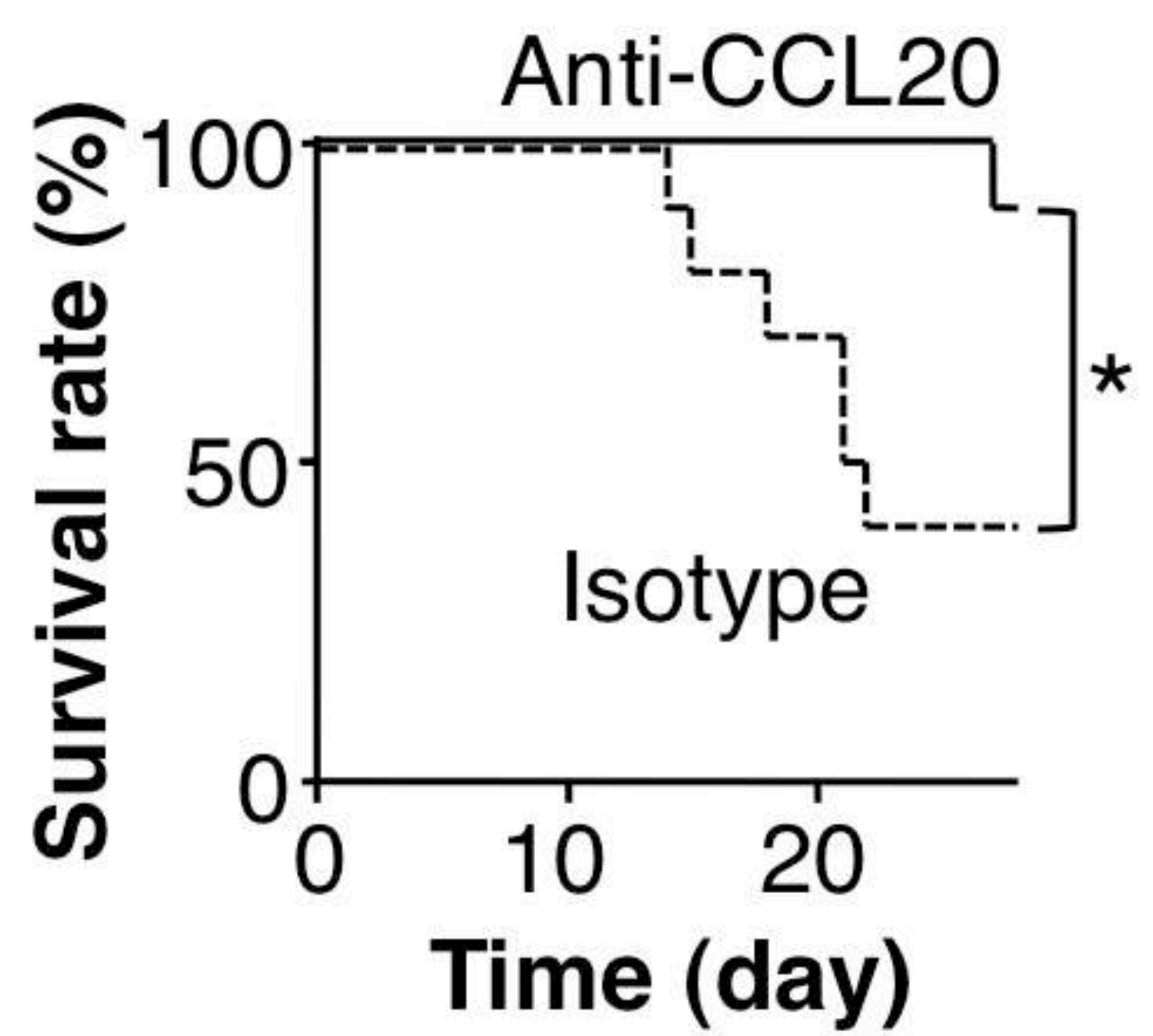




\section{Supplemental Materials:}

\section{Methods:}

Mice

$\mathrm{BALB} / \mathrm{c}$ mice were purchased from Japan SLC (Shizuoka, Japan), and PD- ${ }^{-/-}$and RAG-2 ${ }^{-/-}$mice on a BALB/c background were generated as described. ${ }^{1,2}$ All of these mice were bred and housed under specific pathogen-free conditions. Thymectomy and splenectomy of the mice three days after birth were performed as described. ${ }^{3,4}$ All mouse protocols were approved by the Institute of Laboratory Animals, Graduate School of Medicine, Kyoto University.

\section{ELISA}

Serum Ig levels were determined by ELISA as described, ${ }^{5}$ and Ab sets for detection of mouse IgG1, IgG2a, IgG2b, IgG3, IgA, and IgE from BD Biosciences (San Jose, CA) and anti-mouse IgM from AbD Serotec (Oxford, UK) were used. To detect serum ANAs, microtiter plates (Nunc, Roskilde, Denmark) were incubated with $10 \mu \mathrm{g} / \mathrm{ml}$ antigens, and the nuclear fraction was prepared from normal liver. ${ }^{6} \mathrm{Ab}$ sets for detection of mouse ANA subclasses were the same as above.

\section{Administration of Abs in vivo}

$\mathrm{NTx}-\mathrm{PD}-1^{-/-}$mice at one day after thymectomy were intraperitoneally injected every week with $100 \mu \mathrm{g}$ of Abs. Anti-CD4 (RM4-5) and anti-CD8 (53-6.7) for depletion of $\mathrm{CD}^{+} \mathrm{T}$ cells and $\mathrm{CD}^{+} \mathrm{T}$ cells, respectively, and neutralizing $\mathrm{Abs}$ to mouse ICOS (7E.17G9) were from eBioscience (San Diego, CA). Neutralizing Abs to mouse IL-21 (AF594), IL-12p40 (C17.8) as well as CCL20 (114908) were from R\&D Systems (Minneapolis, MN). Neutralizing Abs to mouse PD-L1 and PD-L2 were purified from ascites as described. ${ }^{7}$ All isotypes were from eBioscience or R\&D Systems. After two to four injections, mice at two to four weeks of age were sacrificed, and their spleens and livers were harvested.

\section{Histological and immunohistological analysis}

Organs were fixed in neutral buffered formalin and embedded in paraffin 
wax. Sections were stained with hematoxylin and eosin for histopathology. Fluorescence immunohistology was performed on frozen sections as described previously $^{3}$ using FITC-conjugated anti-CD4 (RM4-5), anti-CD8a (Ly-2) (eBioscience), peanut agglutinin (PNA, Vector Laboratories, Burlingame, CA), biotin-labeled anti-B220 (RA3-6B2) (BD Biosciences) followed by Texas red-conjugated avidin (Vector Laboratories). Numbers of $\mathrm{CD}^{+} \mathrm{T}$ cells localized within B220 ${ }^{+}$B-cell follicles in the spleen and inflamed liver were counted in several high-power fields in at least three sections of each mouse. Diameter of GCs was measured in several high-power fields in at least three sections of each mouse. Single-cell suspensions of isolated splenic $\mathrm{CD}^{+} \mathrm{ICOS}^{+} \mathrm{T}$ cells from 2.5 -week-old $\mathrm{NTx}-\mathrm{PD}-1^{-/-}$mice were mounted on glass slides by cytocentrifuge preparation. After fixation, these cells were stained with anti-Bcl6 (N3) (Santa Cruz Biotechnology, Santa Cruz, CA) followed by FITC-conjugated goat anti-rabbit Ig (BD Biosciences), or anti-IL-21 (AF594) (R\&D Systems) followed by FITC-conjugated rabbit anti-goat Ig (ab6737) (Abcam, Cambridge, MA), and DAPI (Sigma-Aldrich, St. Louis, MO). Rabbit IgG isotype (DA1E) and normal goat IgG isotype (AB-108-C) were from Cell Signaling (Danvers, MA) and from R\&D Systems, respectively.

\section{Flow cytometry analysis and isolation of lymphocytes}

Single cells from the livers and spleens were prepared as described. ${ }^{3}$ The following mAbs were used for staining: FITC-conjugated anti-CD3e (145-2C11), anti-CD8a (eBioscience); anti-CXCR5 (2G8), anti-GL7, anti-Ki67 (B56) (BD Biosciences); PE-conjugated anti-CD3e, anti-CD4, anti-CD25 (PC61.5), anti-ICOS (eBioscience); anti-B220, anti-CD95/Fas (Jo2) (BD Biosciences); anti-CCR6 (140706), anti-CCR9 (242503), anti-CXCR3 (220803) (R\&D Systems); APC-Cy7-conjugated anti-CD4 (GK1.5), biotin-labeled B220 (BD Biosciences); and APC-conjugated streptavidin, and anti-CD8a (eBioscience). In flow cytometric analysis of $\mathrm{CD}^{+} \mathrm{T}$ cells and $\mathrm{B} 220^{+} \mathrm{B}$ cells in Figure 3, cells were stained with FITC-anti-CXCR5, PE-anti-ICOS, and APC-Cy7-anti-CD4 for $\mathrm{CD}^{+}{ }^{+}$cells; or with FITC-anti-GL7, PE-anti-CD95/Fas, and biotin-labeled B220 followed by APC-conjugated streptavidin for B220 ${ }^{+} \mathrm{B}$ cells. For Ki-67 antigen staining in Figure 5, a FITC-conjugated $\mathrm{Ab}$ set (BD Bioscience) was used with PE-anti-CD3 and 
APC-Cy7-anti-CD4 or APC-anti-CD8. In flow cytometric analysis of T cells in Figure 6, cells were stained with FITC-anti-CD3e, PE-anti-CCR6, -anti-CCR9, or -anti-CXCR3 and APC-Cy7-anti-CD4, with FITC-anti-CXCR5, PE-anti-CCR6, and APC-Cy7-anti-CD4, or with FITC-anti-CD3e, PE-anti-CCR6, and APC-anti-CD8. Stained cells were analyzed with a FACSCanto ${ }^{\mathrm{TM}}$ II (BD Biosciences). Data were analyzed using Cell Quest Pro ${ }^{\mathrm{TM}}$ (BD Biosciences). Dead cells were excluded on the basis of side- and forward-scatter characteristics, and viable $\mathrm{T}$ cell numbers were calculated as follows: (the percentage of cells in the cell type) $\mathrm{x}$ (the number of viable cells). $\mathrm{CD}^{+} \mathrm{CD}^{+}, \mathrm{CD}^{+} \mathrm{CD}^{+}, \mathrm{CD}^{-} \mathrm{B} 220^{+}$cells from the spleen or liver, and $\mathrm{CD}^{+} \mathrm{ICOS}^{+}, \mathrm{CD}^{+} \mathrm{ICOS}^{-} \mathrm{T}$ cells and $\mathrm{CD}^{+} \mathrm{CD} 25^{+}$Tregs from the spleen were obtained by a FACS Aria ${ }^{\mathrm{TM} I I}$ (BD Biosciences) to reach $>99 \%$ purity, as described. ${ }^{3}$

\section{Adoptive transfer}

$\mathrm{CD} 4^{+} \mathrm{CD} 25^{+}$Tregs prepared from the spleen of adult BALB/c PD- $1^{+/+}$or PD- $1^{-/-}$mice as described. ${ }^{3}$ Tregs $\left(1 \times 10^{6}\right)$ were intraperitoneally injected into $\mathrm{NTx}-\mathrm{PD}-1^{-/-}$mice at one day after thymectomy. For transfer of $\mathrm{T}_{\mathrm{FH}}$ cells or non- $\mathrm{T}_{\mathrm{FH}}$ cells, $\mathrm{CD}^{+} \mathrm{ICOS}^{+} \mathrm{T}$ cells or $\mathrm{CD}^{+} \mathrm{ICOS}^{-} \mathrm{T}$ cells, respectively were prepared from the spleen of 2.5 -week-old NTx-PD- $1^{-/-}$mice as described above. Isolated T cells $\left(1 \times 10^{6}\right)$ were intravenously injected into RAG2-deficient recipient mice on a BALB/c background at 4 weeks of age. Three weeks after transfer, recipient mice were examined.

\section{Real-time quantitative RT-PCR}

Real-time quantitative RT-PCR was performed as described previously. ${ }^{8}$ Spleen and liver tissues or isolated lymphocytes were frozen in RNAlater. RNA was prepared with an RNeasy mini kit (Qiagen, Hilden, Germany), and single-strand cDNA was synthesized with SuperScript II reverse transcriptase (Invitrogen, Carlsbad, CA). Real-time quantitative RT-PCR was performed using SYBR Green I Master (Roche Applied Science, Basel, Switzerland). The real-time quantitative reactions were performed using a Light Cycler ${ }^{\mathrm{TM}} 480$ (Roche Applied Science) according to the manufacturer's instructions. Values are expressed as arbitrary units relative to GAPDH. The following primers were used: GAPDH: 
5'-CAACTTTGTCAAGCTCATTTCC-3'

and

5'-GGTCCAGGGTTTCTTACTCC-3';

PD-L1:

5'-GGAATTGTCTCAGAATGGTC-3'

and

5'-GTAGTTGCTTCTAGGAAGGAG-3';

PD-L2:

5'-GCATGTTCTGGAATGCTCAC-3' and 5'-CTTTGGGTTCCATCCGACT-3';

Foxp3: 5'-TCAGGAGCCCACCAGTACA-3'

and

5'-TCTGAAGGCAGAGTCAGGAGA-3';

Bcl6:

5'-ACACATGCAGGAAGTTCATCAAGG-3'

and

5'-CATATTGTTCTCCACGACCTCACG-3';

IL-21:

5'-GACATTCATCATCGACCTCGT-3'

and

5'-TCACAGGAAGGGCATTTAGC-3';

$I L-21 R$ :

5'-AGTGACCCCGTCATCTTTCA-3' and 5'-AGGAGCAGCAGCATGTGAG-3'; $R O R \gamma T$ : 5'-CCGCTGAGAGGGCTTCAC-3'

and

5'-TGCAGGAGTAGGCCACATTACA-3';

IL-17A:

5'-CTCCAGAAGGCCCTCAGACTAC-3'

and

5'-AGCTTTCCCTCCGCATTGACACAG-5';

T-bet:

5'-TCAACCAGCACCAGACAGAG-3'

and

5'-AAACATCCTGTAATGGCTTGTG-3';

GATA-3:

5'-TTATCAAGCCCAAGCGAAG-3' and 5'-TGGTGGTGGTCTGACAGTTC-3'; CCL20: 5'-ATGGCCTGCGGTGGCAAGCGTCT-3'

and

5'-TAGGCTGAGGAGGTTCACAGCCC-3';

CCL25:

5'-GAGTGCCACCCTAGGTCATC-3' and 5'-CCAGCTGGTGCTTACTCTGA-3'.

\section{T-cell coculture}

$\mathrm{CD}^{+}$and $\mathrm{CD}^{+} \mathrm{T}$ cells were isolated from the spleen of 2 -week-old PD- $1^{-/-}$ mice with or without NTx using a FACS Aria ${ }^{\mathrm{TM}}$ II (BD Biosciences) to reach $>99 \%$ purity, as described. ${ }^{3}$ Isolated $\mathrm{CD}^{+} \mathrm{T}$ cells $\left(5 \times 10^{5}\right)$ were cocultured with $5 \times 10^{5}$ freshly isolated $\mathrm{CD}^{+} \mathrm{T}$ cells in round-bottomed 96-well culture plates in D-MEM supplemented with $10 \%$ fetal bovine serum, $50 \mathrm{mmol} / \mathrm{L}$ 2-mercaptoethanol, $100 \mathrm{U} / \mathrm{ml}$ penicillin, and $100 \mu \mathrm{g} / \mathrm{ml}$ streptomycin. In some experiments, we used the following reagents in these culture conditions: $10 \mu \mathrm{g} / \mathrm{ml}$ of anti-IL-21 (AF594), $10 \mu \mathrm{g} / \mathrm{ml}$ of goat IgG isotype, and 1-100 ng/ml of recombinant IL-21 (all from R\&D Systems). 
After 24 hours of culture, cells were stained with PE-anti-CD3, APC-anti-CD8, and FITC-anti-Ki67 or -isotype control and analyzed with a FACSCanto ${ }^{\mathrm{TM}}$ II.

\section{References:}

1. Nishimura H, Okazaki T, Tanaka Y, et al. Autoimmune dilated cardiomyopathy in PD-1 receptor-deficient mice. Science 2001;291:319-322.

2. Shinkai Y, Rathbun G, Lam KP, et al. RAG-2-deficient mice lack mature lymphocytes owing to inability to initiate $\mathrm{V}(\mathrm{D}) \mathrm{J}$ rearrangement. Cell 1992;68:855-867.

3. Kido M, Watanabe N, Okazaki T, et al. Fatal autoimmune hepatitis induced by concurrent loss of naturally arising regulatory $\mathrm{T}$ cells and PD-1-mediated signaling. Gastroenterology 2008;135:1333-1343.

4. Klonowski KD, Marzo AL, Williams KJ, et al. CD8 T cell recall responses are regulated by the tissue tropism of the memory cell and pathogen. $\mathrm{J}$ Immunol 2006; 177:6738-6746.

5. Muramatsu M, Kinoshita K, Fagarasan S, et al. Class switch recombination and hypermutation require activation-induced cytidine deaminase (AID), a potential RNA editing enzyme. Cell 2000;102:553-563.

6. Blobel G, Potter VR. Nuclei from rat liver: isolation method that combines purity with high yield. Science 1966;154:1662-1665.

7. Ishida M, Iwai Y, Tanaka Y, et al. Differential expression of PD-L1 and PD-L2, ligands for an inhibitory receptor PD-1, in the cells of lymphohematopoietic tissues. Immunol Lett 2002;84:57-62.

8. Kido M, Tanaka J, Aoki N, et al. Helicobacter pylori promotes the production of thymic stromal lymphopoietin by gastric epithelial cells and induces dendritic cell-mediated inflammatory Th2 responses. Infect Immun 2010;78:108-114. 


\section{Supplementary Data}

\section{Supplementary Figure 1.}

Splenic $\mathrm{CD}^{+} \mathrm{T}$ cells are preferentially localized within $\mathrm{B} 220^{+}$B-cell follicles in the induction phase of AIH in NTx-PD-1 ${ }^{-/-}$mice. The spleens from 2-week-old NTx-PD-1 ${ }^{-/-}$mice were stained with biotin-labeled anti-B220 and FITC-conjugated anti-CD4 followed by Texas red-conjugated avidin. A scale bar, $100 \mu \mathrm{m}$.

\section{Supplementary Figure 2.}

The size of GCs is increased in the spleen of NTx-PD-1 ${ }^{-/-}$mice from one to three weeks of age. Spleens from NTx-PD-1 ${ }^{-/-}$mice at the indicated age in weeks were stained with FITC-conjugated PNA and biotin-labeled anti-B220 followed by Texas red-conjugated avidin. Each open circle represents a size of GC as measured in high-power fields. Horizontal bars indicate the mean size (diameter) of GCs in at least three sections. Horizontal short bars indicate the SD. *; P < 0.05 .

\section{Supplementary Figure 3.}

Three-week-old NTx-PD-1 ${ }^{-/-}$mice show hyper-gammaglobulinemia and vast production of class-switched anti-nuclear antibodies (ANAs). The serum levels of total Ig subclasses and ANAs in IgM, IgG1, and IgG2a of 3-week-old PD-1 ${ }^{-/-}$ mice with (closed bars) or without (open bars) NTx determined by ELISA. Bars indicate the mean of each group, and horizontal short bars indicate the SD. *; $P$ $<0.05$.

\section{Supplementary Figure 4.}

Administration of anti-IL-12p40 induces increase of IgG1 and decrease of IgG2a classes of anti-nuclear antibodies (ANAs). NTx-PD- $1^{-/-}$mice were injected intraperitoneally at one day after NTx and then once a week with anti-IL-12p40 $(n=5)$ Abs. After four injections, mice at four weeks of age were sacrificed, and 
the serum levels of ANAs in $\lg G 1$ and $\lg G 2 a$ were determined by ELISA. Bars indicate the mean of NTx-PD-1 $1^{-/-}$with or without administration of anti-IL-12p40, and horizontal short bars indicate the SD. *; $P<0.05$.

\section{Supplementary Figure 5.}

Administration of anti-ICOS suppresses not only $\mathrm{T}_{\mathrm{FH}}$-cell generation but also induction of fatal $\mathrm{AlH}$, including hyper-gammaglobulinemia and vast production of class-switched anti-nuclear antibodies (ANAs). (A-C) NTx-PD-1 $1^{-/-}$mice were injected intraperitoneally at one day after NTx and then once a week with either anti-ICOS $(n=5)$ or isotype $(n=7)$ Abs. After four injections, mice at four weeks of age were sacrificed and the spleens and livers harvested. Double immunostainings of the spleen. The spleens from indicated mice were stained with FITC-conjugated anti-CD4, or PNA (green) and biotin-labeled anti-B220 followed by Texas red-conjugated avidin (red) $(A)$. Stainings of the liver for hematoxylin and eosin ( $\mathrm{HE}), \mathrm{CD} 4$, and CD8 $(B)$. The serum levels of total Ig subclasses and ANAs in IgM, IgG1, and IgG2a were determined by ELISA (C). Bars indicate the mean of indicated each group, and horizontal short bars indicate the SD. *; $\mathrm{P}<0.05$. All scale bars, $100 \mu \mathrm{m}$.

\section{Supplementary Figure 6.}

Administration of anti-IL-21 suppresses not only $\mathrm{T}_{\mathrm{FH}}$-cell generation but also induction of fatal AlH. NTx-PD-1/- mice were injected intraperitoneally at one day after NTx and then once a week with either anti-IL-21 $(n=5)$ or isotype $(n=5)$ Abs. After four injections, mice at four weeks of age were sacrificed and the spleens and livers were harvested. $(A)$ Double immunostainings of the spleen. The spleens from indicated mice were stained with FITC-conjugated anti-CD4, or PNA (green) and biotin-labeled anti-B220 followed by Texas red-conjugated avidin (red). (B) Stainings of the liver for hematoxylin and eosin (HE), CD4 and CD8. All scale bars, $100 \mu \mathrm{m}$. 


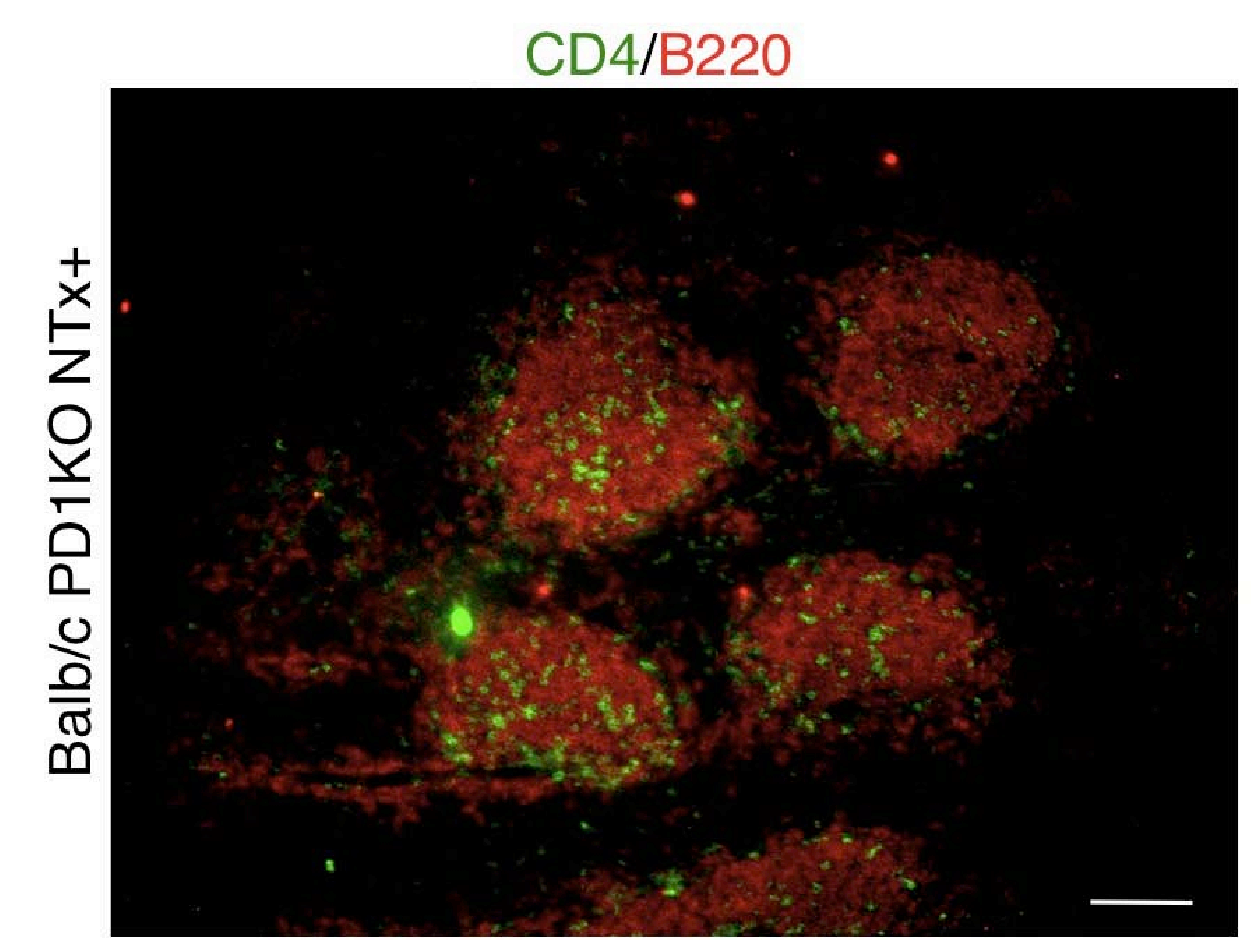

Supplementary Figure 2

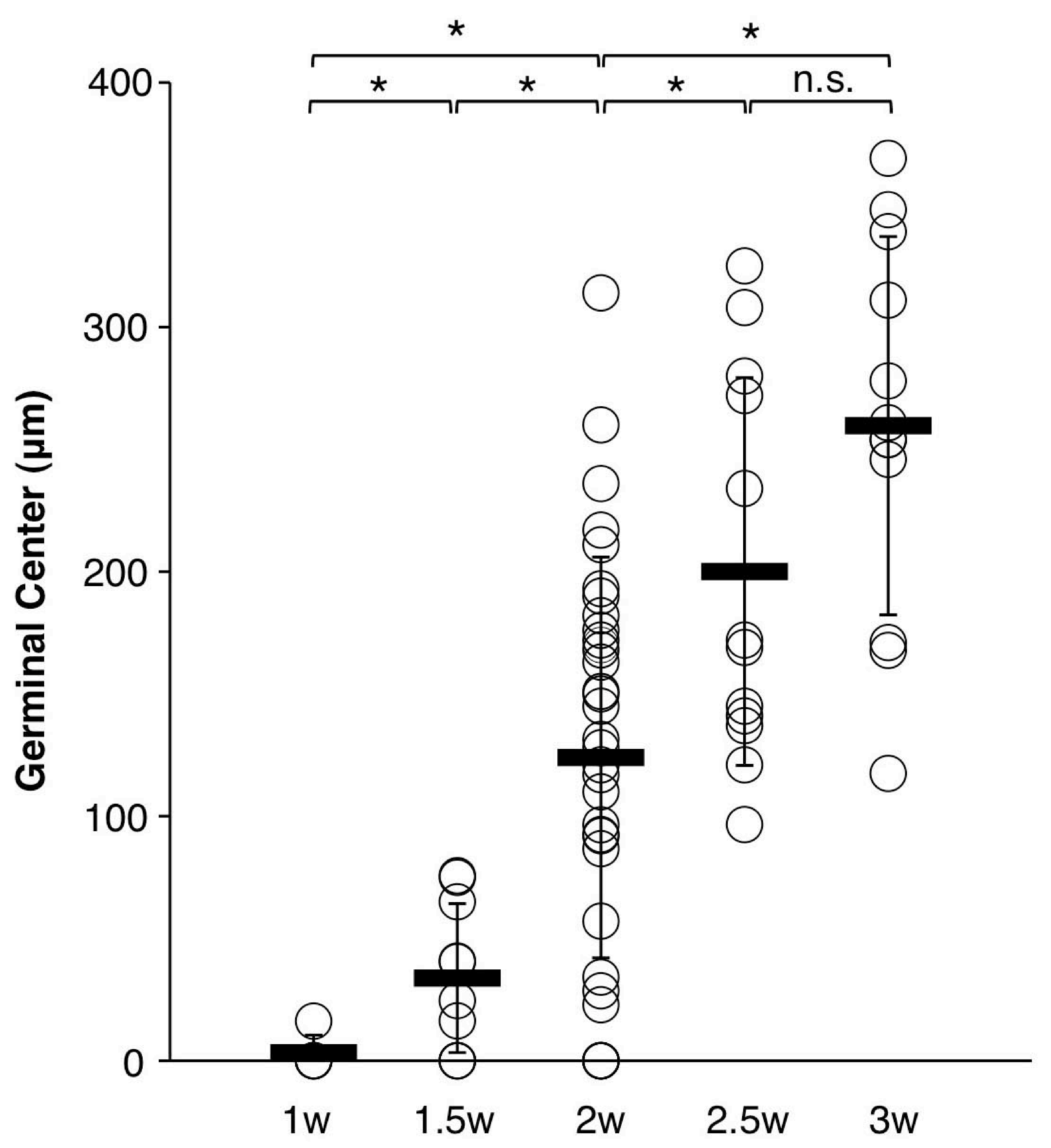



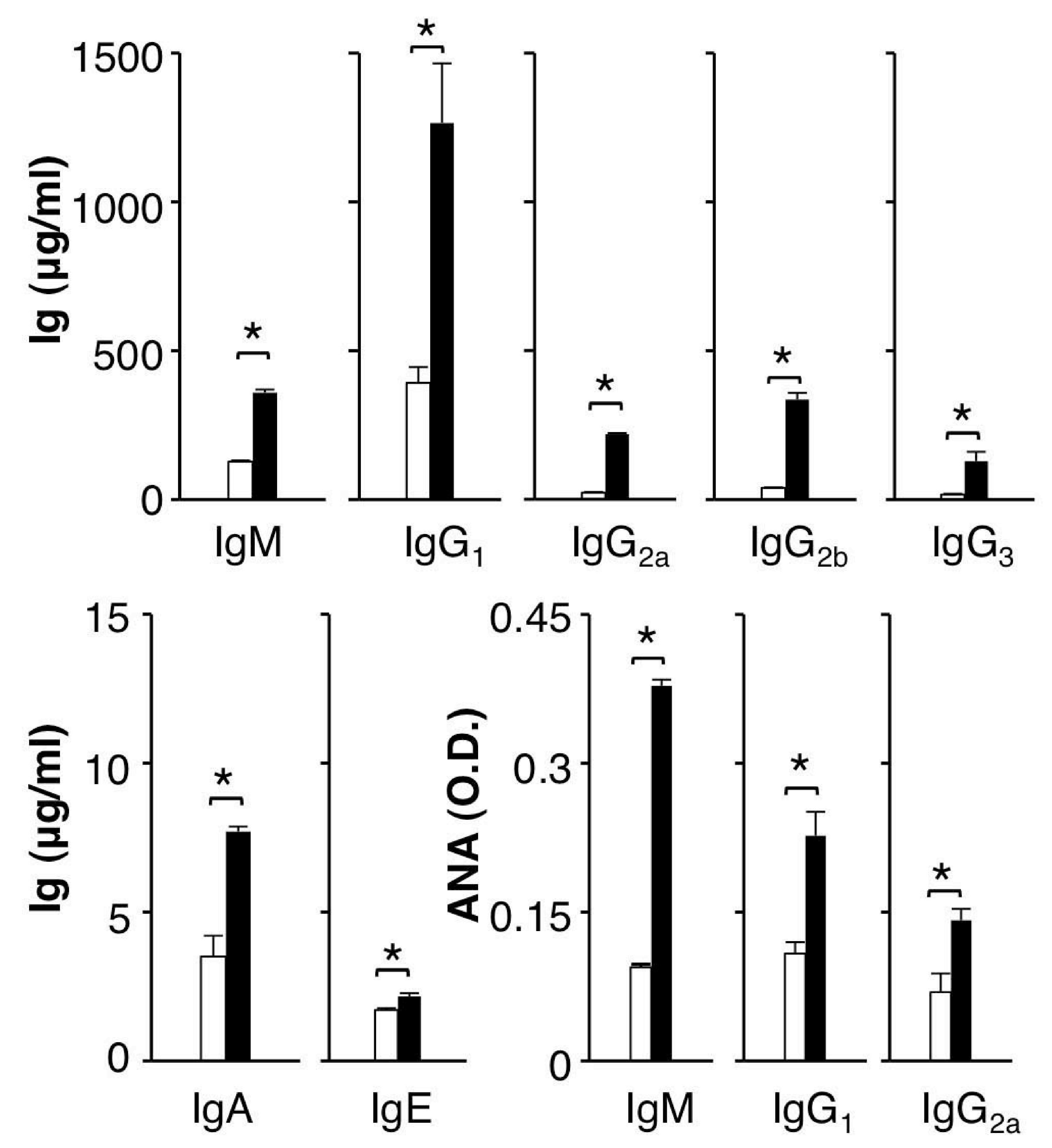

\section{Supplementary Figure 4}
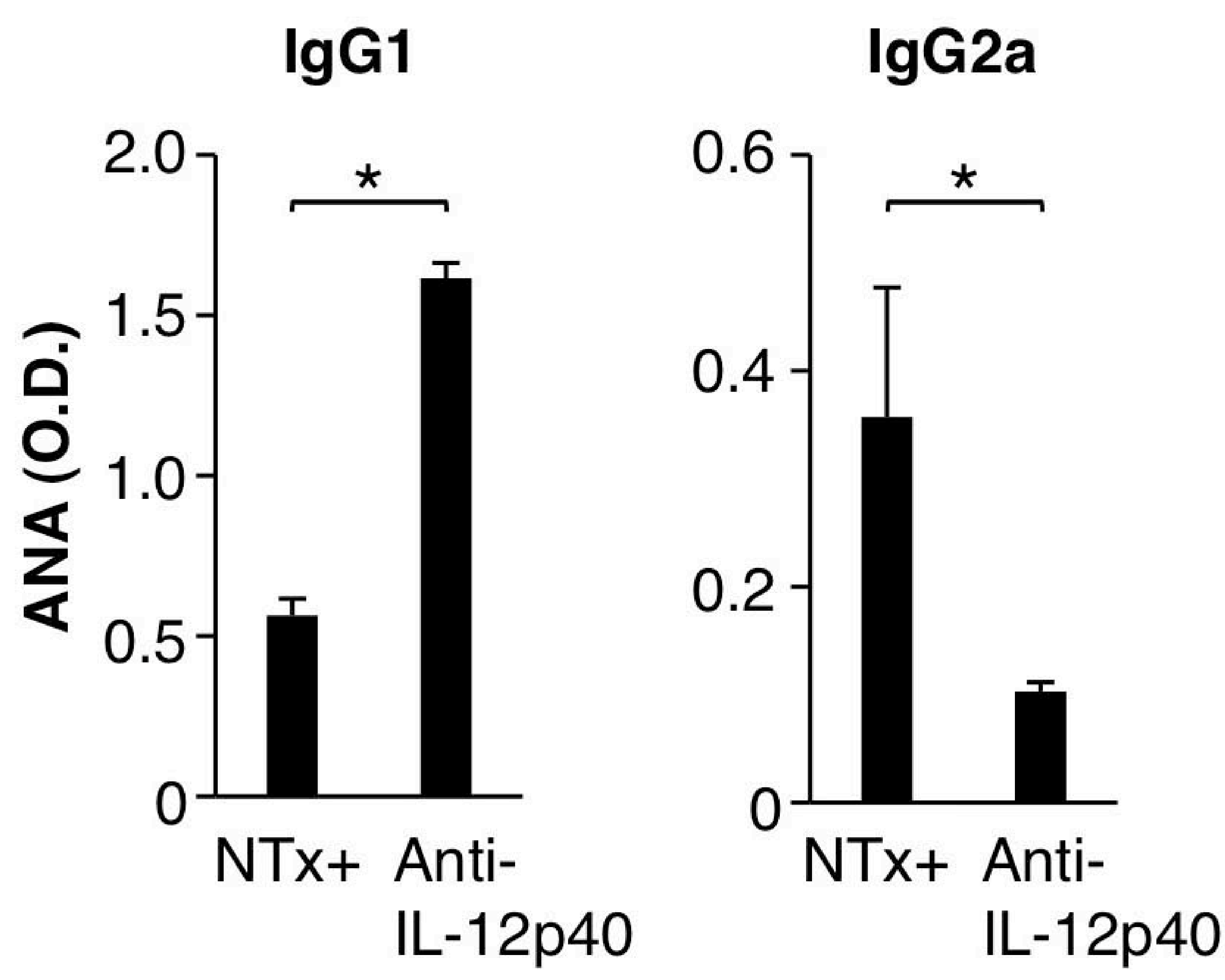


\section{Supplementary Figure 5}

A

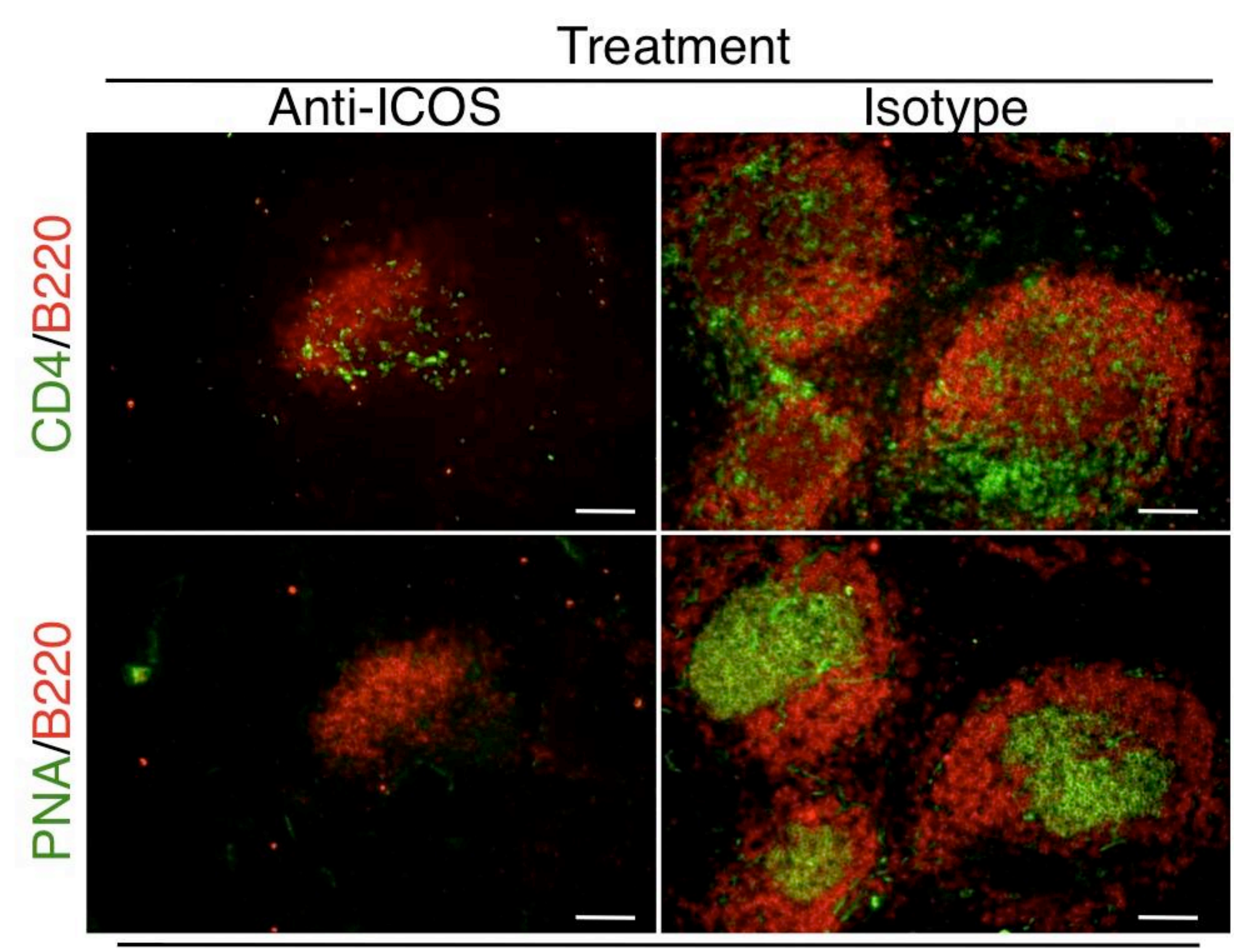

Spleen
B

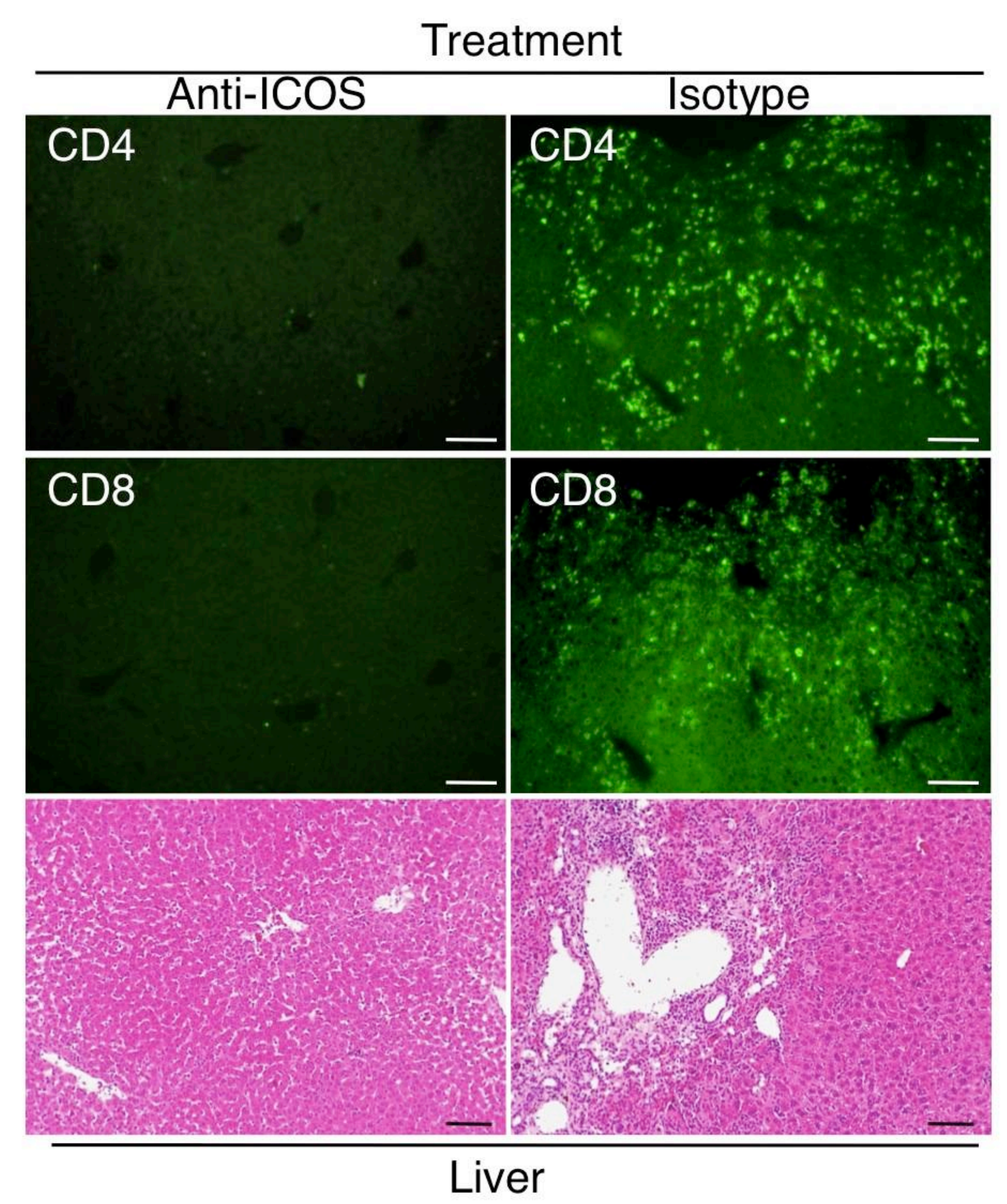

C

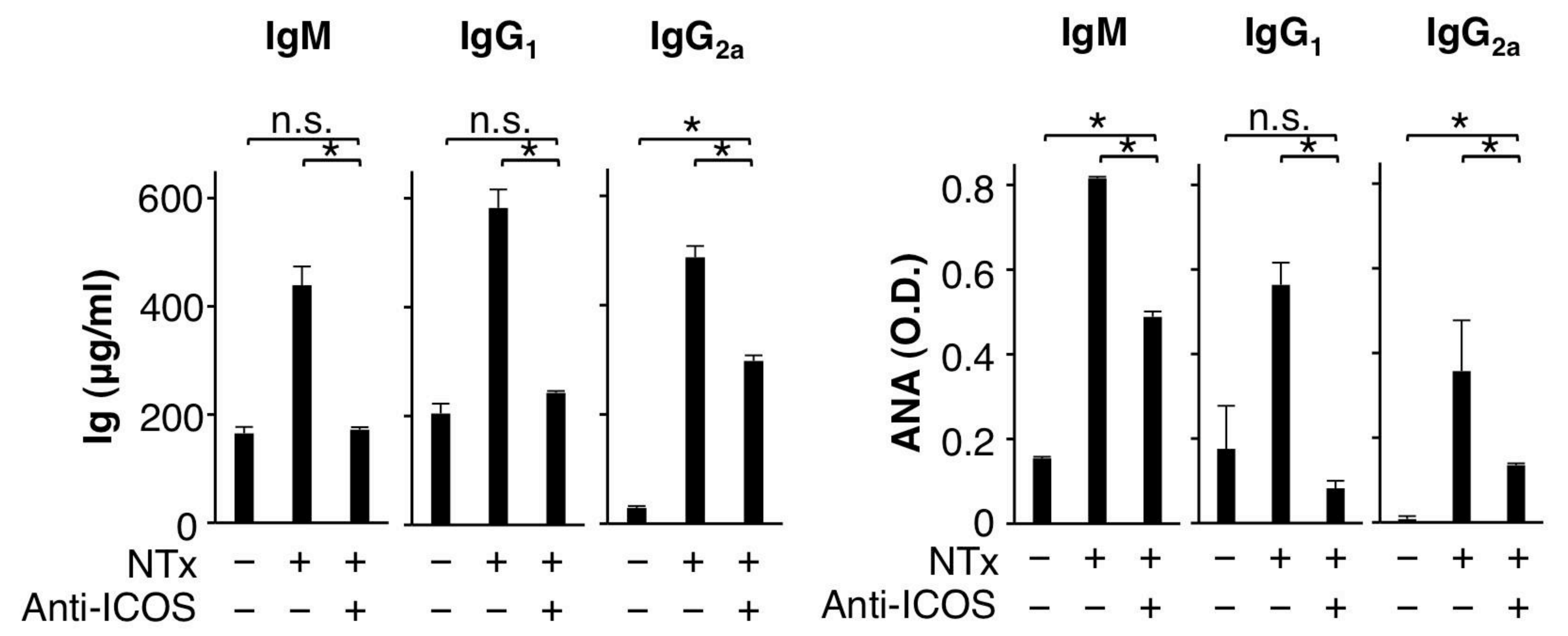




\section{Supplementary Figure 6}

A

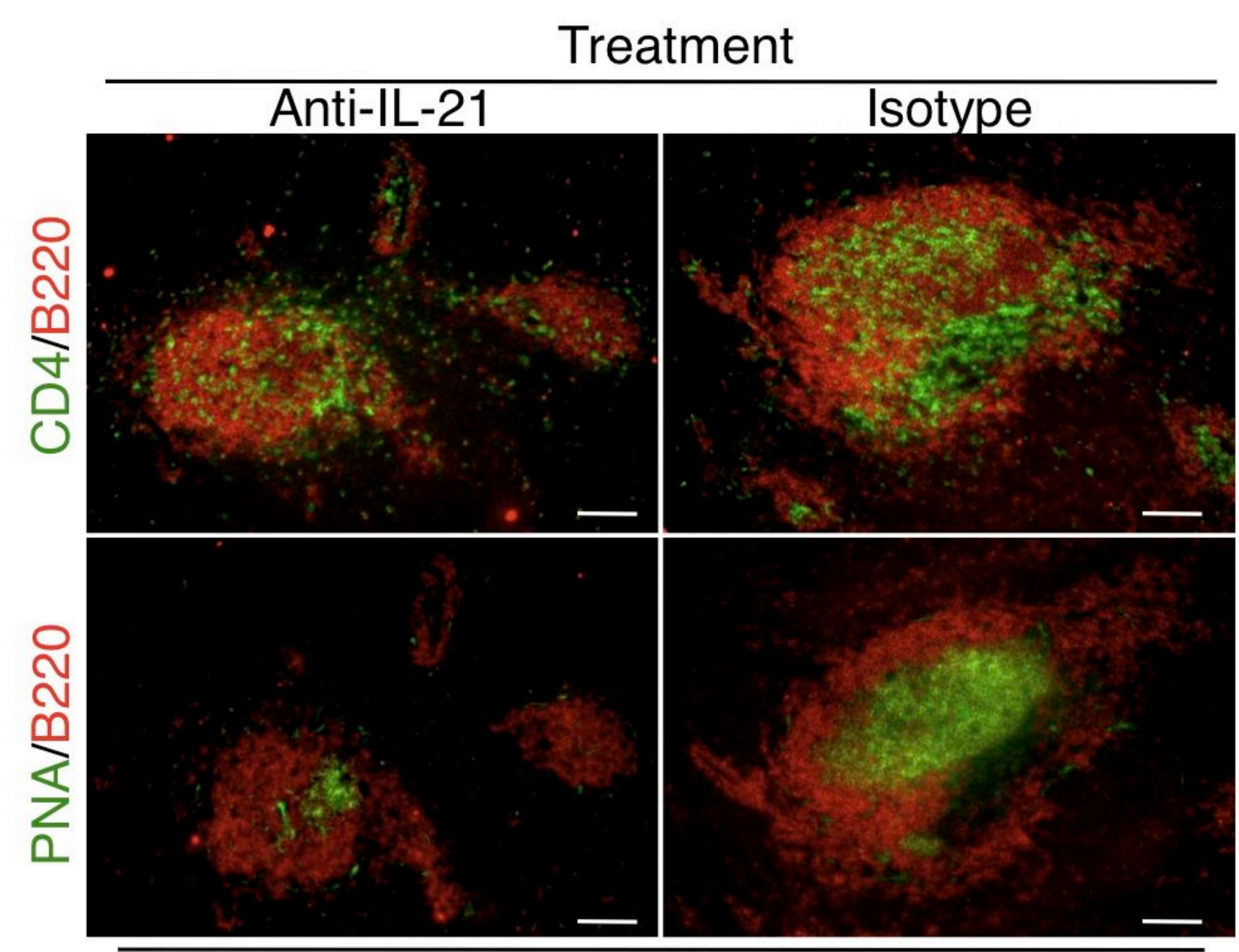

Spleen
B

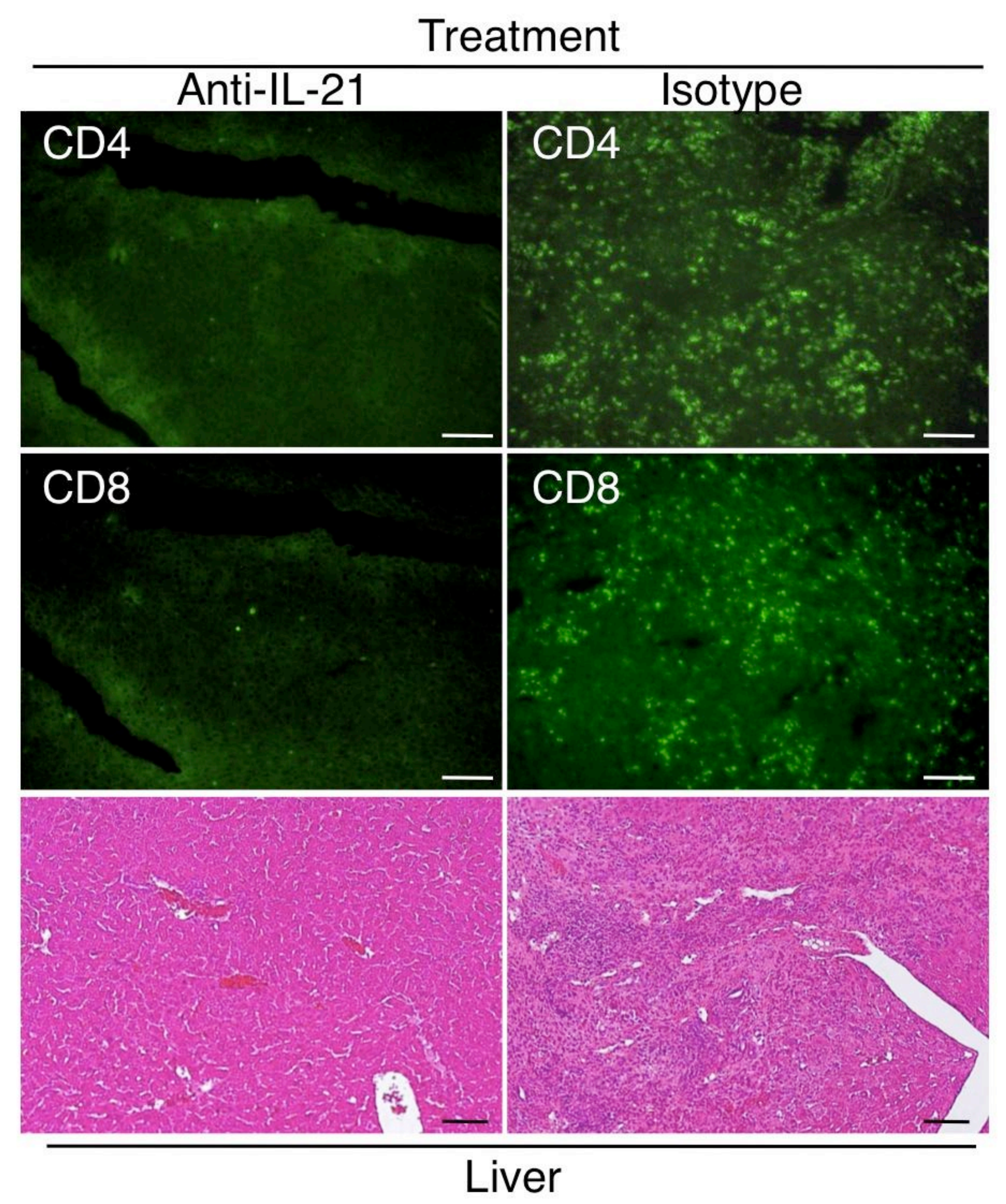

